Uma ferramenta geradora de código Bluespec SystemVerilog a partir de máquina de estados finitos descrita em UML e C

Sérgio Henrique Moraes Durand 

Data de Depósito:

Assinatura:

\title{
Uma ferramenta geradora de código Bluespec SystemVerilog a partir de máquina de estados finitos descrita em UML e C
}

\author{
Sérgio Henrique Moraes Durand
}

Orientador: Prof. Dr. Vanderlei Bonato

\begin{abstract}
Dissertação apresentada ao Instituto de Ciências Matemáticas e de Computação - ICMC-USP, como parte dos requisitos para obtenção do título de Mestre em Ciências - Ciências de Computação e Matemática Computacional. VERSÃO REVISADA
\end{abstract}


Ficha catalográfica elaborada pela Biblioteca Prof. Achille Bassi e Seção Técnica de Informática, ICMC/USP, com os dados fornecidos pelo(a) autor(a)

\begin{tabular}{|c|c|}
\hline \multirow[t]{3}{*}{ D948f } & $\begin{array}{l}\text { Durand, Sérgio Henrique Moraes } \\
\text { Uma ferramenta geradora de código Bluespec } \\
\text { SystemVerilog a partir de máquina de estados finitos } \\
\text { descrita em UML e C / Sérgio Henrique Moraes Durand; } \\
\text { orientador Vanderlei Bonato. -- São Carlos, } 2013 \text {. } \\
\quad 88 \text { p. }\end{array}$ \\
\hline & $\begin{array}{l}\text { Dissertação (Mestrado - Programa de Pós-Graduação en } \\
\text { Ciências de Computação e Matemática Computacional) -- } \\
\text { Instituto de Ciências Matemáticas e de Computação, } \\
\text { Universidade de São Paulo, } 2013 \text {. }\end{array}$ \\
\hline & $\begin{array}{l}\text { 1. ARQUITETURA RECONFIGURÁVEL. 2. COMPUTAÇÃO } \\
\text { RECONFIGURÁVEL. 3. CIÊNCIA DA COMPUTAÇÃO. I. Bonato, } \\
\text { Vanderlei, orient. II. Título. }\end{array}$ \\
\hline
\end{tabular}




\section{Agradecimentos}

À minha esposa Uiara pelo total apoio durante todo o mestrado, principalmente nos meses que estive ausente.

Ao meu orientador Prof. Dr. Vanderlei Bonato por suas valiosas contribuições durante a elaboração deste trabalho.

Aos meus colegas do laboratório LCR, do Instituto de Ciências Matemáticas e de Computação, e do laboratório SPeCS, da Faculdade de Engenharia da Universidade do Porto, pela ótima convivência.

Às funcionárias da secretaria de pós-graduação do Instituto de Ciências Matemáticas e de Computação, que sempre foram muito atenciosas.

À Coordenação de Aperfeiçoamento de Pessoal de Nível Superior pelo auxílio financeiro que possibilitou minha dedicação exclusiva ao mestrado. 



\section{Resumo}

O contínuo avanço da capacidade dos circuitos integrados e a necessidade de sistemas embarcados cada vez mais complexos para lidar com os problemas atuais, com prazos cada vez mais curtos, estão direcionando o desenvolvimento de sistemas de circuitos integrados para ambientes de alto nível de abstração cada vez mais distantes dos detalhes de hardware. O uso de linguagens de alto nível para auxiliar o desenvolvimento de sistemas embarcados é uma tendência atual pois tal abordagem tende a reduzir a complexidade e o tempo de desenvolvimento. Este trabalho propõe o desenvolvimento de uma nova ferramenta para geração de arquiteturas de hardware em Bluespec em um ambiente gráfico utilizando diagramas da UML. Esta ferramenta permite que o projetista descreva o comportamento utilizando máquina de estados finita no padrão UML 2.0, onde cada estado pode conter a codificação do comportamento com as linguagens Bluespec e C. Dada uma máquina de estados, a mesma é traduzida para a linguagem Bluespec por meio de um compilador e templates. Como resultado, é apresentado a geração de duas arquiteturas de hardware a fim de demonstrar as vantagens e limitações da ferramenta desenvolvida.

Palavras-chave: Sistemas Embarcados, Bluespec, UML, ESL. 



\section{Abstract}

The continuous advancement of integrated circuits capacity and the need for embedded systems even more complex to deal with current problems, with shorter time-to-market, are driving the development of integrated circuits systems to environments with high level abstraction more and more distant from the hardware details. The use of high level languages to assist the embedded systems development is a current trend for such an approach tends to reduce the complexity and development time. This work proposes the development of a new tool in Bluespec to generate hardware architectures in a graphical environment using UML diagrams. This tool allows the designer to describe the behavior using finite state machine in UML 2.0 standard, where each state can contain the coding behavior with Bluespec and C languages. Given a state machine, it is translated to Bluespec language through a compiler and templates. As a result is presented the generation of two hardware architectures in order to demonstrate the advantages and limitations of the developed tool.

Keywords: Embedded Systems, Bluespec, UML, ESL. 



\section{Sumário}

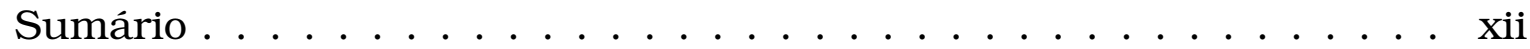

Lista de Figuras . . . . . . . . . . . . . . . xv

Lista de Tabelas . . . . . . . . . . . . . . . . . xvii

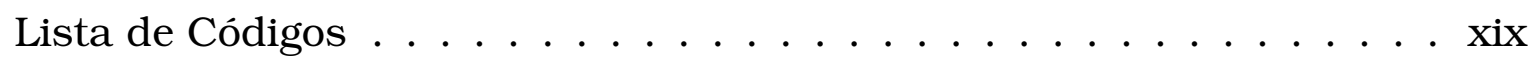

Lista de Abreviaturas . . . . . . . . . . . . . . . . . . xxi

1 Introdução 1

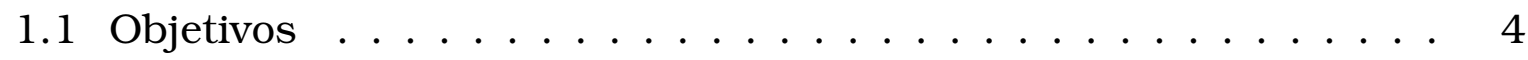

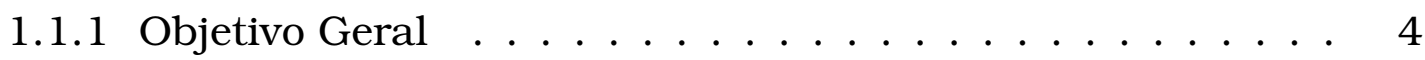

1.1 .2 Objetivos Específicos $\ldots \ldots \ldots \ldots \ldots$

1.2 Justificativa . . . . . . . . . . . . . . . . . 5

1.3 Organização do Texto . . . . . . . . . . . . . . . . 6

2 Fundamentação Teórica $\quad 7$

2.1 Unified Modeling Language (UML) . . . . . . . . . . . . . . . 7

2.2 Máquina de Estados Finitos . . . . . . . . . . . . . 10

2.2.1 Minimização de estados . . . . . . . . . . . . . . . 13

2.3 Compiladores . . . . . . . . . . . . . . . . . . 14

2.3 .1 Frontend . . . . . . . . . . . . . . . 16

2.3 .2 Backend . . . . . . . . . . . . . . . 17

2.4 RoboArch . . . . . . . . . . . . . . . . . . . . . . 18

2.5 Trabalhos Relacionados . . . . . . . . . . . . . . . . . . . 18

2.5 .1 ASM++ . . . . . . . . . . . . . . 19

2.5.2 GenERTiCA com mapeamento em VHDL . . . . . . . . 20

3 Material e Métodos 23

3.1 JavaCC . . . . . . . . . . . . . . . . . . . 23

3.2 Apache Velocity . . . . . . . . . . . . . . . . . . . . 24

3.3 Bluespec SystemVerilog . . . . . . . . . . . . . . . . . 25

3.4 Padrão IP-XACT . . . . . . . . . . . . . . . . . . . . . . . . . . . . . 29 
4 Implementação da Ferramenta Proposta 31

4.1 UML2BSV . . . . . . . . . . . . . . . . . 33

4.1 .1 Modelagem UML $\ldots \ldots \ldots \ldots$

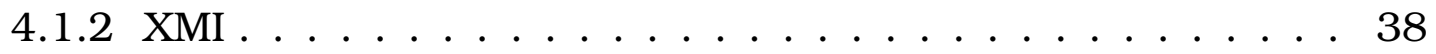

4.1 .3 Parser do XMI . . . . . . . . . . . . . . . . 4 41

4.1 .4 Geração de código . . . . . . . . . . . . . . . . . 44

4.1 .5 Exemplos de geração de código BSV . . . . . . . . . . . 47

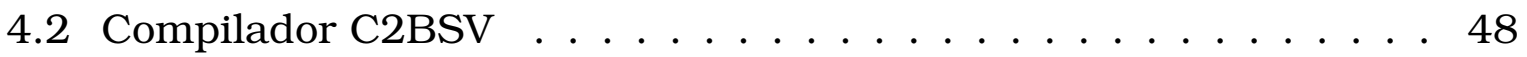

5 Aplicações da Ferramenta Proposta 53

5.1 Processador . . . . . . . . . . . . . . . 53

5.1 .1 Modelagem do processador . . . . . . . . . . . . 54

5.1 .2 Resultados . . . . . . . . . . . . . . . 57

5.2 Elemento de Processamento de Imagem Sobel . . . . . . . . . . 59

5.2 .1 Modelagem do filtro Sobel . . . . . . . . . . . . . 60

5.2 .2 Resultados . . . . . . . . . . . . . . . . . 64

$\begin{array}{ll}\text { Conclusão } & 67\end{array}$

$\begin{array}{ll}\text { Referências Bibliográficas } & 69\end{array}$

A Código fonte BSV do Processador gerado automaticamente pela ferramenta UML2BSV

B Código fonte BSV do filtro Sobel gerado automaticamente pela ferramenta UML2BSV

C Gramática do compilador C2BSV 


\section{Lista de Figuras}

1.1 Diagrama de blocos dos principais elementos do projeto RoboArch com o destaque do módulo onde este trabalho está situado.

1.2 Visão geral do processo de geração de código Bluespec System-

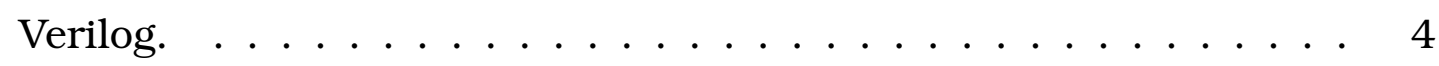

2.1 Diagrama de classes com a classificação dos 14 diagramas da UML. Adaptado de (Fowler, 2003). . . . . . . . . . . . . . . 8

2.2 Exemplo de uma MEF tipo Moore para detectar a sequência '11'. 11

2.3 Exemplo de uma MEF tipo Mealy para detectar a sequência '11'. . 12

2.4 Elementos de um diagrama ASM adaptado de (Brown, 2005). . . 12

2.5 Representação de um diagrama ASM (Nelson et. al., 1995). . . . . 13

2.6 Fases de um compilador. Adaptado de (Aho et. al., 1986). . . . . . 15

2.7 Analisador Léxico. Adaptado de (Norvell, 2007). . . . . . . . . . 16

2.8 Analisador Sintático. Adaptado de (Norvell, 2007). . . . . . . . . 17

2.9 Exemplo de simulação de sistema embarcado via Player/Stage. . 19

2.10 Exemplo da notação ASM++. Adaptado de (Pablo et. al., 2010). . . 20

2.11 Visão geral do processo de geração de código VHDL a partir de especificações UML utilizando a ferramenta GenERTiCA. Adaptado de (Moreira et. al., 2010) . . . . . . . . . . . . . . . . . . 21

3.1 Fluxo de desenvolvimento do Bluespec. Adaptado de (Bluespec

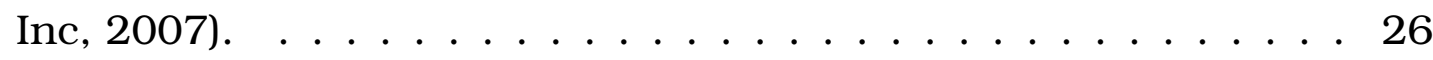

3.2 Ilustração para representar a complexidade de desenvolver precisando fazer o controle de recursos compartilhados e a simplicidade proporcionada pelo Bluespec permitindo ao desenvolvedor focar-se apenas em uma parte de seu sistema (Bluespec Inc, 2010). 27

3.3 Bluespec Workstation (janela superior), editor de texto Vim (janela inferior) e lista de arquivos que fazem parte do projeto (janela à esquerda). . . . . . . . . . . . . . . 28 
4.1 Fluxo do processo de geração automática da ferramenta proposta. A entrada do fluxo recebe um modelo em UML, no formato XMI, e é interpretado pela UML2BSV que, com o suporte do compilador C2BSV, são responsáveis pela geração de código Bluespec automaticamente. . . . . . . . . . . . 32

4.2 Definição de tipos de dados utilizando classes. . . . . . . . . . . 34

4.3 Ação actionTrafficLight do diagrama de atividades que está relacionada à máquina de estados que controla o tempo de um semáforo. Na borda do elemento gráfico que representa uma ação encontram-se as declarações dos sinais de entrada, saída e variáveis. ...................... 36

4.4 Diagrama de estados representando o controle de tempo de um semáforo. Dentro de cada estado existe a referência para o código que descreve seu comportamento. . . . . . . . . . . . . . 37

4.5 Diagrama de classes que representa a estrutura da modelagem do circuito. . . . . . . . . . . . . . . . . 42

4.6 Estrutura de templates de um módulo BSV. . . . . . . . . . . . . . 45

4.7 Representação de um conjunto de estados e suas respectivas definições em Bluespec. O código na parte inferior da imagem representa a declaração de um novo tipo de dado State, da categoria enumerator, onde estão incluídos todos os estados da modelagem. E o código à direita mostra trecho das rules para cada estado que foi modelado.

4.8 Definição de um estado inicial por meio de uma transição de um pseudo-estado, representado por um círculo preto, para um estado comum. Na parte inferior da figura é ilustrado o código BSV correspondente que cria e inicializa a variável state.

4.9 Parte do diagrama de estados mostrando uma transição com a condição count $==20$. Abaixo da figura é destacado o trecho de código BSV dentro da rule onde uma verificação condicional é realizada.

4.10Instrução resultado $=9 /(1+3) * 4+5$; representada no formato da AST gerada pelo frontend. . . . . . . . . . . . .

4.11 Representações de estruturas de decisões e laços como máquina de estados.

5.1 Definição dos tipos de dados utilizados na modelagem do processador.

5.2 Diagrama de estados do processador. . . . . . . . . . . . . 56

5.3 Ação que representa o processador com as variáveis utilizadas localmente na região inferior. . . . . . . . . . . . . . . . 
5.4 Definição dos tipos de dados utilizados na modelagem do filtro Sobel. . . . . . . . . . . . . . . . . . 61

5.5 Diagrama de estados do filtro Sobel. . . . . . . . . . . . . . 61

5.6 Captura de tela da ferramenta UML onde o comportamento do estado $\mathrm{CalcHV}$ é definido utilizando a linguagem C. . . . . . . . 63

5.7 Ação que representa o filtro Sobel com os sinais de entrada localizados à esquerda, os de saída à direita e as variáveis de uso local na região inferior. . . . . . . . . . . . . . . . . . . . 64

5.8 Resultado da aplicação do filtro Sobel na imagem (a) pelo circuito modelado em UML na figura $5.5 . \ldots \ldots$. . . . . . . . . . 65 



\section{Lista de Tabelas}

2.1 Tabela de estado da MEF da figura $2.2 \ldots \ldots$. . . . . . . . 14

4.1 Equivalência entre os tipos de dados em C e Bluespec. . . . . . . 35

4.2 Nós da AST do compilador C2BSV que foram implementados. . . 51

5.1 Instruções de manipulação de dados. . . . . . . . . . . . . 55

5.2 Instruções aritméticas. . . . . . . . . . . . . . . . 55

5.3 Instruções de controle. . . . . . . . . . . . . . . 56 



\section{Lista de Códigos}

3.1 Exemplo de um template do Apache Velocity. . . . . . . . . . . . . 24

3.2 Exemplo de um código renderizado à partir de um template do Apache Velocity. . . . . . . . . . . . . . . . . . 24

3.3 Exemplo de código Bluespec utilizando a biblioteca de máquina de estado finita (Nikhil e Czeck, 2010). . . . . . . . . . . 28

4.1 Trecho de um arquivo XMI do circuito modelado para controlar o tempo de um semáforo. . . . . . . . . . . . . . . . . . 38

4.2 Trecho de um arquivo XMI do circuito modelado para controlar o tempo de um semáforo. . . . . . . . . . . . . . . . . . . 42

4.3 Código utilizado para localizar o elemento que representa um diagrama de atividade no arquivo XMI. . . . . . . . . . . . . . . 43

4.4 Código utilizado para localizar os elementos que representam estados no arquivo XMI. . . . . . . . . . . . . . . . . . . . 43

4.5 Código de um template na linguagem VTL que representa um módulo em BSV, com chamadas à outros templates. . . . . . . . . 44

4.6 Exemplo de um template no qual é realizada uma iteração em uma coleção de regras da linguagem BSV. . . . . . . . . . . . . 46

4.7 Trecho de código utilizado para passar as informações coletadas durante o parser do arquivo XMI para os templates do Velocity. . 46

4.8 Saída da AST gerada pelo frontend do compilador C2BSV. . . . . 49

4.9 Saída da AST indicando que uma instrução ainda não foi imple-

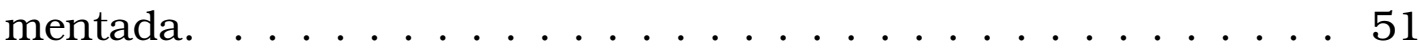

5.1 Instruções utilizadas para testar o processador. . . . . . . . . . . 57

5.2 Resultado da síntese do processador pela ferramenta Quartus II. 58

5.3 Resultado da síntese do filtro Sobel pela ferramenta Quartus II. . 65

A. 1 Código gerado do Processador. . . . . . . . . . . . . . . . 75

B.1 Código gerado do Sobel. . . . . . . . . . . . . . . . . . . . 79

C.1 Gramática do compilador C2BSV. . . . . . . . . . . . . . 85 



\section{Lista de Abreviaturas}

ASM Algorithmic State Machine

AST Abstract Syntax Tree

BSV Bluespec SystemVerilog

EDA Electronic Design Automation

ESL Electronic System Level

FPGA Field-Programmable Gate Array

HDL Hardware Description Language

IDE Integrated Development Environment

IP Intellectual Property

MEF Máquina de Estados Finitos

OMG Object Management Group

RTL Register Transfer Level

UML Unified Modeling Language

VHDL VHSIC Hardware Description Language

VHSIC Very High Speed Integrated Circuit

XML eXtensible Markup Language 



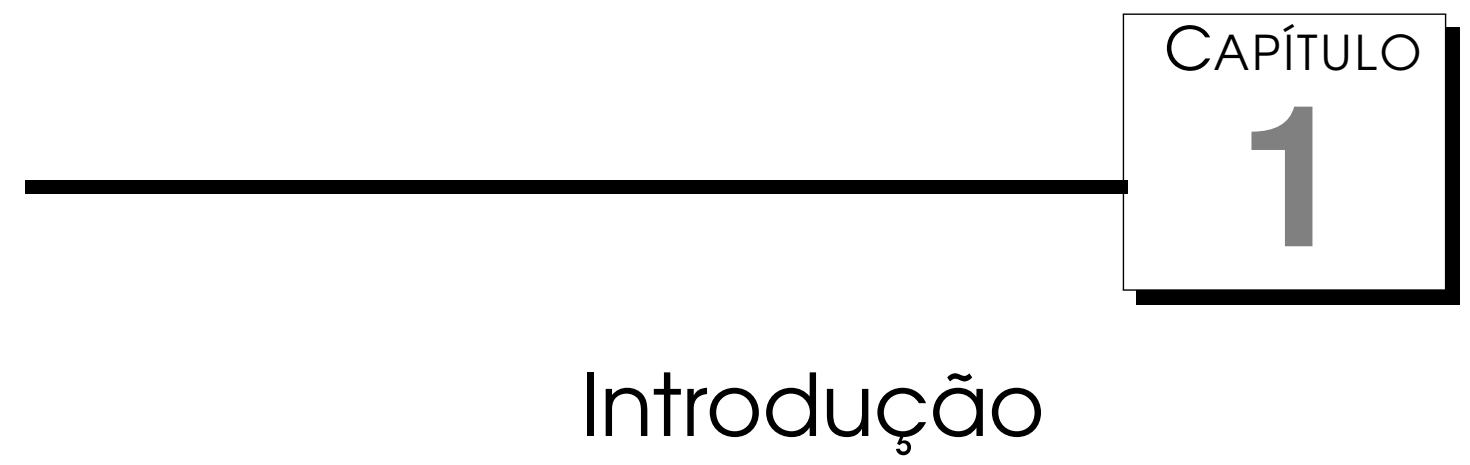

O contínuo avanço da capacidade dos circuitos integrados e a necessidade de arquiteturas de hardware cada vez mais complexas para lidar com os problemas atuais estão direcionando o desenvolvimento de sistemas digitais para ambientes de alto nível de abstração cada vez mais distantes dos detalhes do hardware (Shukla et. al., 2006). Inicialmente, os sistemas eram projetados no nível de portas lógicas (gates), mais adiante no nível de registradores (RTL Register Transfer Language), e agora, está tornando-se cada vez mais comum o desenvolvimento no nível de sistema (ESL - Electronic System-Level) (Densmore e Passerone, 2006) (Martin et. al., 2007). As vantagens deste tipo de desenvolvimento relacionam-se ao fato de facilitar o co-projeto de hardware e software, exploração do espaço de projeto, proporcionar maior velocidade na simulação e permitir o teste e o ajuste da arquitetura do sistema em alto nível. Além disso, permite o reuso do mesmo testbench tanto na fase de validação do modelo como no teste da arquitetura do sistema.

Com o desenvolvimento a partir de modelos ESL, o software pode ser tanto sintetizado para hardware como ser executado em processador embarcado (Berger, 2001), permitindo que sistemas cada vez mais complexos sejam criados com tempo de desenvolvimento cada vez menor, pois os recursos avançados das linguagens ESL, como o suporte à orientação a objetos, permitem uma melhor estruturação do problema, incentiva o reuso de código e ainda possibilita que projetistas de software desenvolvam e testem seus códigos antes mesmo da existência da arquitetura de hardware. No entanto, este processo na maioria das vezes exige o uso de metodologias e ferramentas extremamente complexas e caras.

Avançando um degrau no nível de abstração, encontram-se as ferramentas 
EDA (Electronic Design Automation) que por meio de um ambiente de programação visual, é possível modelar sistemas, realizar verificações e sínteses.

$\mathrm{O}$ uso de linguagens gráficas para modelar sistemas embarcados é uma abordagem que tem sido adotada por ferramentas comerciais e acadêmicas, uma vez que elas ajudam os desenvolvedores a visualizar e organizar sistemas complexos.

A UML é uma das linguagens gráficas mais adotadas através de seus diversos diagramas. Isto pode ser observado nos trabalhos de Moreira et. al. (2010); Wood et. al. (2008); Rieder et. al. (2006); Xi et. al. (2005) no qual usam os diagramas de Classes, Objetos, Pacotes e Estados para projetar hardware.

Entretanto, outros trabalhos tem utilizado outras abordagens para representar um modelo graficamente como em Abdel-Hamid et. al. (2004) que usa a linguagem DOT, ou então através do uso de ferramentas de terceiros para desenhar diagramas, como em de Pablo et. al. (2007), que desenvolveram um compilador para o diagrama ASM, e Tran et. al. (2005), onde os autores desenvolveram um complemento baseado em VBA (Visual Basic for Applications), ambos utilizando a ferramenta Microsoft Visio.

As vantagens por utilizar a linguagem UML é que ela já é um padrão bem estabelecido, tem uma popularidade alta dentre os desenvolvedores e existem diversas ferramentas de modelagens disponíveis, tanto comerciais quanto livres.

Além de trabalhos acadêmicos, algumas companhias importantes também mostram interesse nesta área, desenvolvendo ferramentas como Aldec (2010); Mentor Graphics Corporation (2006); HDL Works (2011), fornecendo aos programadores um ambiente completo para modelar complexos sistemas, realizar simulações interativas e na geração de código de descrição de hardware como VHDL e Verilog.

Nesta mesma linha, também há projetos open source como Duffner e Strobel (2010); University of Mannheim - Computer Architecture Group (2010) que fornecem não apenas boas soluções de sistemas mas também, por serem livres, permitem adicionar novas extensões ampliando suas funcionalidades.

Este trabalho está inserido no projeto RoboArch (Bonato e Marques, 2009), que teve início em 2008 durante o pós-doutoramento de Bonato com apoio da FAPESP (processo 2008/03446-1), e teve continuidade durante o desenvolvimento deste trabalho com um novo apoio da FAPESP (processo 2010/127481). O RoboArch, representado na figura 1.1, é uma ferramenta baseada em componentes para desenvolvimento de arquitetura de hardware para robôs móveis. Ela fornece uma plataforma de desenvolvimento em um ambiente visual baseado em componentes. Ainda na figura 1.1 é possível visualizar em destaque onde este trabalho está situado. 


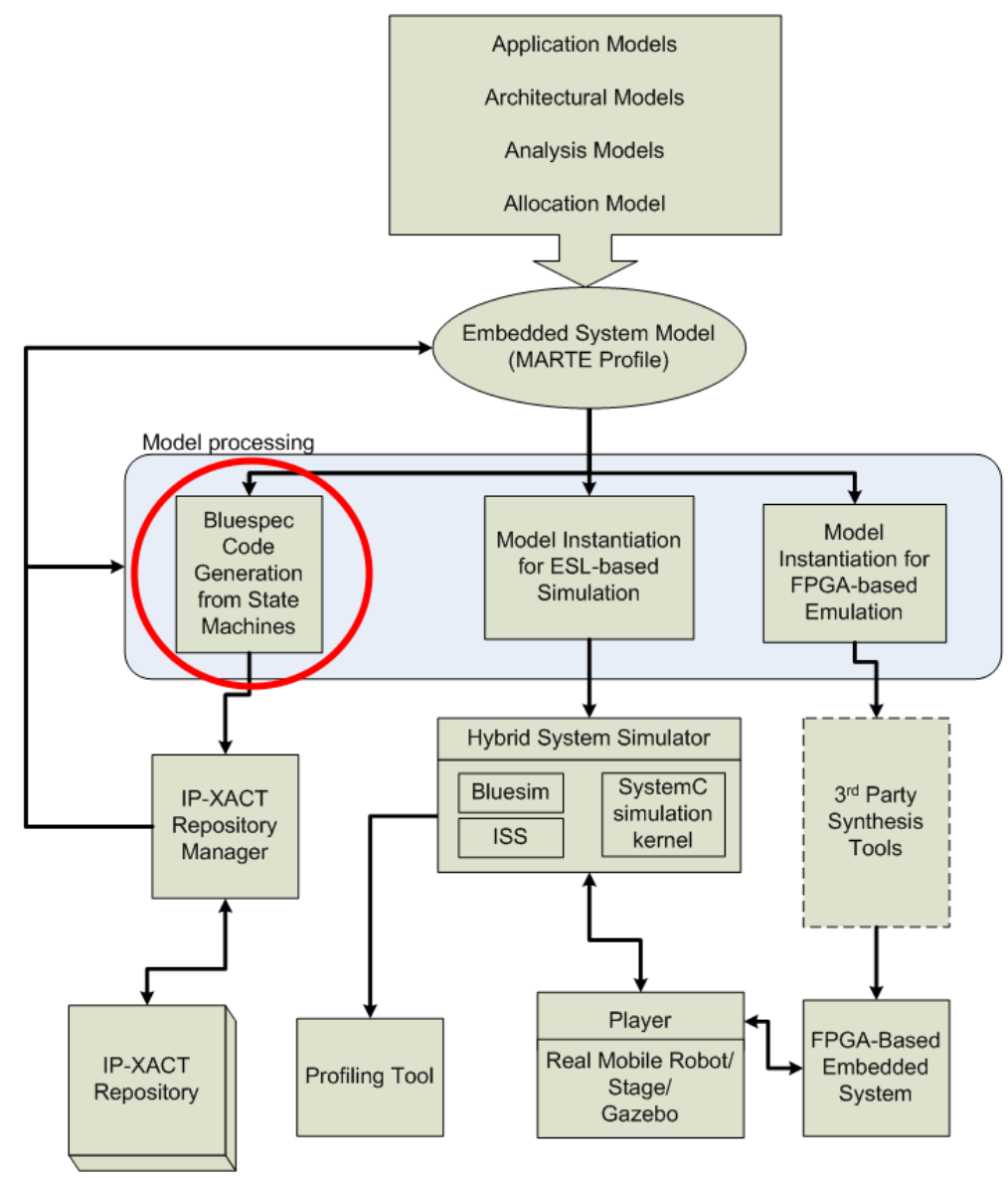

Figura 1.1: Diagrama de blocos dos principais elementos do projeto RoboArch com o destaque do módulo onde este trabalho está situado.

Este trabalho propõe o desenvolvimento de uma ferramenta que permite o projeto de arquiteturas de hardware modeladas com Máquinas de Estados Finitos (MEF) representadas em UML (Unified Modeling Language). Esta ferramenta, denominada UML2BSV, é capaz de traduzir automaticamente um modelo UML para a linguagem de descrição de hardware em alto nível Bluespec SystemVerilog (BSV) (Bluespec Inc, 2010). O código gerado representa todo o controle da máquina de estados, deixando o desenvolvedor responsável por descrever o comportamento de cada estado utilizando a linguagem $\mathrm{C}$. A ferramenta também aceita código BSV para descrever as ações no estado, sendo nesse caso, a linguagem fonte a mesma de destino. Porém, com o controle das ações dado por meio da máquina de estados em UML.

Para traduzir a linguagem C, a ferramenta UML2BSV faz chamadas ao compilador C2BSV, que também faz parte deste trabalho, para traduzir o respectivo código $\mathrm{C}$ em BSV e, desta forma, manter o código gerado automaticamente totalmente sintetizável.

Uma visão geral do fluxo deste processo está representado na figura 1.2, 
onde uma modelagem é passada como parâmetro de entrada à ferramenta UML2BSV. Durante o processo de geração de código, o compilador C2BSV pode ser chamado diversas vezes pela UML2BSV . O resultado final é o código BSV gerado automaticamente.
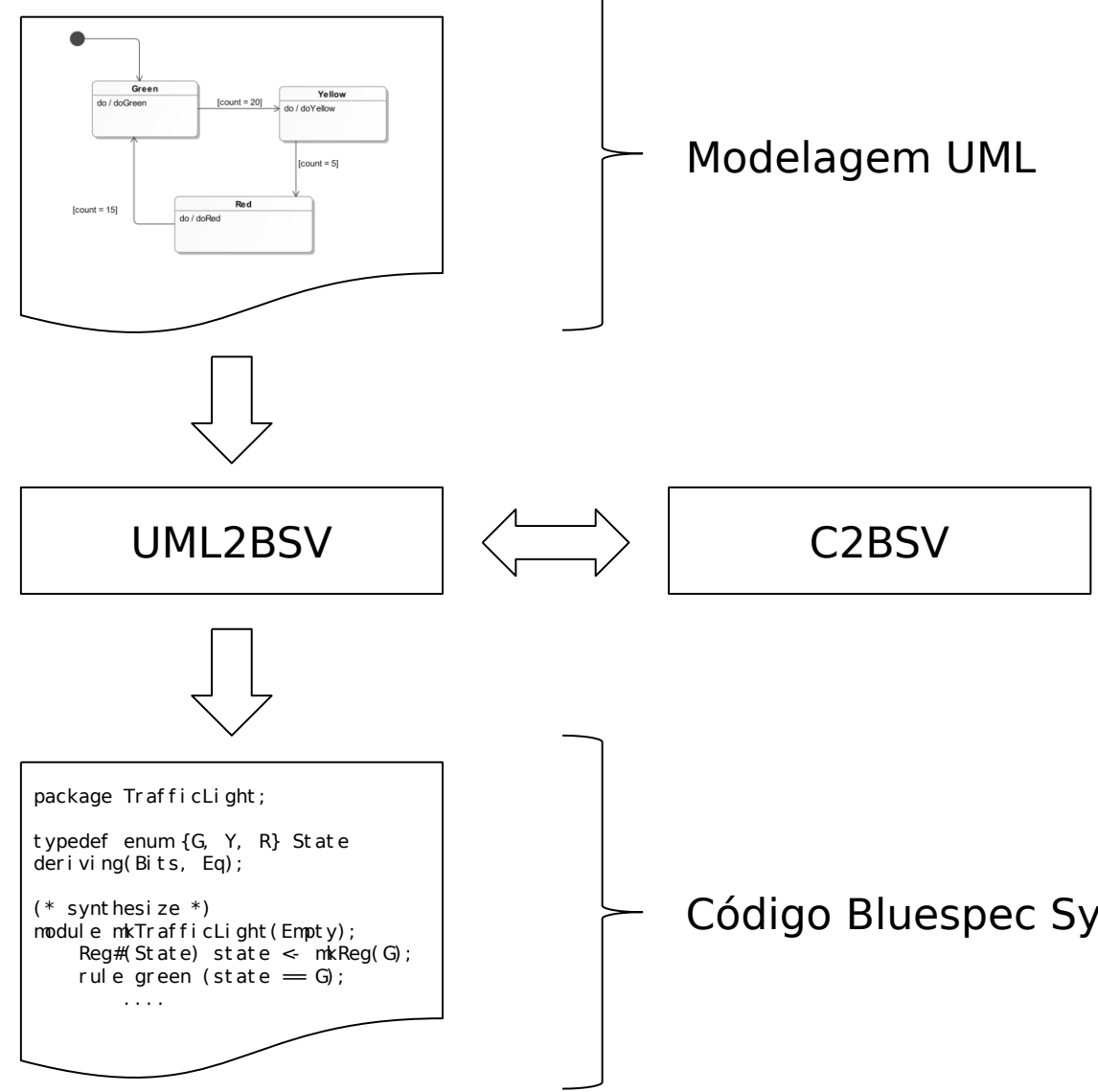

Figura 1.2: Visão geral do processo de geração de código Bluespec SystemVerilog.

\subsection{Objetivos}

Nesta seção será apresentado o objetivo geral deste projeto assim como seus objetivos específicos.

\subsubsection{Objetivo Geral}

O objetivo deste trabalho é gerar código Bluespec SystemVerilog a partir de modelagem de diagramas da UML em conjunto com a linguagem de programação C. 


\subsubsection{Objetivos Específicos}

Os objetivos específicos deste trabalho são:

- estudar os diagramas da UML para determinar quais deles serão necessários durante o processo de desenvolvimento de um hardware;

- pesquisar meios para que não seja necessária a criação de novas extensões na UML;

- desenvolver uma ferramenta para interpretar uma modelagem UML e gerar o respectivo código em Bluespec SystemVerilog;

- definir uma representação intermediária da modelagem UML;

- criar templates para auxiliar o processo de geração de código;

- desenvolver um compilador para traduzir código C para a linguagem Bluespec SystemVerilog;

- realizar testes com estudos de caso para validar a ferramenta.

\subsection{Justificativa}

Com sistemas embarcados cada vez mais complexos e prazos de desenvolvimento cada vez menores, os desenvolvedores dependem cada vez mais de ferramentas ágeis no sentido de acelerar o desenvolvimento por meio da abstração dos detalhes do hardware e da automatização do processo de geração e otimização dos sistemas implementados. Para isso, linguagens de programação de alto nível são necessárias. O mercado está guiando a área de sistemas embarcados neste sentido, sendo necessário criar novas tecnologias para acompanhar esta demanda.

Assim, como a linguagem $\mathrm{C}$ trouxe grandes vantagens para se desenvolver sistemas complexos de forma mais simples e rápida em relação ao assembly, o mesmo está acontecendo na área de hardware onde existem várias linguagens que fornecem ao programador um nivel maior de abstração, saindo do RTL (VHDL ou Verilog) e indo, por exemplo, para o SystemC (OSCI, 2010) ou Handel-C (Mentor Graphics, 2010). Se por um lado, quanto mais alto o nível de abstração mais passos e ferramentas de suporte são necessários para alcançar o grande desafio que é deixar a parte de síntese automatizada, por outro lado, ganha-se em produtividade, acelerando o processo de desenvolvimento. 
Uma das formas utilizadas para diminuir a complexidade no desenvolvimento de sistemas embarcados é através da modelagem visual utilizando diagramas de máquina de estado em conjunto com uma linguagem de programação amplamente utilizada como, por exemplo, a linguagem C (Edwards, 2006; TIOBE Software, 2010; DedaSys LLC, 2010). Outra característica que pode contribuir no desenvolvimento de arquiteturas em hardware é determinar partes do sistema que podem ser executadas em paralelo, sem a necessidade do projetista conhecer detalhes técnicos de como é a implementação em hardware, bastando apenas colocar o respectivo código dentro de um estado. Aliás, esta característica de paralelizar códigos, comum em sistemas digitais, está caminhando para a computação de uso geral, uma vez que os processadores de um único núcleo chegaram no limite de seu desempenho, dando início a era multicore (Fuller e Millett, 2011).

Existem ferramentas comerciais como ActiveHDL (Aldec, 2010) e QFSM (Duffner e Strobel, 2010), open source, onde o objetivo é gerar código por meio de uma modelagem visual. Porém, elas utilizam como entrada uma linguagem de descrição de hardware (HDL), como Verilog ou VHDL, e a saída segue a mesma linguagem utilizada na entrada. Já a proposta deste trabalho é ter como entrada, além de Bluespec, a linguagem C e saída a linguagem Bluespec.

A escolha pela utilização de máquina de estado se deve ao fato de que ela pode simplificar consideravelmente o processo de desenvolvimento de sistemas mais complexos, deixando bem definida as tarefas a serem realizadas.

A grande vantagem de gerar código Bluespec é que ele permite realizar simulações muito rápidas, se comparado com VHDL ou Verilog, reaproveitar os testbenchs para outras finalidades, melhorar o desempenho e detectar erros de forma mais fácil, fazer exploração e verificação da arquitetura e posteriormente gerar um código RTL. Além disso, ela é totalmente sintetizável e o hardware gerado pelo compilador Bluespec é considerado eficiente, segundo Gruian e Westmijze (2008) e Agarwal (2009).

\subsection{Organização do Texto}

Este trabalho está organizado como segue: O Capítulo 2 apresenta uma revisão dos assuntos que estão ligados diretamente com este projeto e alguns trabalhos relacionados. O Capítulo 3 aborda as ferramentas que foram utilizadas neste trabalho. No Capítulo 4, encontra-se a implementação desta ferramenta. No Capítulo 5 são demonstradas as aplicações desta ferramenta. Por fim, o texto é finalizado com a Conclusão e trabalhos futuros. 


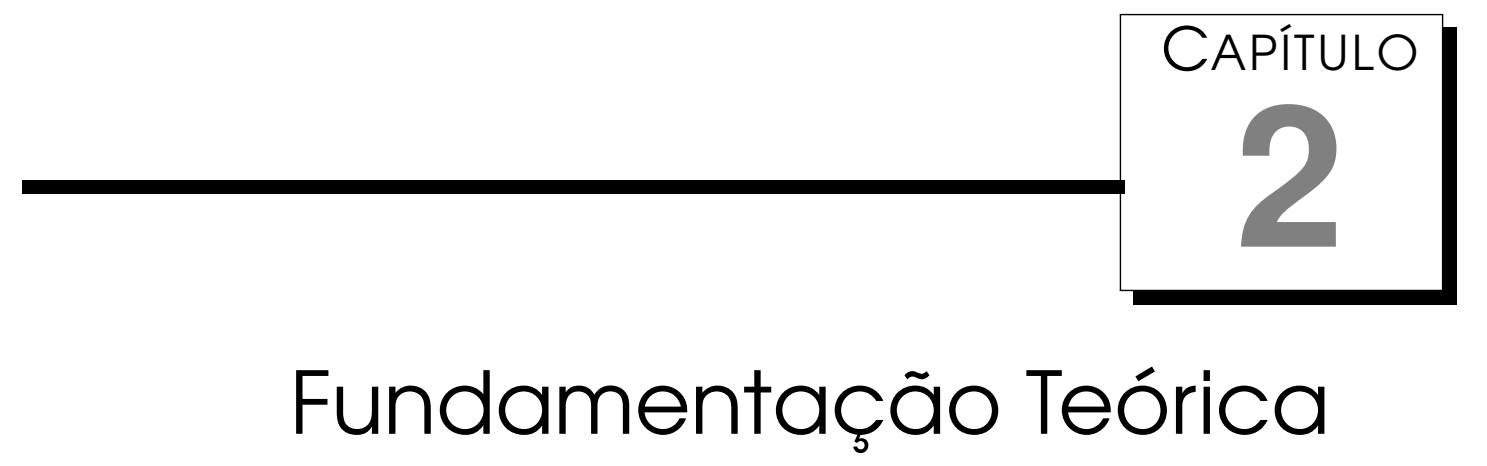

Alguns conceitos utilizados neste trabalho serão descritos nas próximas seções deste capítulo, assim como alguns trabalhos relacionados à geração de código a partir de uma linguagem visual.

\subsection{Unified Modeling Language (UML)}

A UML é uma linguagem gráfica utilizada para especificar, visualizar, construir e documentar sistemas por meio de seus diversos diagramas. Além disso, com o uso da UML, uma equipe de desenvolvimento passa a ter um padrão permitindo a seus membros realizarem colaborações através de uma linguagem comum a todos (Pilone e Pitman, 2005).

Seu surgimento teve como base três técnicas que já estavam sendo aplicadas com sucesso na modelagem de sistemas. Estas técnicas e seus respectivos autores foram:

- Projeto orientado a objeto (Object-oriented design), por Grady Booch;

- Técnica de modelagem de objetos (Object-modeling technique), por James Rumbaugh;

- Engenharia de software orientado a objetos (Object-oriented software engineering), por Ivar Jacobson.

A união destes três métodos deu origem à primeira versão da UML, em 1994. Já em 1997, a UML passou a ser aceita como um padrão pela OMG (Object Management Group), um consórcio internacional sem fins lucrativos responsável por definir alguns padrões adotados na indústria da computação. 
Toda a definição da UML está descrita em dois documentos: um de infraestrutura e outro de superestrutura. O primeiro define as construções básicas da linguagem e é mais direcionado aos desenvolvedores de ferramentas de modelagem. Já o segundo aborda todos os elementos da UML disponíveis para a modelagem de sistemas (Grässle, 2005).

A figura 2.1 ilustra um diagrama de classes onde estão representados todos os 14 diagramas da UML. Eles estão divididos em duas categorias principais, onde metade deles são classificados como estruturais e a outra metade como comportamentais.

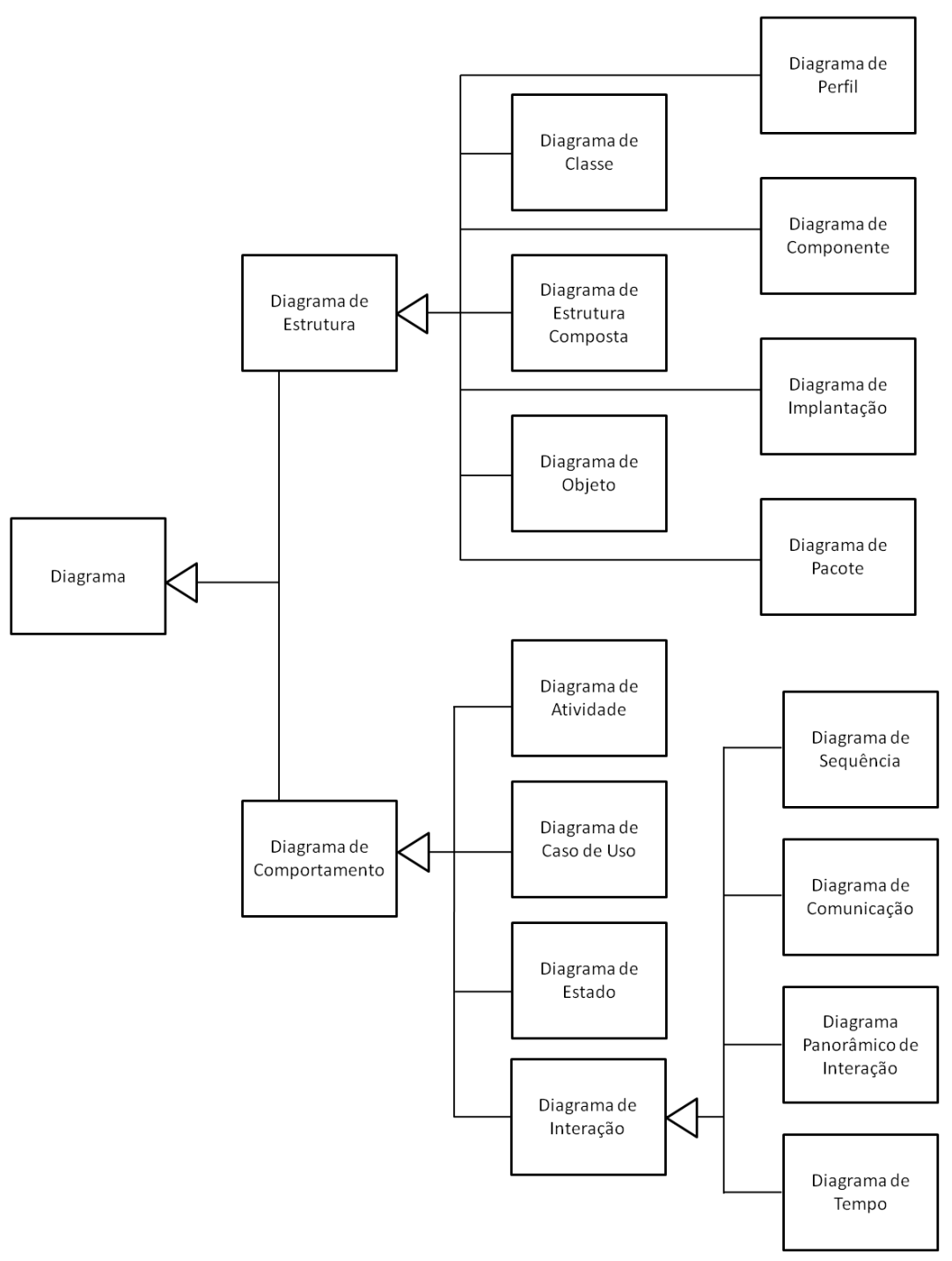

Figura 2.1: Diagrama de classes com a classificação dos 14 diagramas da UML. Adaptado de (Fowler, 2003).

Com os diagramas estruturais é possivel representar todas as características que um sistema deve possuir, onde são abordados aspectos das estruturas de um sistema que está sendo modelado. Os diagramas que fazem parte desta categoria, são:

- Diagrama de classe: descreve a estrutura do sistema através de classes, 
que podem possuir atributos e operações, e seus respectivos relacionamentos com as outras classes do diagrama;

- Diagrama de objeto: é a visão, em um momento de tempo específico, das instâncias de classes;

- Diagrama de pacote: utilizado para mostrar a divisão lógica dos módulos de um sistema e suas respectivas dependências;

- Diagrama de estrutura composta: mostra a estrutura interna de uma classe;

- Diagrama de componente: mostra como as classes de sistema são divididas em componentes e suas dependências;

- Diagrama de implantação: utilizado para descrever os equipamentos e o ambiente de execução utilizado na implantação do sistema;

- Diagrama de perfil: utilizado para definição de perfis através de esteriótipos.

Já os diagramas comportamentais tem foco nas atividades, operações, fluxos das informações, lógica de negócios que devem ocorrer no sistema, onde é possivel detalhar passo a passo o comportamento em cada etapa. Ainda nesta categoria, existe uma sub-categoria com 4 diagramas onde é possível representar o fluxo de controle e dos dados de um sistema. Os diagramas da categoria dos comportamentais, são:

- Diagrama de caso de uso: representa um sistema baseado em atores e seus respectivos relacionamentos com os casos de uso;

- Diagrama de estado: descreve um sistema por meio de uma máquina de estados;

- Diagrama de atividade: mostra o passo a passo de todos os fluxos de atividades que ocorrem em um sistema;

- Diagrama de sequência: mostra a comunicação entre os objetos por meio de uma sequência de mensagens;

- Diagrama de comunicação: mostra como se dá a interação entre os objetos;

- Diagrama panorâmico de interação: fornece uma visão geral no qual os nós representam diagramas de comunicação; 
- Diagrama de tempo: representa as interações de um sistema com o foco nas restrições de tempo.

Durante a modelagem de um sistema não é necessário utilizar todos os diagramas. Pelo contrário, Fowler (2003) cita a mítica proporção de que $20 \%$ da UML é o suficiente para realizar $80 \%$ das tarefas. Alguns destes diagramas tem suas funcionalidades bem parecidas e a escolha dentre eles acaba dependendo do foco que se deseja dar a um determinado aspecto da modelagem.

Estão disponíveis diversas ferramentas para realizar modelagem UML que vão desde aplicações bem simples, oferecendo os recursos básicos, até ambientes complexos com várias funcionalidades. Também é possível realizar a opção por ferramentas open source, onde normalmente recebe colaboração de vários desenvolvedores ao redor do mundo, ou então versões comerciais, normalmente utilizada por equipes de desenvolvimento nas empresas.

\subsection{Máquina de Estados Finitos}

O estudo de máquina de estados finitos (MEF) faz parte da teoria dos autômatos. Uma MEF tem o objetivo de modelar o comportamento de um sistema que pode ser representado por um número finito de estados. Máquina de estado está relacionada a modelos matemáticos que tentam abstrair fenômenos físicos. Elas são muito utilizadas na área de projeto de circuito digitais e na área de compiladores para realizar a análise léxica de código fonte. Porém, o uso de $\mathrm{MEF}$ não é restrito a área da computação, podendo ser aplicado também em problemas de vários campos de investigação, como na biologia, medicina e administração (Gill, 1962).

Através de um modelo matemático, uma $\mathrm{MEF} M$ pode ser representada formalmente pela sêxtupla $M=\left(\Sigma, \Gamma, Q, q_{0}, \delta, \omega\right)$, onde:

- $\Sigma$ é o alfabeto (conjunto) de entrada

- $\Gamma$ é o alfabeto (conjunto) de saída

- $Q$ é um conjunto finito de estados

- $q_{0}$ é o estado inicial de $Q$

- $\delta$ é a função de transição de estados: $\delta: Q \times \Sigma \rightarrow Q$

- $\omega$ é a função de saída, onde:

- $\omega: Q \rightarrow \Gamma$ (modelo Moore)

- $\omega: Q \times \Sigma \rightarrow \Gamma$ (modelo Mealy). 
Uma MEF também pode ser representada de forma gráfica através de um diagrama de estados ou por um diagrama algorítmico (ASM), ambos mostrando os estados, entradas, saídas e transições. Uma máquina de estado pode ser projetada a partir de dois modelos: Moore (1956) e Mealy (1955). Esses nomes são em homenagem a Edward Moore e George Mealy que investigaram estes comportamentos na década de 50 .

Na máquina de estado do tipo Moore, as saídas ocorrem depois que a transição para um novo estado é completada e elas dependem apenas do estado atual da máquina. Na máquina de estado do tipo Mealy, a saída é gerada na transição entre os estados e é baseada em função do estado atual e do valor de suas entradas. Com isso, consegue-se uma maior flexibilidade durante o projeto.

Uma máquina de estados é formada por nós, que representam os estados e são desenhados como círculos, e por arcos direcionados representando as transições entre os estados. Uma expressão lógica é associada a cada transição, representando uma condição específica, e ela ocorre sempre que for avaliada como verdadeira, como resposta a um evento de entrada. Uma transição pode estar associada a dois estados diferentes $\left(q_{i}, q_{j}\right)$ ou ao mesmo estado $\left(q_{i}, q_{i}\right)$ (Hopcroft et. al., 2000).

Como forma de ilustrar um exemplo, na figura 2.2 é apresentada uma MEF do tipo Moore. Sua função é detectar a sequência '11' na entrada. Para isto, foram necessários utilizar três estados. A cada entrada '1' ocorre uma transição para o próximo estado. Quando o estado $\mathrm{C}$ fica ativo significa que foi detectada uma sequência de ' 11 ' e a saída passa de 0 para 1 .

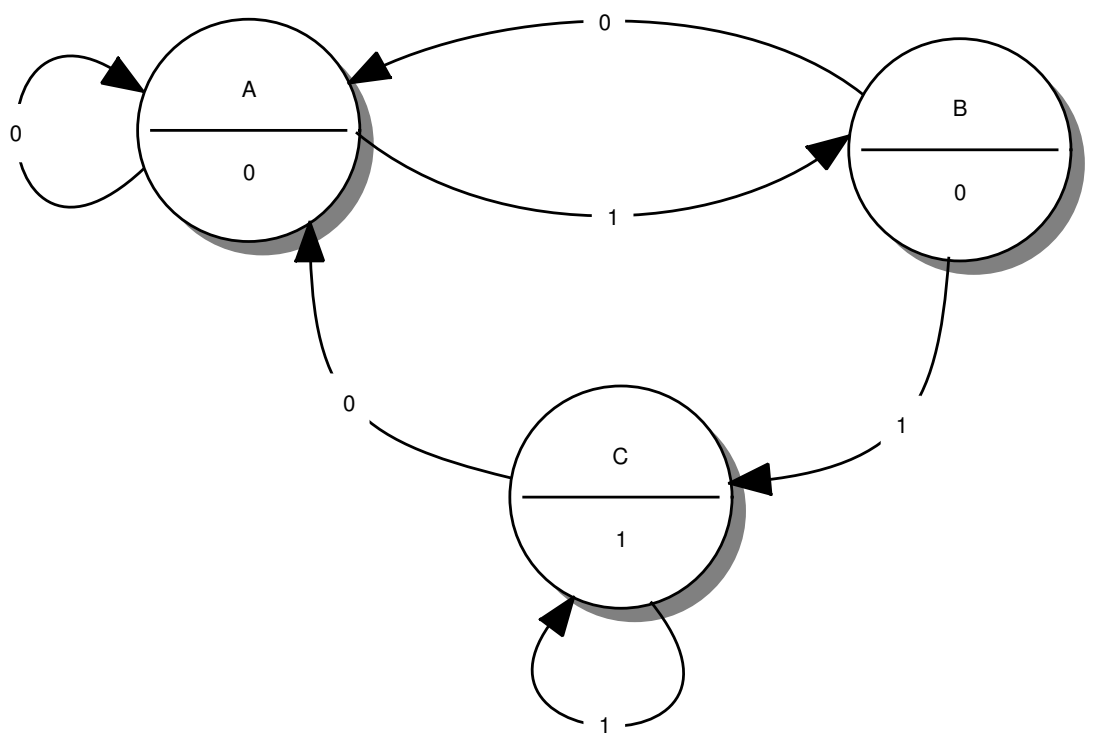

Figura 2.2: Exemplo de uma MEF tipo Moore para detectar a sequência '11'.

Na figura 2.3, encontra-se um exemplo de uma máquina de estado do tipo Mealy baseado no mesmo exemplo anterior da máquina do tipo Moore (figura 
2.2). Neste caso pode-se observar que foram necessários utilizar apenas dois estados para manter o mesmo comportamento do exemplo anterior.

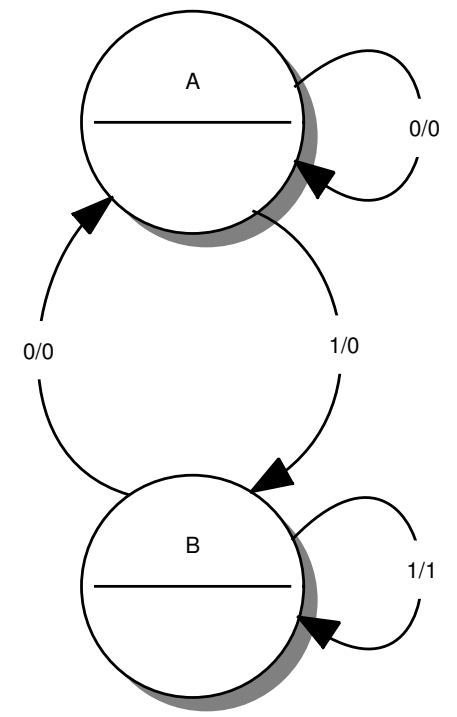

Figura 2.3: Exemplo de uma MEF tipo Mealy para detectar a sequência '11'.

A principal vantagem na utilização do modelo de Mealy em relação ao de Moore é que, como as saídas de um modelo de Mealy são em funções tanto da entrada quanto do estado, o projetista tem mais flexibilidade na concepção de funções de saída e de transição de estados, e com isso poderá ter uma MEF com menos estados do que uma MEF equivalente no modelo de Moore (Nelson et. al., 1995). Além disso, nada impede que o projetista utilize um modelo misto de Moore e Mealy.

A outra maneira de representar uma MEF graficamente é através do diagrama ASM, que é parecido com um fluxograma e possui três elementos básicos, mostrados na figura 2.4 .

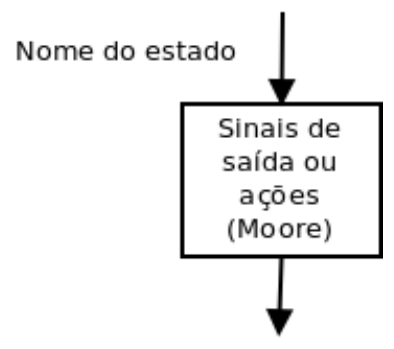

(a) Caixa de estado

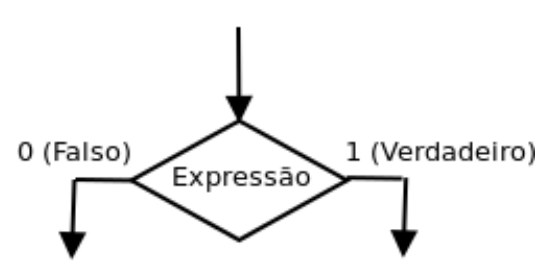

(b) Caixa de decisão

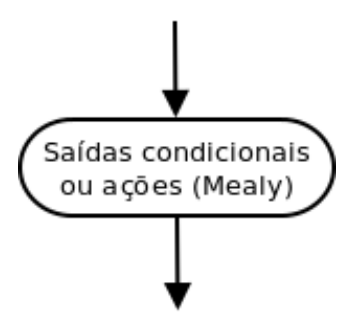

(c) Caixa de saída condicional

Figura 2.4: Elementos de um diagrama ASM adaptado de (Brown, 2005).

- A caixa de estado (2.4(a)) é o equivalente ao estado em uma MEF com seu nome indicado fora da caixa. As saídas (no modelo Moore) e ações ficam dentro do retângulo. 
- A caixa de decisão (2.4(b)) indica a condição que será testada na transição de um estado para outro em relação às entradas da MEF. Ela representa a transição em uma MEF.

- A caixa de saída condicional $(2.4(\mathrm{c}))$ representa os sinais de saída (no modelo Mealy) dependendo do valor do estado e das entradas da MEF. Este elemento fica localizado no caminho entre a caixa de decisão e a de estado.

Com estes elementos é possível criar um diagrama ASM conforme ilustrado na figura 2.5 .

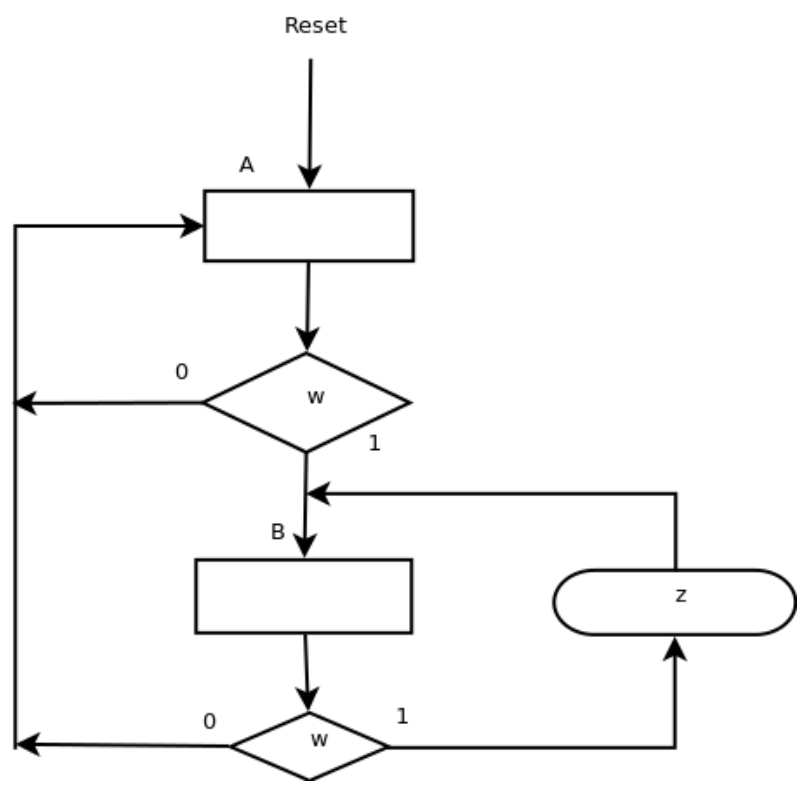

Figura 2.5: Representação de um diagrama ASM (Nelson et. al., 1995).

Embora um diagrama de estado descreva todo o comportamento de uma MEF graficamente, pode ser conveniente representar estas informações do diagrama em um formato tabular. Esta outra forma de representação pode ser útil ao projetista na elaboração de uma $\mathrm{MEF}$, por exemplo, durante o processo de redução de estados. A tabela de estados mostra todas as transições do estado atual para o próximo, com diferentes valores de entrada, e a respectiva saída. A tabela 2.1 mostra representação tabular da máquina de estado Moore da figura 2.2 .

\subsubsection{Minimização de estados}

Nos projetos iniciais de MEF mais complexas, as primeiras versões podem resultar no uso de mais estados do que o necessário. Minimizar o uso de estados é importante pois com isso o circuito gerado será menor e ocupará menos espaço em um dispositivo lógico. Dizer que o número de estados de uma MEF 
Tabela 2.1: Tabela de estado da MEF da figura 2.2

\begin{tabular}{|c|c|c|c|}
\hline Estado Atual & Entrada & Próximo Estado & Saída \\
\hline \hline A & 0 & A & 0 \\
\hline A & 1 & B & 0 \\
\hline B & 0 & A & 0 \\
\hline B & 1 & C & 1 \\
\hline C & 0 & A & 0 \\
\hline C & 1 & C & 1 \\
\hline
\end{tabular}

podem ser reduzidos é afirmar que alguns estados podem ser considerados equivalentes no âmbito geral do comportamento da MEF.

Gill (1962) formaliza esta definição utilizando a notação $M_{1} \mid \sigma_{i}$ e $M_{2} \mid \sigma_{j}$ que deve ser compreendida como "máquina $M$ no estado $\sigma$ ". Assim, ele define que um estado $\sigma_{i}$ de uma máquina $M_{1}$ e um estado $\sigma_{j}$ de uma máquina $M_{2}$ são ditas equivalentes se para cada sequência de entrada em $M_{1} \mid \sigma_{i}$ e $M_{2} \mid \sigma_{j}$ for produzida uma sequência de saída idêntica. $M_{1}$ e $M_{2}$ podem se referir a uma mesma máquina.

\subsection{Compiladores}

O estudo de compiladores envolve o conhecimento de diversas áreas como linguagens formais, autômatos finitos, estrutura de dados, matemática discreta, teoria de linguagens e gramática. Quando os primeiros compiladores começaram a surgir nos anos 50, eles eram considerados programas extremamente difíceis de serem implementados. Mas com o passar das décadas, foram aperfeiçoadas diversas técnicas e ambientes de programação que tem facilitado muito a construção destes programas (Aho et. al., 1986).

Compilador pode ser definido como um programa que faz tradução de um outro programa de entrada escrito em uma linguagem (código fonte) para um programa de saída equivalente em outra linguagem (código objeto) (Delamaro, 2004). Durante este processo podem ocorrer erros e, neste caso, o compilador deve ser capaz de informar ao usuário qual foi o erro e em que local ele foi gerado (Parr, 2007).

Os compiladores tem uma importância muito grande na computação pois ele precisa garantir que o código objeto gerado produza o mesmo comportamento esperado pelo programador. Além disso, o compilador pode também melhorar o programa objeto realizando diversas medidas de otimizações do código, algo que é essencial em sistemas embarcados, visando ter um código mais enxuto onde o tempo de execução, tamanho e consumo de energia sejam 
os menores possíveis (Wolf, 2005).

O processo de compilação pode ser dividido em seis etapas, onde a saída de uma etapa serve como entrada para a seguinte. As etapas são: análise léxica, análise sintática (também conhecida como parsing), análise semântica, geração de código intermediário, otimização e a geração de código objeto. Além destas etapas, um compilador também possui uma tabela de símbolos que está disponível em todas as fases do processo de compilação (Muchnick, 1997).

As quatro primeiras compõem o frontend do compilador e as duas últimas fazem parte do backend. No backend é gerado o código objeto a partir de uma representação intermediária, além de utilizar informações importantes que constam em uma estrutura de dados chamada Tabela de Símbolos, ambos gerados no frontend (Aho et. al., 1986).

A figura 2.6 mostra as fases de um compilador e a respectiva divisão do frontend e do backend. Esta divisão facilita na manutenção de um compilador, onde, se for necessário gerar um código objeto para uma nova arquitetura, é possivel aproveitar o frontend e apenas criar um novo backend.

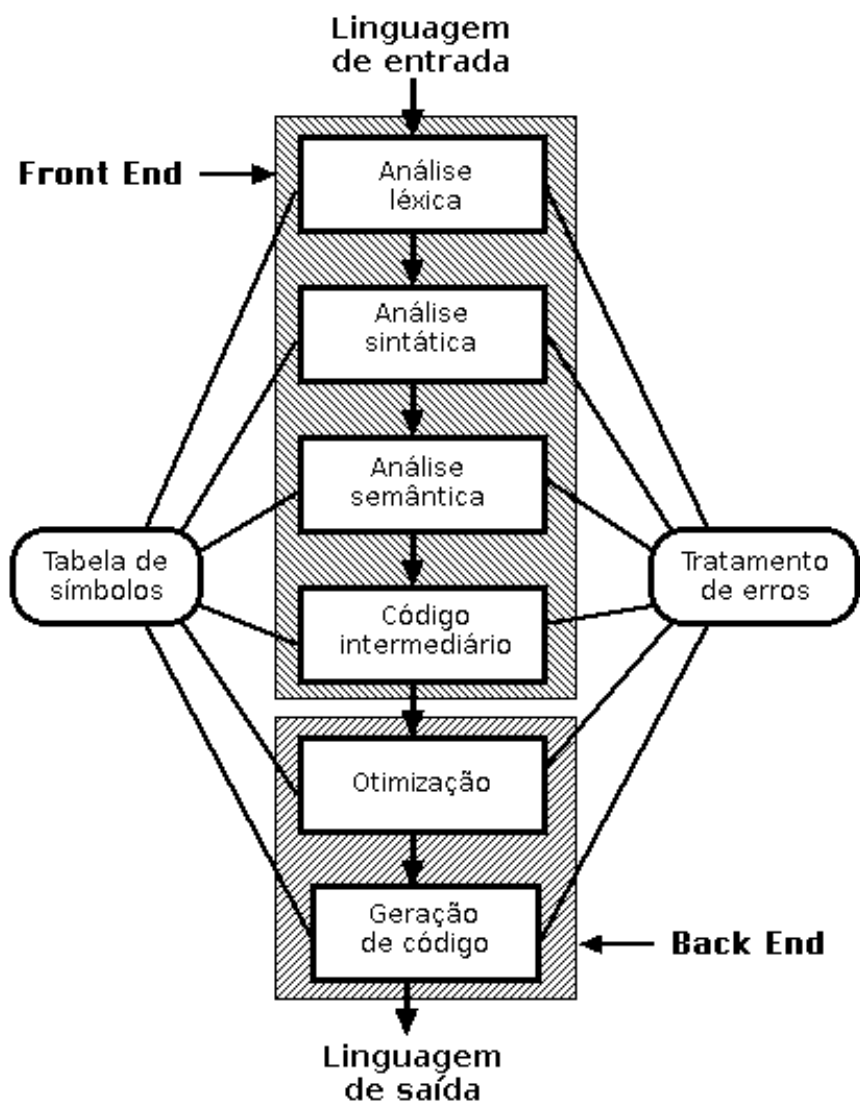

Figura 2.6: Fases de um compilador. Adaptado de (Aho et. al., 1986). 


\subsection{Frontend}

É no frontend onde se inicia o processo de compilação a partir de um arquivo texto com o código fonte que é lido pelo analisador léxico e que sua função é criar uma cadeia de tokens à partir deste arquivo texto. Esta etapa está ilustrada na figura 2.7 .

Token pode ser definido como uma unidade primitiva de uma linguagem de programação como identificadores, palavras-chave, números, cadeias de caracteres, operadores e delimitadores (Safonov, 2010). Nesta fase são ignorados os espaços em branco e os comentários.

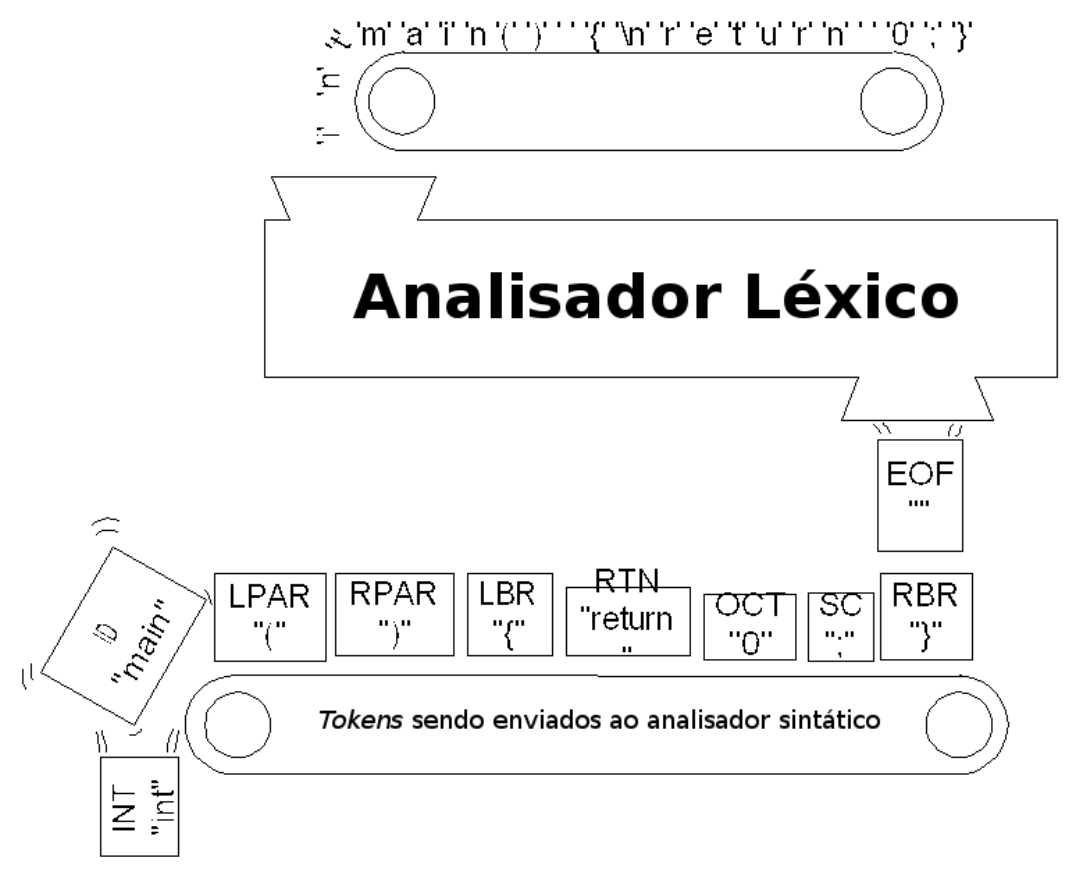

Figura 2.7: Analisador Léxico. Adaptado de (Norvell, 2007).

Na sequência, essa cadeia de tokens é enviada ao analisador sintático onde será gerada uma estrutura de árvore representando a hierarquia do programa a ser compilado. Outra função importante nesta fase é a de reportar erros de sintaxe ao programador, como por exemplo, a falta de um parêntese ou do sinal ponto-e-vírgula. Esta etapa está representada na figura 2.8.

Ao final da análise sintática, tem-se a árvore sintática abstrata (AST). Ela é uma importante estrutura de dados, fundamental para facilitar as tarefas do analisador semântico, otimizador e do gerador de código.

A análise semântica, que vem em seguida, pode ser a última etapa realizada no frontend. Ela faz uso da AST para realizar a checagem de tipos, fluxo de controle e ocorrência de declarações de variáveis em duplicidade. Nesta etapa pode ocorrer a coerção, que é quando o compilador realiza a conversão automática de um tipo de dado para que ele fique adequado à instrução, emitindo uma mensagem de alerta, mas não de erro, para o usuário no momento da compilação. 


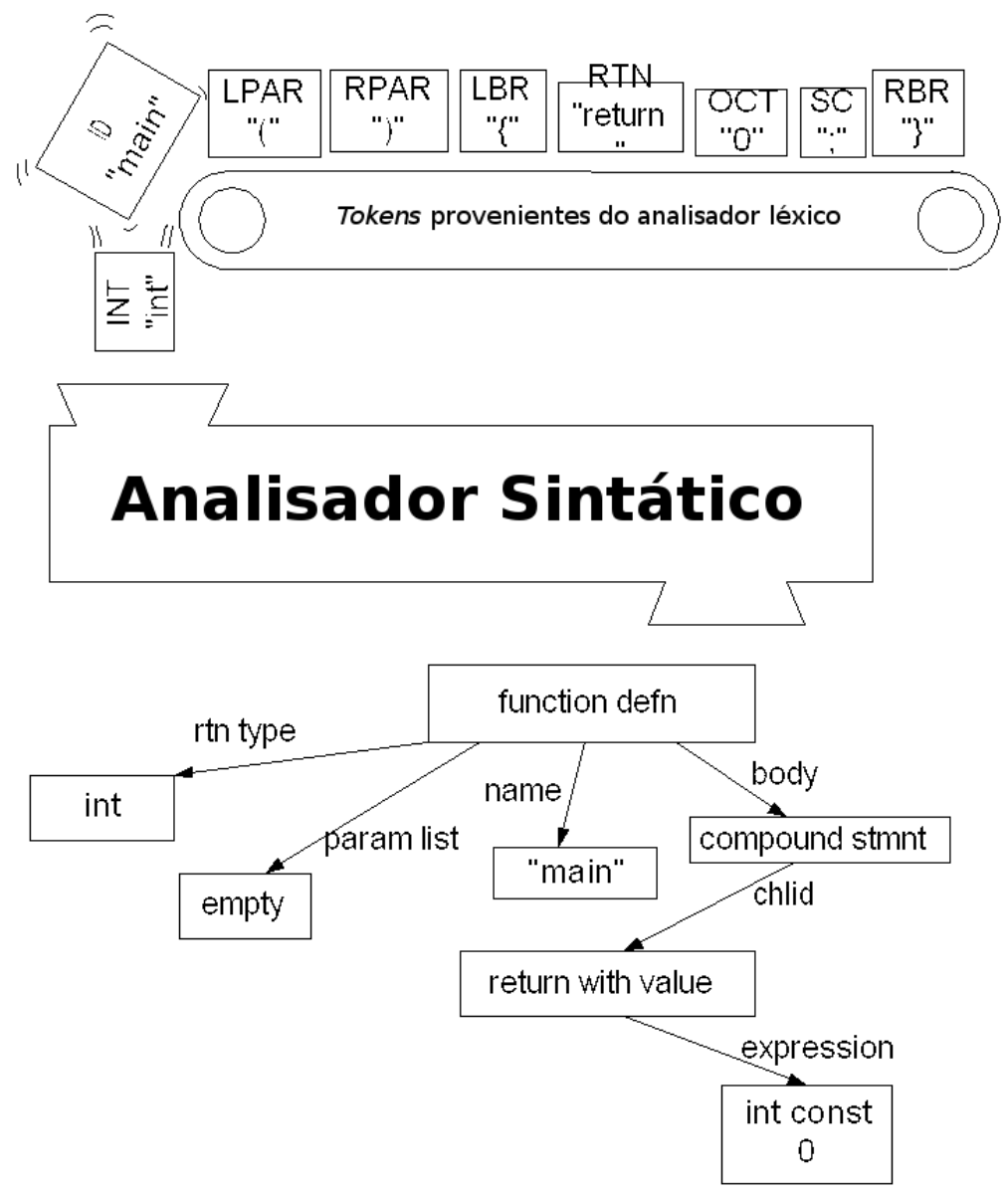

Figura 2.8: Analisador Sintático. Adaptado de (Norvell, 2007).

Opcionalmente, um compilador também pode gerar um código intermediário como um programa para uma máquina abstrata. Espera-se que esta representação possua as características de ser facilmente gerada e facilmente traduzida para o código objeto, mitigando assim o trabalho que será realizado no backend.

\subsubsection{Backend}

As etapas finais do processo de compilação, compreendida por otimização e geração de código, ocorrem no backend.

A otimização de código, que é uma etapa opcional neste processo de compilação, pode ser divida em duas categorias: as que são independentes de plataforma e as que geram código para uma arquitetura específica. No caso da primeira categoria, pode ocorrer eliminação de instruções redundantes, realização de simplificações algébricas, remoção de região com código que nunca será executado, entre outras. No caso de compilador dependente de uma arquitetura, podem ser realizadas otimizações, por exemplo, analisando quais são as variáveis mais utilizadas e deixá-las sempre que possivel em registradores. Neste caso, o compilador fica preso à uma determinada arquitetura. 
Em alguns compiladores é possivel definir qual o grau de otimização desejado, porém quanto maior for o grau, maior será o tempo gasto na etapa de otimização, podendo consumir boa parte de todo o tempo gasto na compilação. Otimizações simples, que não consomem muito tempo, já podem trazer resultados significativos na melhoria do código gerado (Aho et. al., 1986).

A última etapa da fase de compilação é a geração de código, que utiliza o código intermediário como entrada e tem como saída o código objeto. $\mathrm{O}$ código gerado é específico para uma máquina, mesmo que virtual, e para um determinado sistema operacional. Espera-se também que o código gerado utilize de forma efetiva os recursos disponiveis na arquitetura alvo.

\subsection{RoboArch}

O projeto RoboArch (Bonato e Marques, 2009) propõe um framework para modelagem, simulação e síntese de sistemas embarcados para a robótica móvel baseado na combinação dos recursos de meta-modelagem, que permite representar um sistema heterogêneo em uma única linguagem, e ESL, que possibilita a aproximação dos aspectos de baixo nível da arquitetura de um sistema embarcado ao seu modelo abstrato. Desta forma, é possível criar um fluxo de desenvolvimento completo, partindo das especificações dos requisitos de hardware e software até chegar ao mapeamento das funcionalidades do software aos serviços fornecidos pelos recursos do hardware.

A ferramenta tem o propósito de acelerar o processo de construção e validação de arquitetura de hardware e software e incentivar o ensino e a pesquisa nas áreas de sistemas embarcados e robótica móvel, estando tudo isso apoiado em metodologias recentes de meta-modelagem e desenvolvimento ESL.

A modelagem da aplicação e da arquitetura de hardware se dá através de diagramas UML, onde o usuário poderá gerar IPs em Bluespec seguindo a padronização do IP-XACT, a partir de diagrama de máquina de estado e gerar modelos de hardware para síntese em dispositivos FPGAs. A ferramenta ainda contará com o recurso de profiling para detectar gargalos de processamento.

O usuário poderá realizar a simulação do modelo de modo integrado com um ambiente de robôs móveis, podendo a simulação ser integrada com sensores e atuadores de robôs móveis por meio da plataforma Player, como observado na figura 2.9 .

\subsection{Trabalhos Relacionados}

Nesta seção encontram-se os trabalhos que estão relacionados a este projeto. Nenhum dos trabalhos estão ligados diretamente com geração automática de 


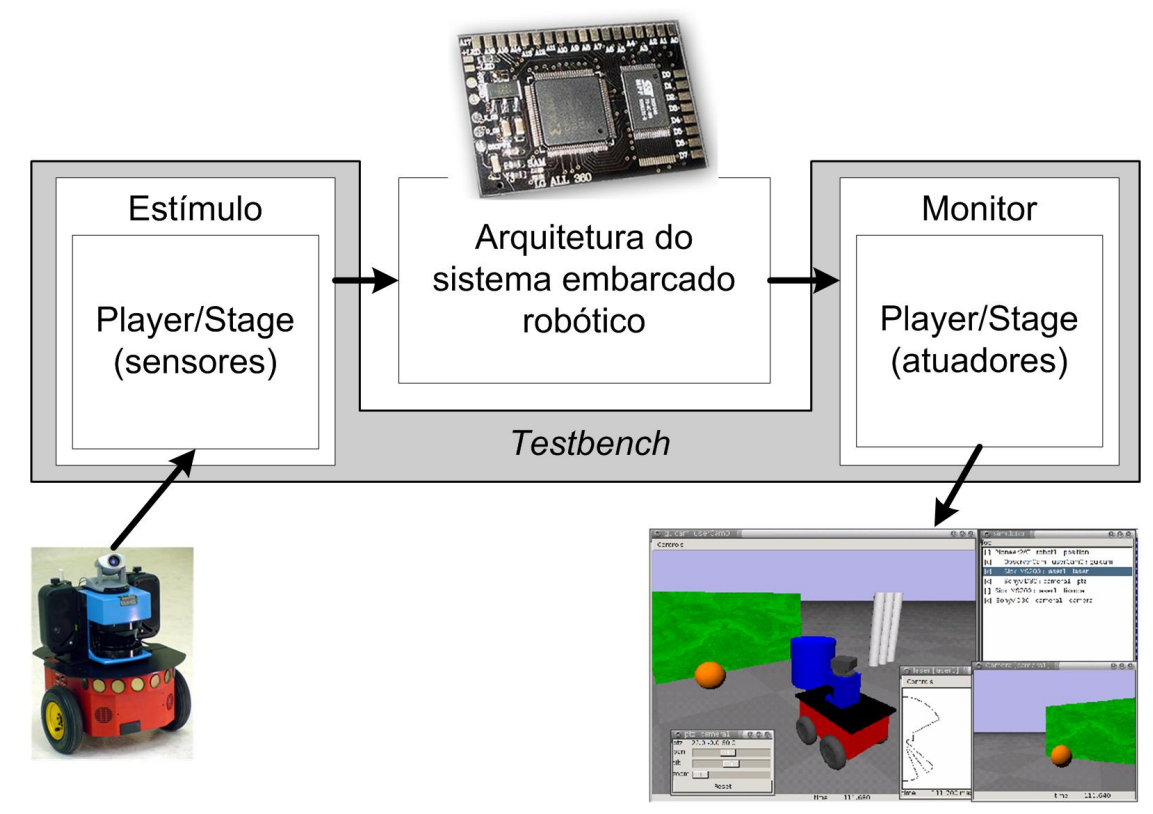

Figura 2.9: Exemplo de simulação de sistema embarcado via Player/Stage.

código Bluespec, porém eles serão úteis como fonte de referência de como foram resolvidas as questões de compilação e de tradução de um diagrama de máquina de estado para uma forma textual.

Os trabalhos de de Pablo et. al. (2007) e Moreira et. al. (2010), dentre todos os que foram apresentados na introdução, foram escolhidos para serem apresentados com mais detalhes nesta seção.

\subsection{ASM++}

O ASM++ é uma linguagem gráfica proposta por de Pablo et. al. (2007) baseada no diagrama de estado algorítmico (ASM chart) desenvolvida na Universidade de Valladolid, Espanha, pelo Departamento de Tecnologia Eletrônica. A finalidade dessa nova linguagem é aumentar suas possibilidades no desenvolvimento de circuitos RTL complexos. Na figura 2.10, encontra-se um exemplo da notação gráfica da linguagem ASM++ onde pode ser observado a extensão da linguagem em relação ao ASM tradicional nos elementos localizados à esquerda da figura.

Para isso foi desenvolvido o compilador $\mathrm{ASM}++$, que recebe como entrada um diagrama ASM++ e gera dois arquivos intermediários: o VDO, que é uma lista de objetos detectados no arquivo VDX; e o A++, que é a versão textual do diagrama. Os diagramas ASM++ devem estar no formato VDX, utilizado pelo MS Visio2003/2007 e ConceptDraw. Estes arquivos intermediários são utilizados para localizar e detectar erros. O processo termina na geração dos arquivos VHDL e/ou Verilog, que podem ser utilizados para realizar simulação ou síntese em um dispositivo como FPGA. Esta ferramenta se limita apenas a produzir arquivos na mesma linguagem em que foram escritos os comporta- 


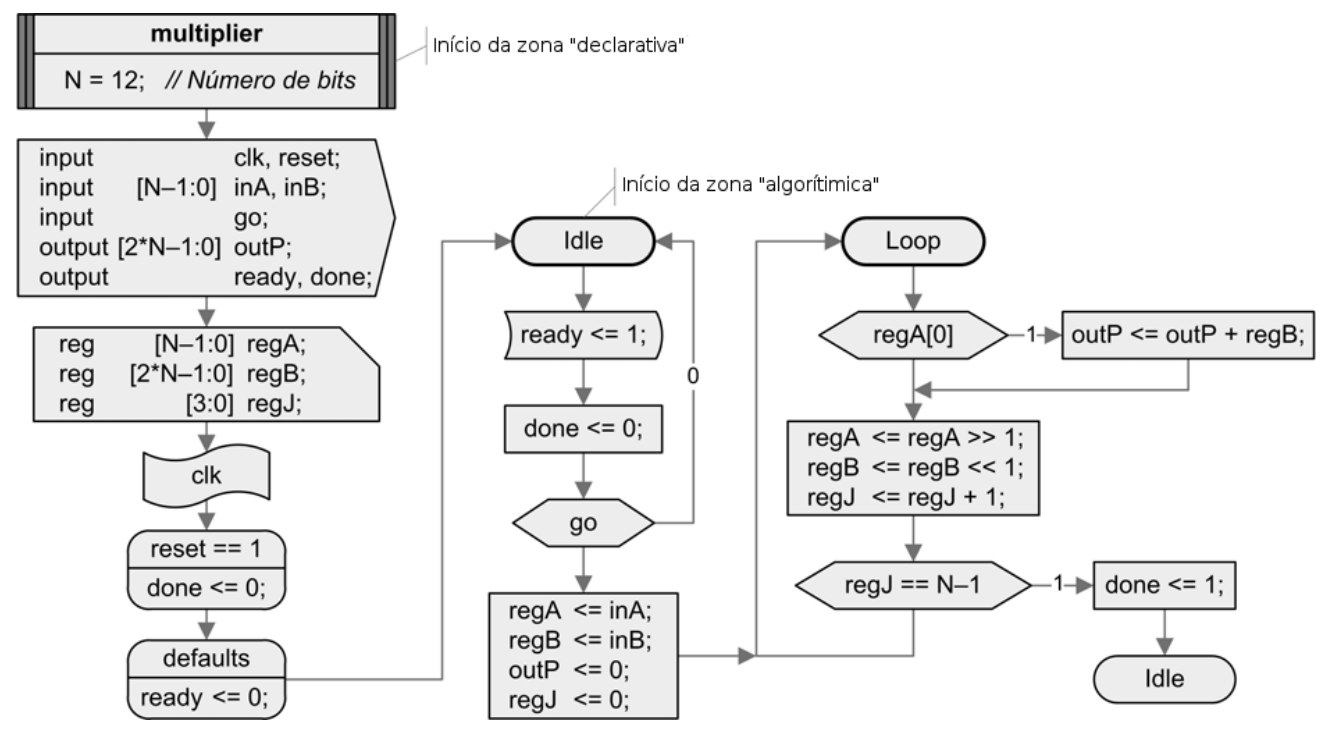

Figura 2.10: Exemplo da notação ASM++. Adaptado de (Pablo et. al., 2010).

mentos no processo de modelagem.

\subsubsection{GenERTICA com mapeamento em VHDL}

Moreira et. al. (2010) propõe estender as funcionalidades da ferramenta GenERTiCA (Generation of Embedded Real-Time Code based on Aspects) (Wehrmeister et. al., 2008) desenvolvendo um novo conjunto de regras de mapeamento, para que ela possa gerar automaticamente código VHDL a partir de um diagrama UML para posteriormente ser utilizado em dispositivos FPGAs.

As regras de mapeamento relacionam elementos da linguagem UML em construções em VHDL. Por exemplo, as Classes são mapeadas no par Entidade e Arquitetura (entity-architecture) do VHDL, os atributos públicos e privados da Classe são mapeados em portas e sinais na Entidade do código VHDL, os métodos são mapeados em processos, e assim por diante.

O processo para a geração do código VHDL é divido em quatro etapas, mostradas na figura 2.11. Primeiro é feito o processo de análise e identificação de requisitos para em seguida realizar a modelagem do sistema utilizando a linguagem UML. A terceira etapa consiste em gerar um novo modelo, que fará o papel da representação intermediária, chamado de DERCS (Distributed Embedded Compact Specification) (Wehrmeister et. al., 2008). Nesta etapa também são verificadas se há algum tipo de inconsistência no modelo gerado para só então seguir para a última etapa, que consiste na geração do código VHDL baseado em um conjunto de regras de mapeamento.

Este trabalho contempla apenas o mapeamento de classes e atributos mas foi o suficiente para desenvolver um pequeno sistema como estudo de caso. Ainda fica faltando completar o mapeamento UML/VHDL introduzindo o conceito de herança, polimorfismo e associações. Também não é realizado ne- 


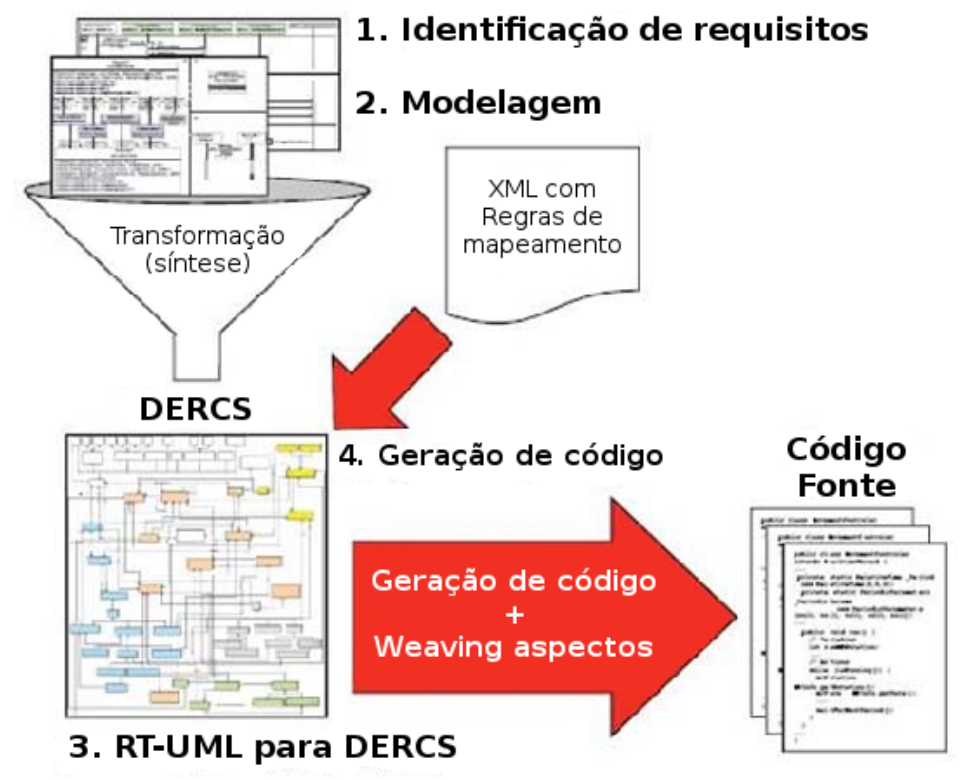

Figura 2.11: Visão geral do processo de geração de código VHDL a partir de especificações UML utilizando a ferramenta GenERTiCA. Adaptado de (Moreira et. al., 2010).

nhum tipo de otimização do código gerado automaticamente, como por exemplo, redução de estados. Além disso a ferramenta também se limita a ter como saída a mesma linguagem de programação utilizada na entrada, já que as regras de mapeamento se limita em montar a estrutura do código fonte. 



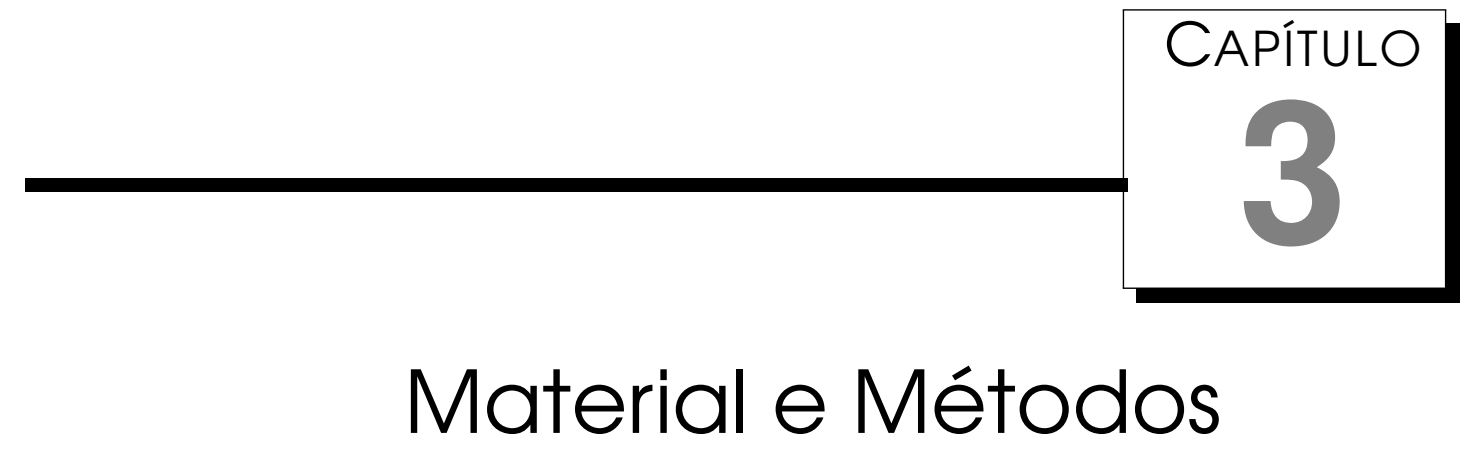

Este capítulo apresenta uma descrição de alguns conceitos e ferramentas utilizados durante a elaboração deste trabalho.

\subsection{JavaCC}

Este projeto utiliza a ferramenta JavaCC para dar suporte a realização das tarefas do frontend do compilador e utilizar a análise resultante (AST) para a geração do backend.

O JavaCC se encaixa na categoria de "Compilador de Compiladores", ou seja, uma ferramenta utilizada para auxiliar na criação de compiladores. Ele foi implementado utilizando a linguagem Java e o código por ele gerado também é apenas na linguagem Java ${ }^{1}$ (Norvell, 2007).

Ele foi criado por dois funcionários que trabalhavam na empresa Sun Microsystems: Sreeni Viswanadha e Sriram Sankar. Desde junho de 2003 ele é um projeto de código aberto e é mantido por desenvolvedores da comunidade, na qual estão incluídos os autores iniciais.

A função do JavaCC é gerar programas que irão fazer a análise léxica e sintática tendo como entrada uma gramática definida pelo usuário. Dessa forma é possível criar um compilador para qualquer linguagem, até mesmo aquelas que não sejam de programação.

O compilador gerado pelo JavaCC irá ler uma cadeia de caracteres (código fonte), gerando uma sequência de objetos conhecidos por tokens baseado na

\footnotetext{
${ }^{1}$ No momento da escrita deste trabalho há uma informação no site http://javacc.java.net/ de que o JavaCC também passará a gerar código $\mathrm{C} / \mathrm{C}++$, e que em breve será lançada uma versão beta com este recurso.
} 
gramática na qual ele foi gerado.

Em seguida, o analisador sintático irá ler esta sequência de tokens e, em conjunto com outras ferramentas, gerar a árvore de sintaxe abstrata (AST). Como o JavaCC não gera a AST por si só, ele depende de ferramentas externas para isso. Dentre as possibilidades para gerar a AST estão as ferramentas JJTree e a JTB. Estas duas etapas representam a análise léxica e sintática e estão representadas respectivamente nas figuras 2.7 e 2.8 do capítulo 2 .

O JJTree atua como um pré-processador para o JavaCC inserindo códigos em diversas regiões do JavaCC. Neste trabalho optou-se trabalhar com o JJTree.

\subsection{Apache Velocity}

O Apache Velocity (Apache Software Foundation, 2010) é uma ferramenta open source feita em Java capaz de gerar cadeias de caracteres baseada em templates. Sua principal utilidade são nos casos em que se deseja gerar arquivos no formato texto, como por exemplo códigos fonte, baseado em alguma lógica. No site Velocity Wiki ${ }^{2}$ é mantida uma lista de alguns projetos que fazem uso desta ferramenta.

Para ilustrar o funcionamento do Velocity é apresentado um pequeno exemplo. As strings em destaque na listagem 3.1 são os locais onde o Velocity irá atuar durante a renderização do template. Todo o texto restante será simplesmente direcionado para a saída sem quaisquer modificação.

Na listagem 3.2 aparecem em destaque os valores que foram substituídos pelo Velocity durante o processo de renderização. Para que isso seja possível, é necessário passar ao Velocity todas as variáveis utilizadas no template juntamente com seus respectivos valores. Neste exemplo, foram passadas as variáveis fsmName e resetName com os valores ExemploFSM e ESTADO_X, respectivamente.

\section{Listagem 3.1: Exemplo de um template do Apache Velocity.}

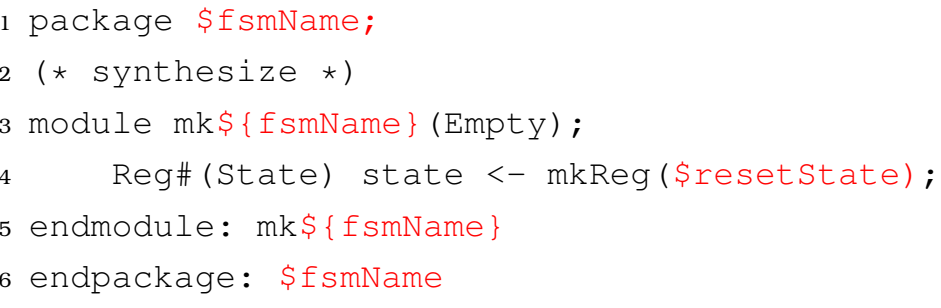

Listagem 3.2: Exemplo de um código renderizado à partir de um template do Apache Velocity.

1 package ExemploFSM;

${ }^{2}$ Disponível em: http://wiki.apache.org/velocity/PoweredByVelocity 


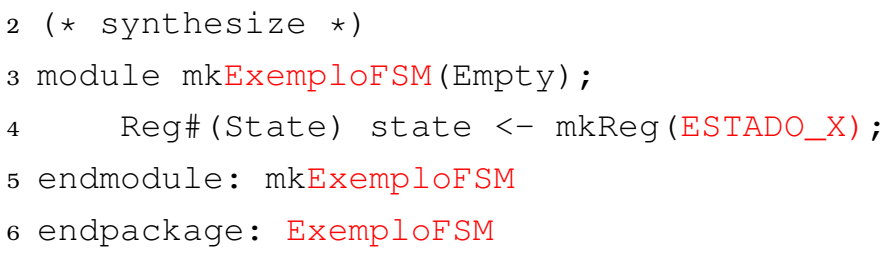

Apesar do exemplo apresentado ser bem simples, onde acontecem apenas substituição de valores, o Velocity é bem poderoso. Ele possui uma linguagem própria, chamada de Velocity Template Language (VTL) na qual permite o uso de variáveis, estruturas de laço e chamadas a outros templates.

\subsection{Bluespec SystemVerilog}

O Bluespec SystemVerilog (BSV) (Bluespec Inc, 2010) é uma linguagem de descrição de hardware de alto-nível e totalmente sintetizável para hardware que foi criada pelo prof. Arvind, do Massachusetts Institute of Technology (MIT), tendo como influência as linguagens SystemVerilog e Haskell. O objetivo desta linguagem é acelerar o desenvolvimento de sistemas digitais, facilitando a exploração da arquitetura, verificação e desenvolvimento do software, tendo um ganho de produtividade de 2 a 10 vezes mais rápido em relação ao desenvolvimento em RTL (Bluespec Inc, 2007). Tal desempenho abre possibilidades para que atividades que antigamente não eram viáveis possam ser colocadas em prática. Além disso, o hardware gerado pelo compilador do Bluespec é considerado eficiente (Gruian e Westmijze, 2008; Agarwal, 2009).

Esta linguagem de programação faz parte da ferramenta Bluespec que também inclui um compilador, um simulador e um ambiente de desenvolvimento integrado (IDE). O fluxo de desenvolvimento de um sistema em Bluespec é mostrado na figura 3.1. O compilador do Bluespec recebe como entrada o código-fonte em BSV. O usuário pode optar por gerar um programa para ser simulado pelo Bluesim ou gerar o código RTL em Verilog para posterior simulação ou síntese.

Um dos grandes destaques do Bluespec é a velocidade nas simulações dos sistemas fora de um dispositivo FPGA, através do simulador Bluesim, acelerando a execução de três até seis ordens de magnitude (Nikhil e Czeck, 2010). Outra característica marcante no Bluespec são as transações atômicas $(R u-$ les), utilizadas para evitar conflitos no acesso a interfaces dos módulos, aumentando significativamente o nível de abstração de concorrência que é frequentemente a fonte de muitas dificuldades e erros de programação.

Um típico programa escrito em BSV é composto por algumas seções, sendo que algumas delas são opcionais. Ele pode começar com uma declaração de pacote (package <nome-do-pacote>). Apesar de não ser obrigatório, esta é uma 


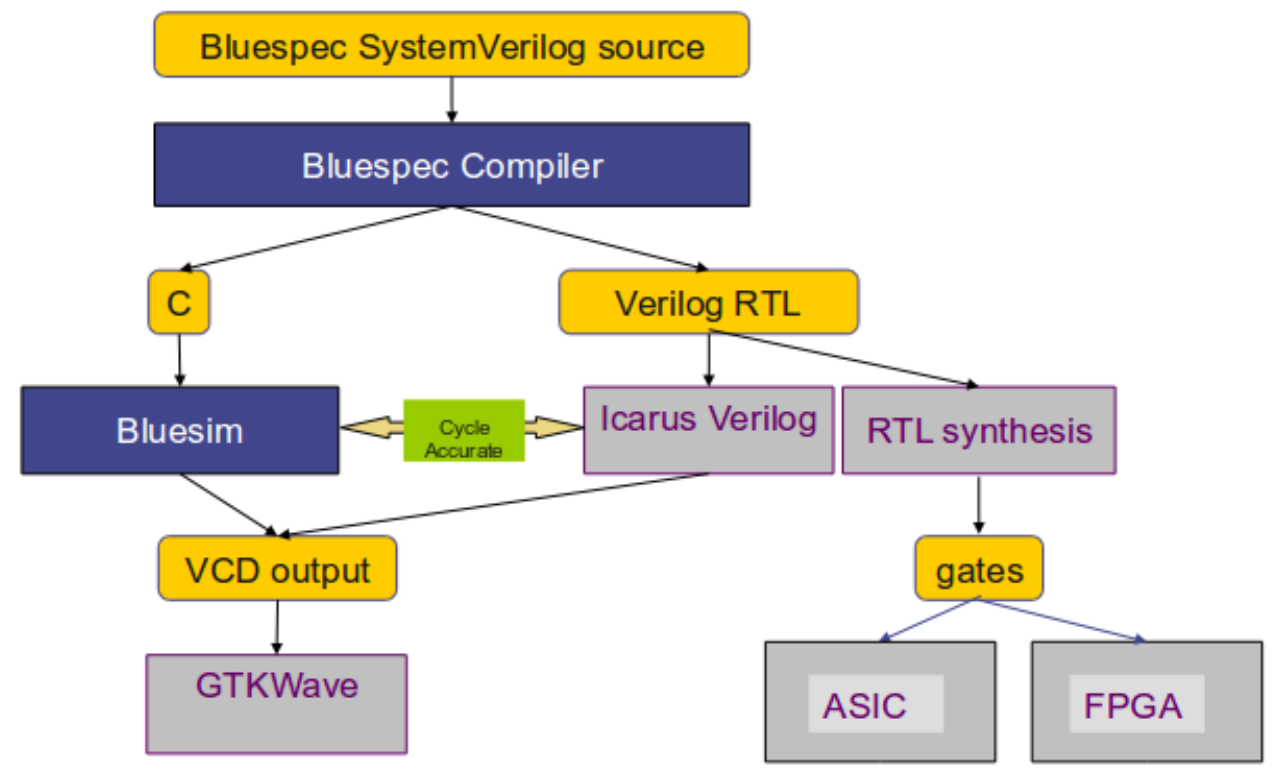

Figura 3.1: Fluxo de desenvolvimento do Bluespec. Adaptado de (Bluespec Inc, 2007).

boa prática de programação pois assim é possivel manter vários programas organizados logicamente. Uma vez que tenha sido declarado um pacote, o arquivo que contém o programa deve ter o mesmo nome deste pacote.

Em seguida pode vir a declaração da Interface. São por meio dos elementos declarados na interface que o hardware que está sendo desenvolvido se comunicará com o meio externo. As Interfaces são desenvolvidas através de métodos e, neste bloco, são declaradas apenas as assinaturas destes métodos. Caso o programa em BSV tenha declarado uma interface, seus respectivos métodos devem ser implementados dentro do módulo correspondente.

Por último, a declaração de um bloco de módulo (module <nome-do-módulo> (nome-da-interface)). Na declaração do módulo é necessário passar uma interface como parâmetro. Caso não tenha sido definida nenhuma interface, então utiliza-se uma interface especial chamada Empty. Para ser sintetizado, o módulo deve ser marcado com o atributo (* synthesize *), colocado imediatamente antes de sua declaração.

Um módulo é composto por rules, métodos (que implementam a interface), declarações de variáveis e instâncias de interfaces de outros módulos.

As rules são blocos onde o programador descreve um comportamento de um hardware em BSV. Elas podem ser declaradas com uma condição, que são expressões booleanas, para garantir que ela seja executada somente no momento certo. Pode-se comparar as rules com os blocos process ou always do VHDL e Verilog respectivamente.

Existem três características importantes a respeito das rules: 
- Atomicidade: as rules são consideradas atômicas, ou seja, todas as ações que fazem parte de uma rule serão executadas num mesmo ciclo de relógio;

- Execução: caso a condição da rule seja verdadeira, ela será executada como um todo, e apenas uma vez, em um ciclo de relógio;

- Conflitos: uma rule não pode entrar em conflito com outra. Esta situação de conflito é verificada pelo compilador do Bluespec. Caso seja detectado um conflito o programador deve optar por uma das duas opções:

- declarar no código fonte, através de parâmetros, qual rule deve ter prioridade em caso de conflito;

- modificar a lógica empregada no código afim de eliminar o conflito.

O Bluespec gera toda a lógica de controle automaticamente para coordenar acessos aos recursos compartilhados. Ao invés do desenvolvedor se preocupar em controlar todos os recursos de seu sistema (figura 3.2(a)), que pode ser uma tarefa complexa e suscetivel a erros, ele pode focar-se apenas em uma parte do problema (figura 3.2(b)), deixando o Bluespec responsável por automatizar todo o controle. Com isso consegue-se a simplicidade necessária para efetuar mudanças rápidas, incremento de funcionalidades, flexibilidade, reusabilidade e um custo menor no desenvolvimento.

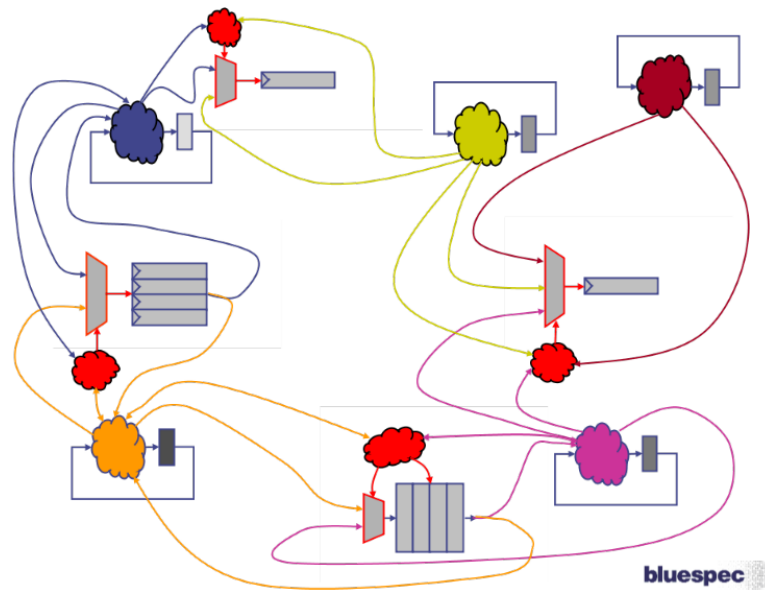

(a) Desenvolvimento complexo

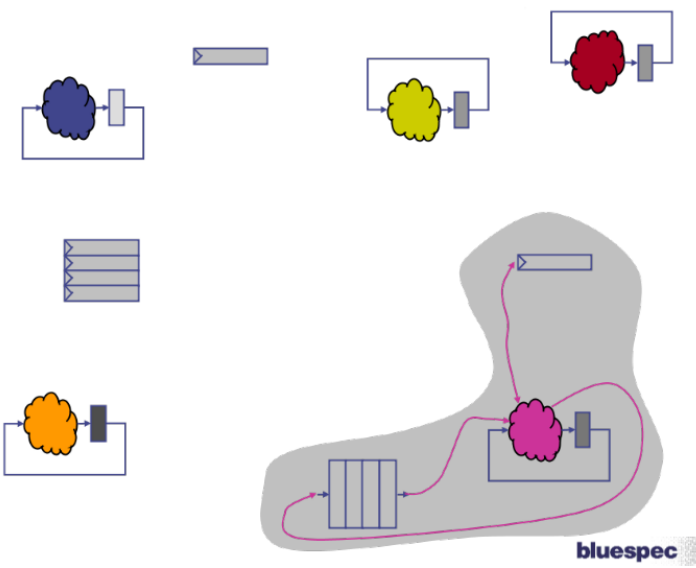

(b) Desenvolvimento simples

Figura 3.2: Ilustração para representar a complexidade de desenvolver precisando fazer o controle de recursos compartilhados e a simplicidade proporcionada pelo Bluespec permitindo ao desenvolvedor focar-se apenas em uma parte de seu sistema (Bluespec Inc, 2010).

O Bluespec Workstation é uma IDE para auxiliar o programador no gerenciamento de um projeto, sendo possível adicionar vários módulos no projeto, 
compilar e simular sem a necessidade de usar um terminal (interface textual). Além disso a IDE fornece um visualizador de formas de onda e a integração com os editores de texto Vim, Emacs (estes dois primeiros com suporte à syntax highlighting, realçando o código fonte com diferentes cores) ou qualquer outro editor que seja de preferência do usuário. A figura 3.3 mostra a tela do Bluespec Workstation com um projeto simples aberto.

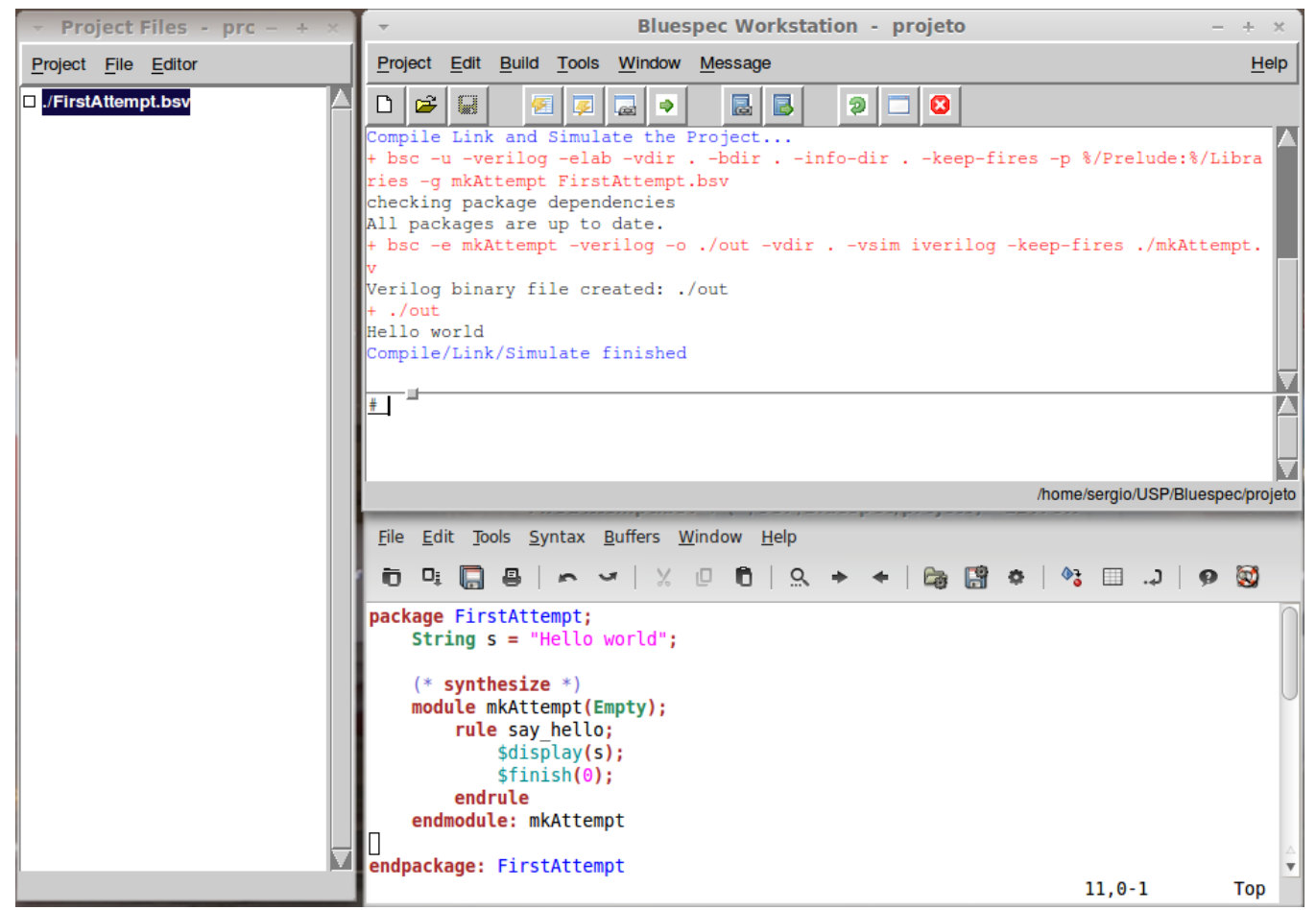

Figura 3.3: Bluespec Workstation (janela superior), editor de texto Vim (janela inferior) e lista de arquivos que fazem parte do projeto (janela à esquerda).

O Bluespec oferece o pacote de biblioteca StmtFSM, que é uma sub-linguagem para facilitar a representação bem estruturada de máquina de estado finita. No momento da compilação o Bluespec expande esta sub-linguagem em regras, da mesma forma que se fosse programar uma MEF sem o auxílio da StmtFSM. Esta biblioteca permite gerar de forma bem rápida laços no estilo da linguagem $\mathrm{C}$, blocos paralelos e sequenciais e condições. A listagem 3.3 mostra um exemplo de código Bluespec utilizando a biblioteca de máquina de estado finita.

Listagem 3.3: Exemplo de código Bluespec utilizando a biblioteca de máquina de estado finita (Nikhil e Czeck, 2010).

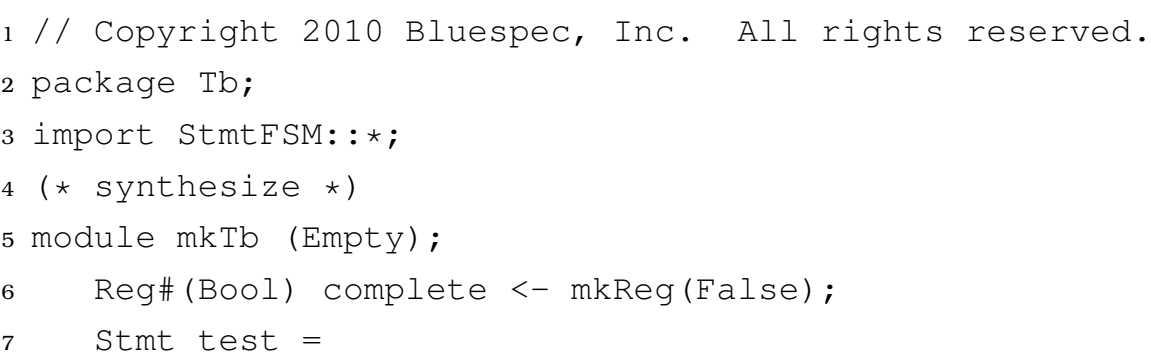




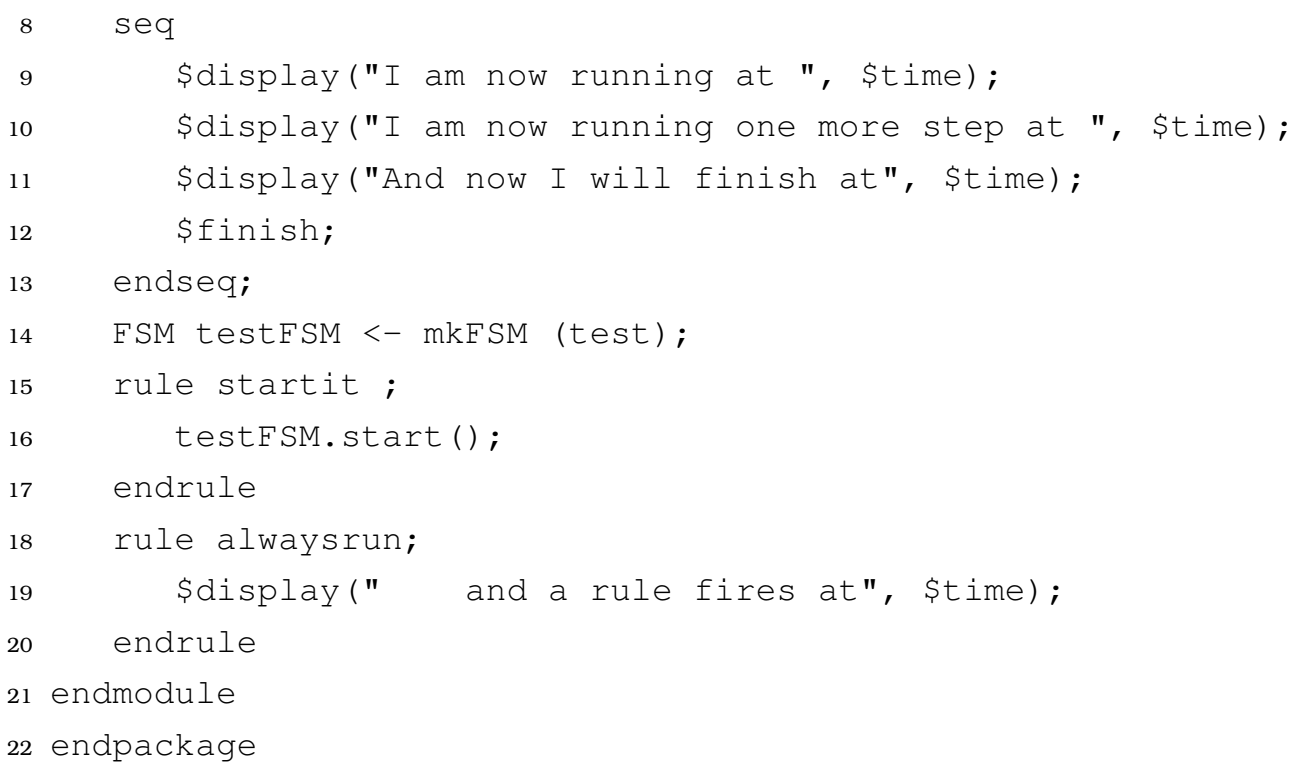

Para utilizá-la é necessário criar um objeto instanciando a MEF através do construtor mkFSM que recebe como parâmetro a máquina de estado criada pelo usuário, entrando em execução depois de chamado o método start. A biblioteca de máquina de estado também fornece um modo chamado de AutoFSM que tem o funcionamento semelhante à maquina instanciada pelo construtor mkFSM, sendo que não é necessário chamar o método start, pois sua execução inicia automaticamente logo após o reset e ela é finalizada assim que completar sua primeira execução.

\subsection{Padrão IP-XACT}

IP-XACT (Accellera Organization Inc., 2011) é um padrão de formato XML que descreve e representa componentes de sistemas eletrônicos. Ele foi criado pelo consórcio SPIRIT como um padrão para permitir a configuração e integração automática entre ferramentas. Este padrão foi aprovado como norma IEEE 1685-2009 (IPX, 2010).

O objetivo da padronização é ter uma interface comum entre vários fornecedores permitindo acessar os metadados dos componentes e assim possibilitar o reúso entre ferramentas compativeis com o padrão IP-XACT.

Para auxiliar no processo de geração de um módulo no padrão IP-XACT Ghosh (2012) desenvolveu ferramenta, disponibilizada gratuitamente, chamada IP-XACT Solutions, no qual é possível gerar uma interface no padrão IP-XACT para um módulo desenvolvido em RTL. 

CAPÍTULO

4

\section{Implementação da Ferramenta Proposta}

A implementação desta ferramenta foi dividida em dois projetos distintos denominados UML2BSV e C2BSV. O primeiro é responsável por realizar toda a análise da modelagem UML e gerar o respectivo hardware de controle da máquina em Bluespec. E o segundo, traduz código descrito em linguagem $\mathrm{C}$ para hardware comportamental, também em Bluespec.

A figura 4.1 ilustra de forma detalhada todo o fluxo de processamento, que tem início com a exportação no formato XMI 2.1 de uma modelagem UML. Este arquivo XMI é utilizado como entrada para a ferramenta UML2BSV iniciar o processo de geração de código BSV. Neste processo é realizado um parser no arquivo XMI onde todos os elementos da modelagem são identificados e, em conjunto com templates, o código fonte é gerado. Durante o processo de parser, ocorrem chamadas ao compilador C2BSV sempre que houver códigos escritos na linguagem $\mathrm{C}$ junto com o modelo UML. É passado ao compilador o código $\mathrm{C}$ e o retorno é o respectivo código traduzido para Bluespec. Os detalhes envolvidos em cada etapa deste processo será explorado no decorrer deste capítulo.

A divisão desta ferramenta em dois projetos distintos permite a utilização das mesmas de forma independente. Nos casos em que o projetista não utilize código C para descrever o comportamento de algum estado, o UML2BSV é capaz de gerar o hardware sozinho. Porém, nesse caso o comportamento do modelo também deverá ser escrito em Bluespec, havendo assim somente a cópia do mesmo para o local correto no código fonte e integrado com o controle gerado da UML. Da mesma forma, o compilador C2BSV pode ser utilizado na 


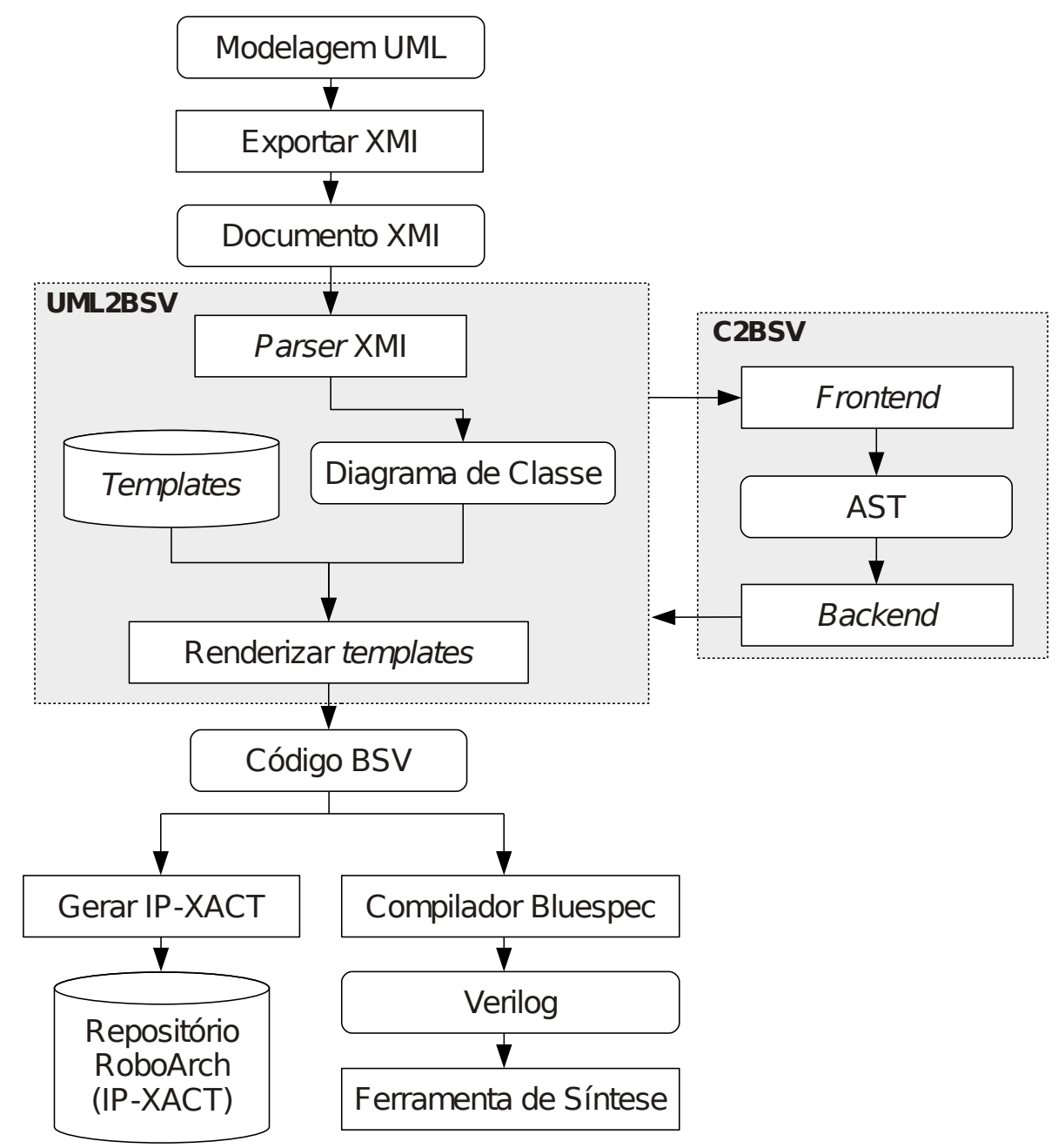

Figura 4.1: Fluxo do processo de geração automática da ferramenta proposta. A entrada do fluxo recebe um modelo em UML, no formato XMI, e é interpretado pela UML2BSV que, com o suporte do compilador C2BSV, são responsáveis pela geração de código Bluespec automaticamente.

forma standalone ou ser acoplado a projetos de terceiros. Além disso, cada projeto pode evoluir de forma independente no futuro, de acordo com as necessidades de novas funcionalidades. Até o momento da elaboração deste trabalho, foram geradas um total de 8.152 linhas de código nos projetos FSM2BSV e C2BSV, de acordo com o programa SLOCCount ${ }^{1}$.

Neste trabalho optou-se por utilizar apenas bibliotecas e frameworks livres com suporte a multiplataformas para possibilitar que a ferramenta possa ser utilizada nos mais diversos ambientes. Há intenção de disponibilizá-la de forma livre para que possa ser utilizada por outras instituições de ensino e também receber contribuições em seu desenvolvimento.

\footnotetext{
${ }^{1}$ O SLOCCount é um programa utilizado para contar o número de linhas nos arquivos de código fonte de um projeto. Disponivel em http://www.dwheeler.com/sloccount/
} 


\section{1 UML2BSV}

Neste trabalho optou-se por utilizar os diagramas da UML 2 para representar o controle do hardware em alto nível de abstração. São utilizados os diagramas de estado, atividade e de classes para representar um circuito a ser desenvolvido.

Um dos cuidados deste trabalho foi utilizar a linguagem UML padrão, sem que houvesse nenhum tipo de extensão na mesma. Assim, o usuário não necessitará aprender uma nova linguagem e poderá modelar seu circuito em qualquer ferramenta que suporte a UML 2 e que tenha a funcionalidade de exportar o modelo no padrão XMI 2.1.

O XMI (XML Metadata Interchange) é um padrão desenvolvido pela OMG (Object Management Group) que busca simplificar a troca de informações por XML (Extensible Markup Language) entre ferramentas de modelagem de empresas diferentes. Por ser um padrão já consolidado, optou-se por sua utilização para gerar o arquivo que será lido pela ferramenta de geração de código fonte em BSV.

$\mathrm{O}$ arquivo XMI exportado da modelagem UML é utilizado como entrada para a ferramenta, tendo como saída o código fonte em BSV. A UML2BSV faz a leitura deste arquivo, analisa toda a estrutura e, com essas informações, cria objetos que representam a modelagem, como por exemplo os estados e transições.

A etapa final deste fluxo é a geração do código BSV com auxílio de um sistema de templates. A ferramenta utiliza todos os objetos que foram extraídos do arquivo XMI e, juntamente com templates, que caracterizam a estrutura da linguagem BSV, gera o produto final que é o código fonte em BSV.

Posteriormente, este código poderá ser armazenado na biblioteca de IPs da ferramenta RoboArch ou então ser compilado pelo Bluespec Compiler para gerar código Verilog sintetizável para FPGA.

Nas próximas seções serão detalhadas cada etapa deste processo representado na figura 4.1 e, como forma de ilustrar melhor todo o funcionamento, será utilizado um exemplo simples de um controlador de semáforo onde o circuito modelado define um temporizador para os estágios deste semáforo.

\subsubsection{Modelagem UML}

Uma das formas esperadas para diminuir a complexidade no desenvolvimento de sistemas embarcados é através da modelagem visual utilizando diagramas UML para representar circuitos. Com a modelagem visual as chances de erros diminui pois o desenvolvedor fica limitado a utilizar os elementos visuais. Além disso, diminui a quantidade de linhas de códigos a serem escritas e fa- 
cilita a geração da documentação dos modelos, o que ajuda no entendimento do projeto por outros membros da equipe.

Neste trabalho são utilizados três diagramas UML para a modelagem de um circuito:

- Diagrama de Classes: utilizado para definir os tipos de dados utilizados na modelagem;

- Diagrama de Atividades: que representa as entradas e saídas do circuito, além de definir uma ação, que será representada por uma máquina de estado;

- Diagrama de Estados: que representa o comportamento do circuito com seus estados e transições.

A seguir serão descritos como cada um destes três diagramas foram utilizados neste trabalho e as orientações de como trabalhar em cada um deles durante o processo de modelagem.

\section{Diagrama de Classes}

O diagrama de classes foi utilizado como forma de apoiar a modelagem de uma determinada arquitetura de hardware. Ele é utilizado no contexto de definir os tipos de dados que serão utilizados no modelo, pois a UML não fornece os tipos necessários ao desenvolvimento de hardware.

São definidas três categorias para os tipos de dados. A distinção entre as categorias é através do uso (ou não) de um determinado esteriótipo na classe como pode ser observado nos exemplos da figura 4.2.
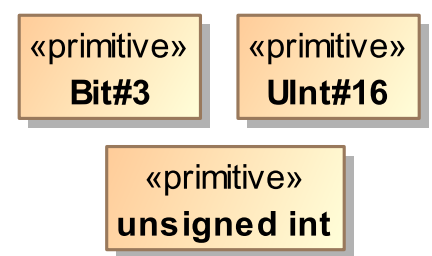

(a) Classes definindo alguns tipos de dados

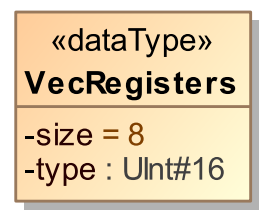

(b) Classe definindo um vetor

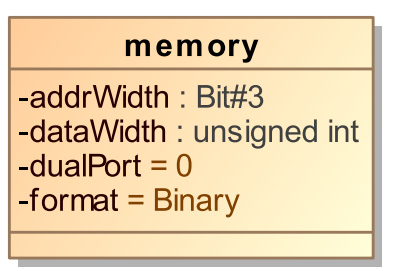

(c) Classe definindo uma BRAM

Figura 4.2: Definição de tipos de dados utilizando classes.

A classe com o esteriótipo «primitive $\gg$ (figura 4.2(a)) é utilizada para definir tipos de dados Bit, Int e UInt do Bluespec e os tipos char, unsigned char, int e unsigned int da linguagem C. Estes tipos da linguagem $\mathrm{C}$ foram adicionados nesta ferramenta para facilitar o programador que não esteja familiarizado com a linguagem BSV. Durante o processo de geração do hardware estes tipos 
são convertidos nos tipos reconhecidos pelo Bluespec, como mostra a tabela 4.1.

Tabela 4.1: Equivalência entre os tipos de dados em $\mathrm{C}$ e Bluespec.

\begin{tabular}{|l|l|}
\hline \multicolumn{2}{|c|}{ Tipo de Dado } \\
\hline \multicolumn{1}{|c|}{$\mathrm{C}$} & Bluespec \\
\hline char & Int\#(8) \\
\hline unsigned char & Unt\#(8) \\
\hline int & Int\#(32) \\
\hline unsigned int & Unt\#(32) \\
\hline
\end{tabular}

A classe com o esteriótipo «dataType» (figura 4.2(b)) é utilizada para definir vetores. Cada tipo Vetor declarado tem um nome que o referencia e sua classe possui dois atributos:

- size: define a quantidade de elementos que o vetor irá comportar;

- type: declara qual será o tipo de elementos do vetor.

É importante lembrar que para definir um vetor é necessário antes definir um tipo de dado («primitive $\gg$ ) para que este possa ser utilizado na declaração do vetor. A declaração desta classe resultará em uma construção do tipo Vector\#(size, type), utilizada no Bluespec.

A classe sem nenhum esteriótipo, (figura 4.2(c)) é utilizada para definir uma memória do tipo BRAM. Ela possui quatro atributos para sua configuração:

- addrWidth: define a largura do endereçamento que será utilizado;

- dataWidth: define o tamanho dos dados que serão armazenados;

- dualPort: define se a BRAM será do tipo dual port, atribuindo valor 1 ou single port atribuindo valor 0 ;

- format: utilizado caso queira especificar um arquivo texto a ser lido com o conteúdo inicial que a memória deve ter. As opções permitidas para este parâmetro são:

- None: caso não seja necessário carregar na memória dados de um arquivo texto;

- Hex: caso os dados no arquivo texto estejam em codificação hexadecimal. Por padrão o arquivo texto a ser lido será o nome da memória com extensão hex (<nome-memória>.hex);

- Binary: caso os dados no arquivo texto estejam em codificação binária. Por padrão o arquivo texto a ser lido será o nome da memória com extensão bin (<nome-memória>.bin); 
Os atributos addrWidth e dataWidth devem estar associados a um tipo de dado declarado anteriormente.

A memória é a única que pode ser utilizada diretamente no diagrama de estados, sem a necessidade de instanciá-la no diagrama de atividades. Basta utilizar o nome dado a ela para invocar os métodos de leitura e escrita.

\section{Diagrama de Atividades}

Como não há uma forma de representar as entradas, saídas e declarações de variáveis diretamente no diagrama de estados, e um dos objetivos é de não criar extensões na linguagem UML mantendo-a original, a alternativa encontrada foi a de sub-utilizar o diagrama de atividades para este fim. Embora o diagrama de atividades visa modelar os fluxos de um processamento através de atividades e decisões, ele também permite a modelagem de sinais de entrada e saída e declaração de variáveis. Neste diagrama também encontram-se as ações, que serão representadas pelo diagrama de estados.

No momento de mapear este diagrama para a linguagem BSV, os sinais de entrada e saída serão declarados como interface e será gerado seus respectivos métodos de escrita e leitura.

Na figura 4.3 estão representados os elementos utilizados do diagrama de atividades. O retângulo define uma ação, identificada pelo nome actionTrafficLight, que representa um módulo em Bluespec. O comportamento desta ação está representado por um diagrama de estados identificado pelo nome fsmTrafficLight, que será abordado na próxima seção. Os sinais de entrada e saída são posicionados na esquerda e na direita respectivamente, e as variáveis ocupam a parte inferior.

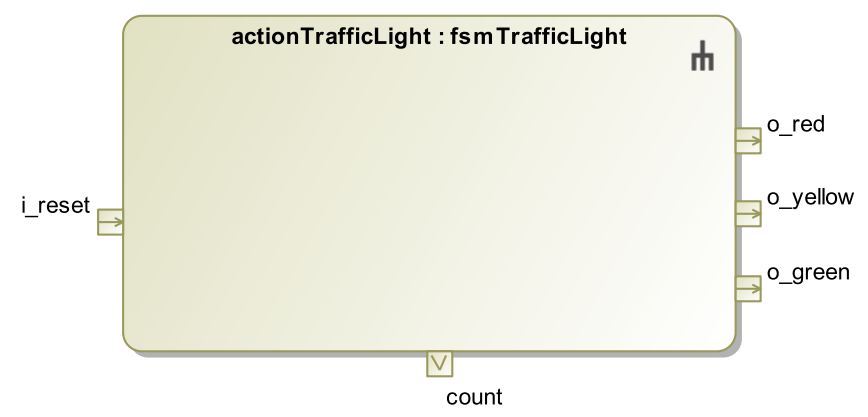

Figura 4.3: Ação actionTrafficLight do diagrama de atividades que está relacionada à máquina de estados que controla o tempo de um semáforo. Na borda do elemento gráfico que representa uma ação encontram-se as declarações dos sinais de entrada, saída e variáveis. 
O diagrama de estados é utilizado para modelar o controle e comportamento de circuitos e é composto de um número finito de estados, transições e suas respectivas ações. Como a UML 2 não dá suporte para a declarações de sinais de entrada e saída, estes devem ser feitos no diagrama de atividades onde esta máquina de estado está inserida.

As ações que irão ocorrer em cada estado da máquina podem ser escritas tanto em BSV quanto em um subconjunto do C, mas não os dois em um mesmo estado. Cada ação encontrada na modelagem é transformada em uma rule da linguagem BSV. As condições declaradas nas transições irão fazer parte da condição associada a uma determinada rule que irá determinar o momento da mesma ser disparada.

A figura 4.4 mostra a modelagem de uma máquina de estado que controla o tempo em que cada estágio do semáforo ficará ligado. Os retângulos representam os estados com seus respectivos nomes aparecendo na parte superior. No restante do retângulo aparece uma referência ao comportamento a ser executado em cada estado. As transições estão representadas por setas e as condições relacionadas aparecem próximas a cada uma delas. Este diagrama omite alguns detalhes, por exemplo, o código escrito em cada estado, com o intuito de deixar a modelagem com um visual mais simples. O pequeno círculo preto representa um pseudo-estado e é utilizado para indicar qual será o estado inicial quando a máquina iniciar sua execução.

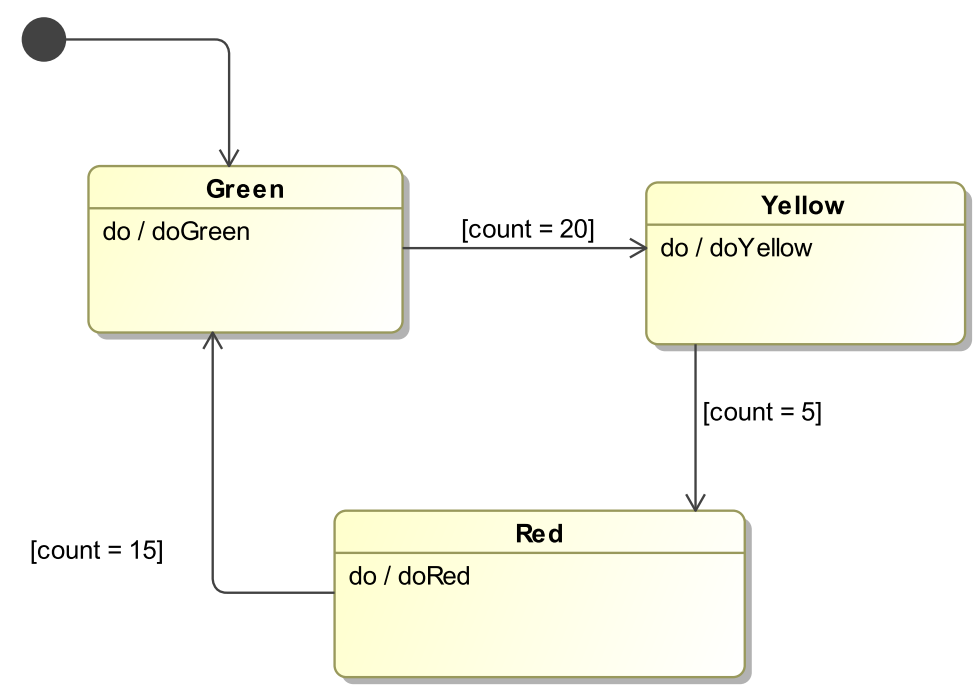

Figura 4.4: Diagrama de estados representando o controle de tempo de um semáforo. Dentro de cada estado existe a referência para o código que descreve seu comportamento. 


\subsubsection{XMI}

Assim como a UML, o padrão XMI também foi definido pela OMG com o objetivo de facilitar a troca de metadados usando como estrutura o XML. O seu uso mais comum é na troca de informações entre ferramentas de modelagem UML. Com isso, através do XMI é possível que uma modelagem feita em uma determinada ferramenta possa ser utilizada por outras. A escolha do padrão XMI foi devido a esta característica de não deixar o desenvolvedor limitado a uma ferramenta específica, tendo que observar apenas se há suporte à exportação de XMI na versão 2.1.

Apesar do arquivo XMI ser gerado automaticamente pela ferramenta de modelagem, é importante conhecer como estão estruturadas as informações neste padrão para tornar mais fácil o próximo passo que é a de extrair as informações da modelagem.

A listagem 4.1 mostra um exemplo de um arquivo XMI referente à modelagem da máquina de estados do semáforo. Devido ao fato do arquivo XMI gerado ser muito verboso tornando-o muito extenso, que é uma característica do XML, esta listagem foi simplificada para melhor visualização sem prejudicar o entendimento.

Foram retirados trechos que se repetiam e longas strings que são utilizadas como identificador de cada elemento da modelagem. Também foram excluídas as tags específicas da ferramenta de modelagem utilizada que guardavam informações que não são necessárias para gerar o código BSV, como por exemplo, a posição e o tamanho dos elementos na tela.

Para deixar o texto com uma leitura mais leve, serão omitidas a explicação de algumas tags já que o objetivo deste trabalho não é a de esgotar todo o assunto sobre XMI.

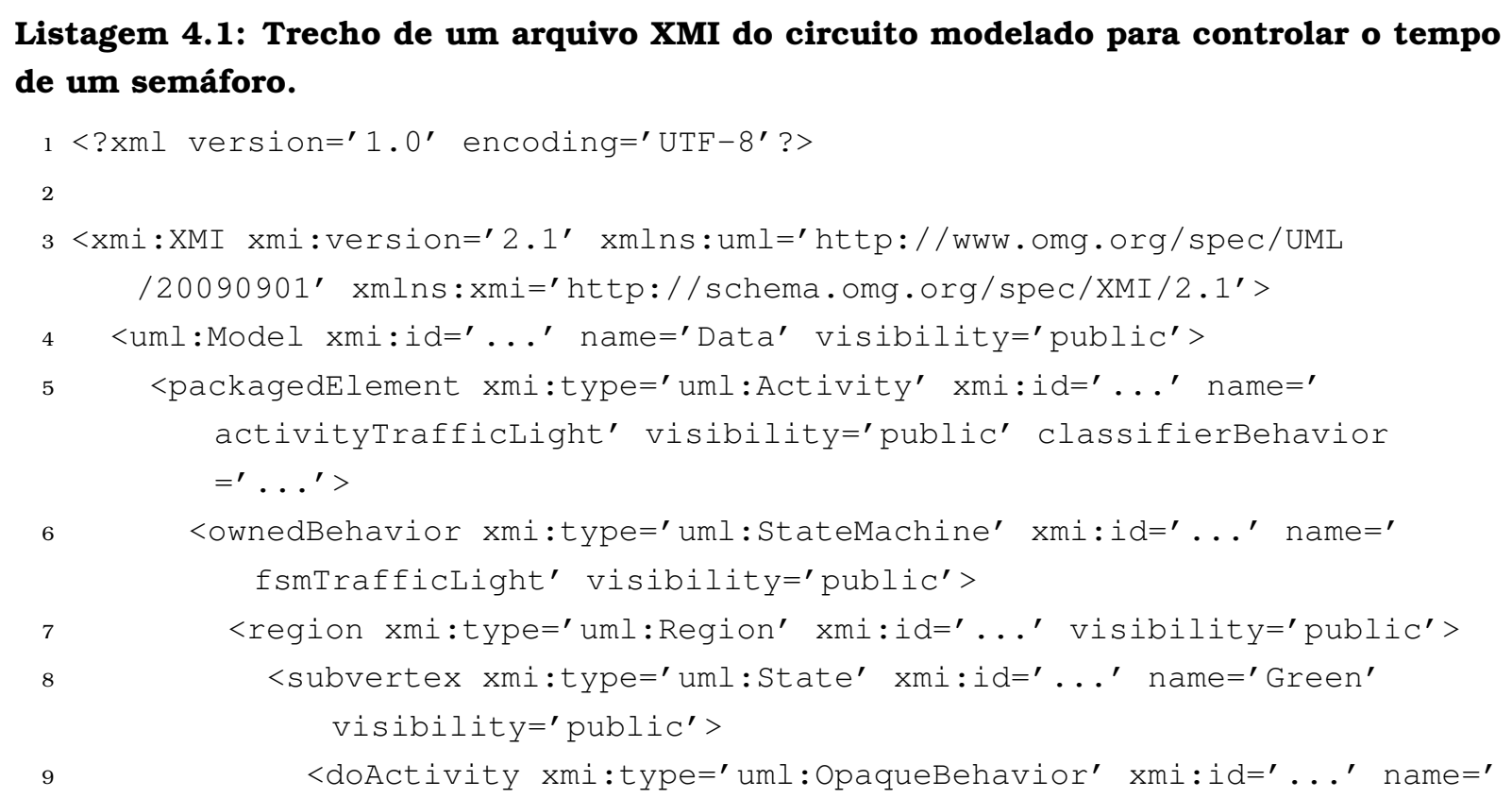


doGreen' visibility='public'>

<body>source code goes here</body $>$

$<$ language $>$ BSV $</$ language $>$

$</$ doActivity $>$

$</$ subvertex $>$

<subvertex xmi:type=' uml:Pseudostate' xmi:id='..' visibility=' public'/>

<transition xmi:type=' uml:Transition' xmi:id=' ..' visibility=' public' source=' ...' target=' ...' guard $={ }^{\prime} \ldots$. $^{\prime}>$

<ownedRule xmi:type='uml:Constraint' xmi:id='..' name=' condition_goYellow' visibility='public'>

<specification xmi:type=' uml: OpaqueExpression' xmi:id=' ...' visibility $={ }^{\prime}$ public'>

$<$ body $>$ time $==20</$ body $>$

$<$ language $>\mathrm{BSV}</$ language $>$

$</$ specification $>$

$</$ ownedRule $>$

$</$ transition $>$

$</$ region $>$

$</$ ownedBehavior $>$

<node xmi:type=' uml:CallBehaviorAction' xmi:id='...' name=' actionTrafficLight' visibility='public' behavior=' ...'> <argument xmi:type='uml:ValuePin' xmi:id=' ..' name='tempo' visibility='public'>

<type xmi:type=' uml:PrimitiveType' href='http://../uml.xml\# Integer'>

<xmi:Extension extender='MagicDraw UML 17.0'>

<referenceExtension referentPath=' UML Standard Profile: : UML2' referentType='PrimitiveType' />

$</ x m i$ :Extension $>$

$</$ type $>$

$</$ argument $>$

<argument xmi:type=' uml:InputPin' xmi:id='..' name='reset' visibility='public'>

<type xmi:type=' uml:PrimitiveType' href='http://../uml.xml\# Integer'>

<xmi:Extension extender='MagicDraw UML 17.0'>

<referenceExtension referentPath=' UML Standard Profile: UML2' referentType='PrimitiveType' />

$</ x m i$ :Extension $>$

$</$ type $>$

$</$ argument $>$

<result xmi:type=' uml:OutputPin' xmi:id=' ...' name='out_red' visibility='public'>

<type xmi:type=' uml:PrimitiveType' href='http://../uml.xml\# Integer'>

<xmi:Extension extender='MagicDraw UML 17.0'>

<referenceExtension referentPath=' UML Standard Profile: :

UML2' referentType='PrimitiveType' /> 


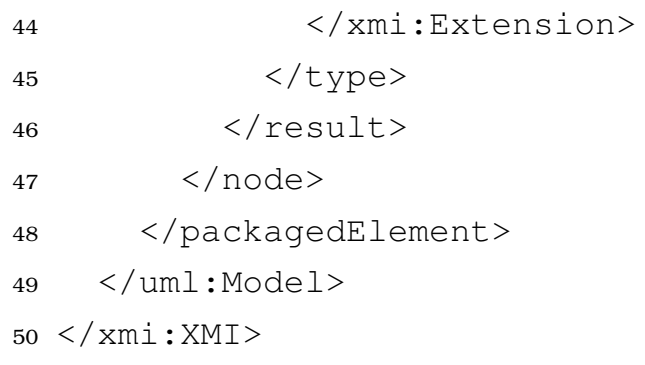

A primeira linha do arquivo XMI é necessária para indiciar qual a versão utilizada e, opcionalmente, declarar a codificação utilizada no conjunto de caracteres do arquivo. O documento XMI inicia-se na linha 3, com a abertura da tag XMI indicando, dentre outras informações, a versão do padrão adotado. Esta tag é um elemento raiz, englobando todos os elementos restantes.

A partir deste ponto as diferentes tags que compõe o arquivo XMI são acompanhadas pelo atributo xmi:type o qual é muito importante durante o processo de parser. É através do valor deste atributo que será possível identificar o que cada tag representa. Portanto, ao invés de referenciar o nome da tag, será citado o valor do atributo xmi:type. Outro atributo importante que aparece nas tags é o xmi:id, onde seu valor é gerado de forma automática pela ferramenta de modelagem com um identificador único. É através deste valor de referência que é utilizado na próxima etapa para relacionar os elementos, por exemplo, os estados e as transições.

Continuando com a análise do arquivo XMI, na linha 5 encontra-se a declaração do diagrama de atividades identificado pelo atributo xmi:type $=$ 'uml:Activity'. Abaixo deste nó existem dois filhos: um uml:StateMachine na linha 6, que representa o diagrama de estados e um uml:CallBehaviorAction na linha 25 que representa uma ação do diagrama de atividades e que está relacionado ao uml:StateMachine através do atributo behavior, que contém o valor correspondente do atributo xmi:id do diagrama de estados.

Seguindo no nó correspondente da máquina de estado encontram-se os estados (uml:State), transições (uml:Transition) e um pseudo-estado (uml: Pseudostate), este último utilizado para indicar qual é o estado inicial desta máquina de estados.

Na linha 8 encontra-se uma declaração de um estado e abaixo deste nó é declarada a ação que será realizada por ele. Esta ação é representada pelo valor uml:OpaqueBehavior que possui duas tags filhas: body que irá armazenar o código que representa o comportamento deste estado e language que indica qual foi a linguagem utilizada na tag body.

O valor uml:Transition (linha 15) representa uma transição que também possui mais três atributos importantes que são source e target que armazenam as referências para os estados de origem e destino, respectivamente, e o atributo guard que armazena a referência para a declaração que contém 
a condição indicando quando esta transição será disparada. Esta condição é declarada como um elemento filho da transição identificado pelo atributo uml:OpaqueExpression. Este elemento possui duas tags filhas, body e language, da mesma forma que ocorre na declaração de um estado.

O pseudo-estado é representado pelo valor uml:Pseudostate (linha 14) e sua construção é bem simples, resumindo-se a apenas uma tag sem filhos. Ele é utilizado apenas para indicar qual o estado inicial da máquina de estados, sendo relacionado à ele uma transição para este estado.

Por fim, existe o nó uml:CallBehaviorAction (linha 25) que é um dos filhos do elemento uml:Activity. Este elemento representa uma ação no diagrama de atividades e seus filhos são as declarações dos sinais de entrada e saída identificados por uml:InputPin e uml:OutputPin respectivamente, e de variáveis que são identificadas por uml:ValuePin. Todos estes elementos tem filhos que declaram qual o tipo de dado de cada elemento, representados pelo elemento uml:PrimitiveType.

\subsubsection{Parser do XMI}

Esta etapa do processo se dá através da análise do conteúdo do arquivo XMI exportado pela ferramenta de modelagem. Para fazer esta análise foi utilizada a biblioteca xmltool (Carbou, 2011) que fornece um conjunto de funcionalidades para auxiliar nas operações comuns quando se manipula um arquivo XML. Com essa biblioteca, que é disponibilizada de forma open source sob a Apache License 2.0, as funções mais utilizadas foram a de navegação entre os nós do arquivo XMI e a leitura de tags e seus respectivos atributos.

Devido à característica de estrutura de árvore de um arquivo XML, onde cada elemento está representado em um nível diferente, a estratégia escolhida para analisar o arquivo foi a de usar funções auxiliares responsáveis por cada parte desta árvore. Portanto, uma função inicia a busca de um determinado padrão, por exemplo, o início de uma máquina de estado. Neste momento esta função chama outra que é responsável por buscar os estados e assim por diante. Cada função fica responsável por buscar e instanciar os elementos que encontrar no arquivo XMI e adicioná-los no objeto que representa a máquina de estado.

A listagem 4.2 mostra o código referente ao início do processo onde é instanciando um objeto que representa uma máquina de estado (objeto: $f s m$ ) e que será utilizado por este código, sendo passado por parâmetro para as várias funções que compõe todo o código. Nesta função inicial são instanciadas estruturas de ArrayList que são responsáveis por armazenar os Estados, Transições, Variáveis e Sinais de uma máquina de estados e cada ArrayList é associada ao respectivo atributo do objeto $f s m$. 


\section{Listagem 4.2: Trecho de um arquivo XMI do circuito modelado para controlar o tempo} de um semáforo.

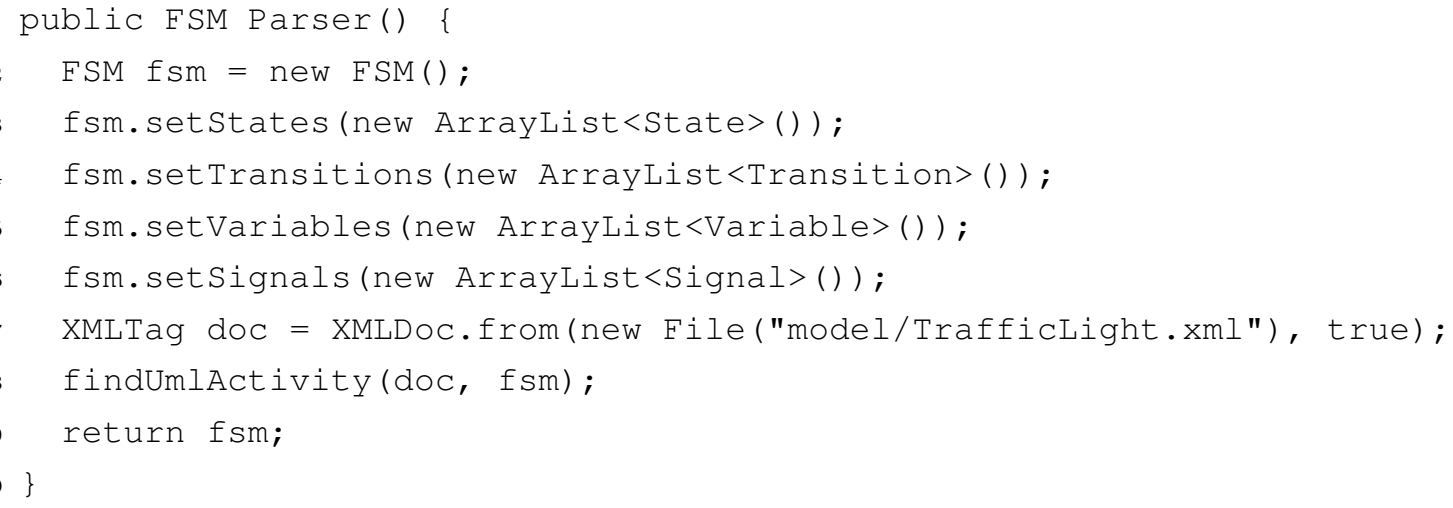

Ainda na função principal, é realizada a operação de abertura do arquivo XMI invocando a função from da biblioteca $x m l t o o l$, que retorna um objeto do tipo XMLTag contendo toda a estrutura de árvore do arquivo XMI e que será utilizado durante todo o processo. Para facilitar a geração do código optou-se por criar uma representação intermediária do arquivo XMI com a estrutura representada por um diagrama de classes ilustrado na figura 4.5, onde cada elemento utilizado na modelagem está associado a uma classe ou a um atributo de uma classe deste diagrama. Nele observa-se a classe principal FSM no qual está associada com as classes State e Transition. Ainda foram utilizadas classes Variable e Signal que mapeiam as variáveis e os sinais, respectivamente. E estas duas classes fazem o uso de enumerators que possuem os possiveis tipos para uma variável e o tipo e direção de um sinal.

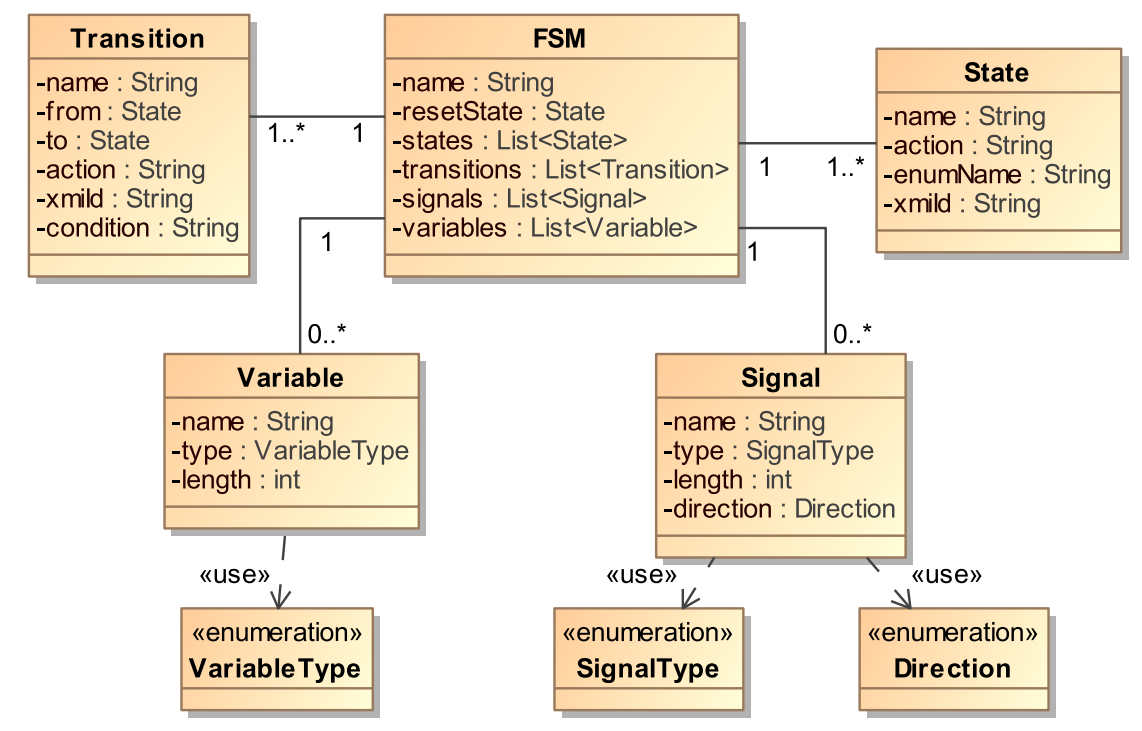

Figura 4.5: Diagrama de classes que representa a estrutura da modelagem do circuito.

Na sequência é feita uma chamada a função findUmlActivity, responsável por localizar o nó relativo à declaração do diagrama de atividades, conforme mostra o código na listagem 4.3. Essa busca é feita de forma recursiva, anali- 
sando todos os nós e suas respectivas ramificações. A cada chamada recursiva é feita uma verificação para identificar se foi encontrado o nó desejado e, no momento em que é encontrado, é chamada a função findUmlStateMachine, responsável por localizar o nó relativo à máquina de estado, que também se comporta de forma semelhante à função anterior, com a diferença que agora a busca são pelos elementos de estados e as transições, nesta ordem, pois quando for realizada a busca pelas transições será necessário já ter os objetos Estados instanciados.

\section{Listagem 4.3: Código utilizado para localizar o elemento que representa um diagrama de atividade no arquivo XMI.}

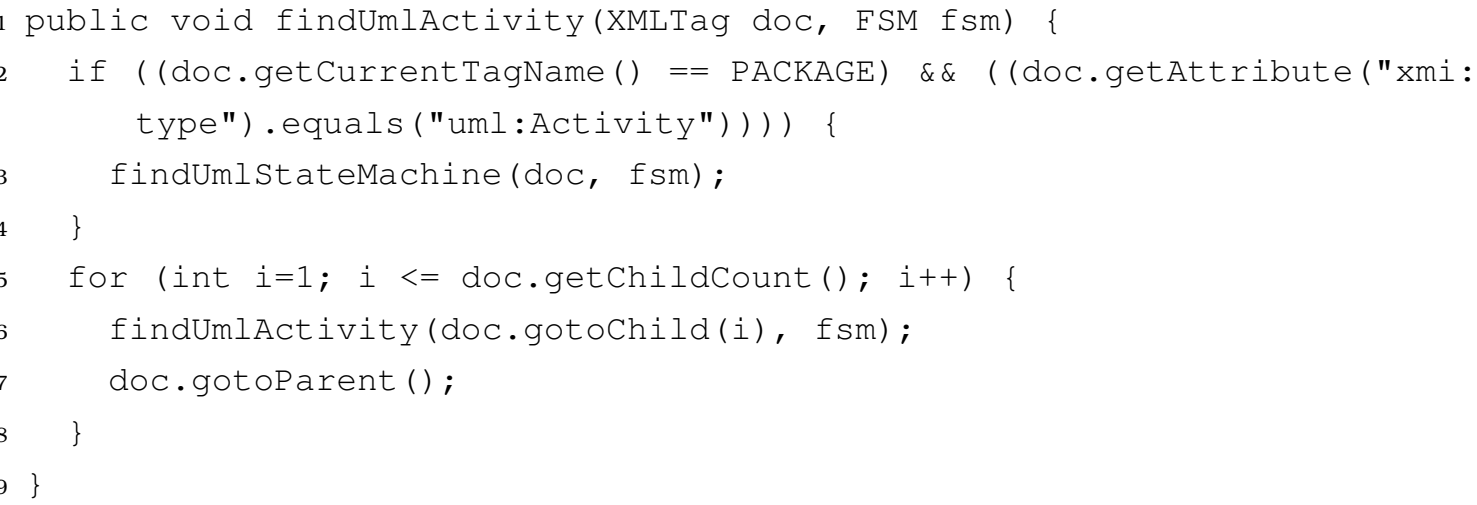

As funções findUmlStates, que aparece na listagem 4.4, e findUmlTransitions são bem semelhantes, distinguindo-se apenas no fato de que a primeira é responsável por instanciar um objeto Estado, seus respectivos atributos e adicioná-lo no ArrayList correspondente e a segunda por instanciar cada transição encontrada, criar o relacionamento com os respectivos estados no qual ela está associada e também adicioná-la no respectivo ArrayList. Devido a esta dependência é necessário percorrer duas vezes este trecho da árvore.

\section{Listagem 4.4: Código utilizado para localizar os elementos que representam estados no arquivo XMI.}

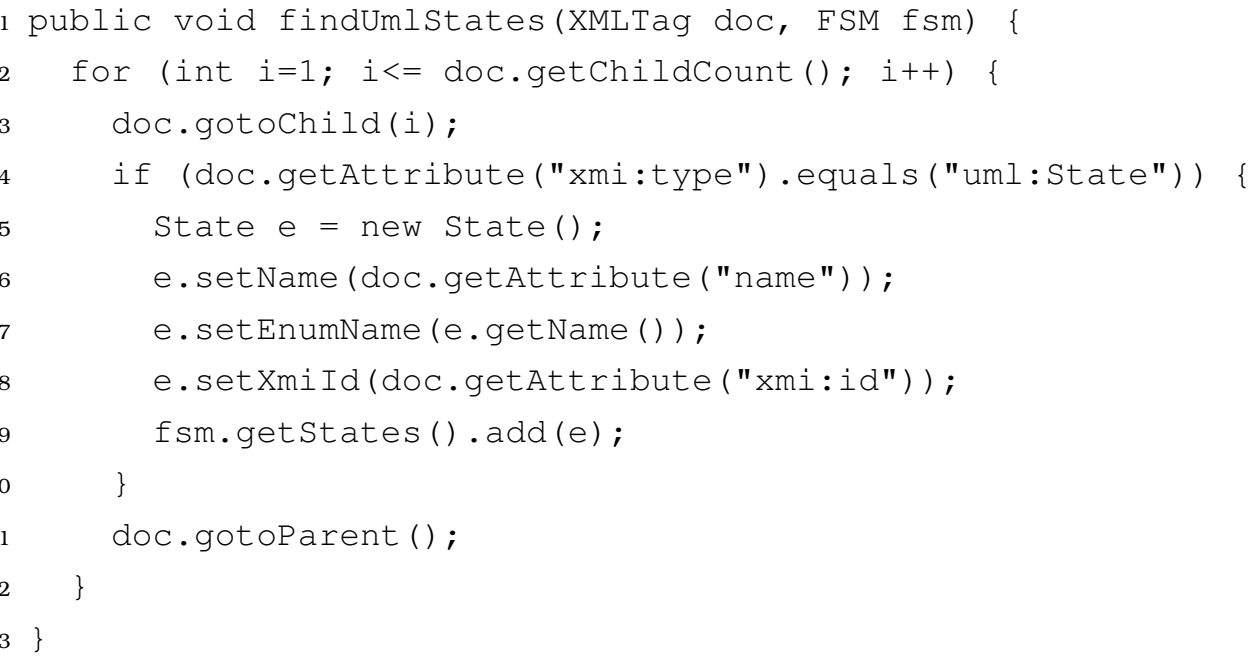




\subsubsection{Geração de código}

Esta é a última etapa no fluxo da UML2BSV para gerar o código fonte. Neste momento todos os elementos representados no arquivo XMI foram identificados e instanciados em seus respectivos objetos. Qualquer inconsistência ou erro no arquivo XMI que possa ter ocorrido será reportado antes deste passo.

A abordagem escolhida para a geração de código foi com a utilização de templates, que representam as estruturas de um código fonte em BSV. O uso destes templates é facilitada pela biblioteca Velocity, um projeto open source mantido pela Apache Software Foundation, que se adaptou muito bem nas necessidades deste trabalho.

O primeiro passo foi definir os templates a serem utilizados, abstraindo uma estrutura padrão encontrada em um código BSV. O Velocity possui um sistema de templates bem flexível através do uso de sua própria linguagem, VTL. Esta característica é importante pois desta forma cada template fica com um tamanho reduzido, facilitando o entendimento e manutenção dos mesmos.

Os templates são formados por: constantes, que são textos que não irão sofrer mudanças durante o processo de renderização e que, neste caso, representam a estrutura do código fonte; por variáveis, que são os trechos de códigos que representam a lógica da programação; e por estruturas de código da linguagem VTL como IFs ou LOOPs.

O diagrama representado pela figura 4.6 mostra como está organizada a estrutura de templates responsável pela geração do código deste trabalho. Ela é formada por um template principal que representa todo o módulo de um código em BSV e que engloba templates menores, fazendo chamadas a eles durante o processo de renderização. Estes templates filhos foram criados para simplificar o desenvolvimento, deixando o template principal com menos linhas de código. Eles representam determinados trechos de um módulo como interface, enumerator (utilizado para a representar os estados) e as regras.

A listagem 4.5 mostra o conteúdo do template que representa um módulo em BSV. Na linha 1 pode-se observar um exemplo simples do funcionamento do sistema de templates do Velocity. A palavra-chave package aparece como uma constante e a variável $\$$ fsmName será substituída pelo nome do pacote do módulo a ser gerado.

Listagem 4.5: Código de um template na linguagem VTL que representa um módulo em BSV, com chamadas à outros templates.

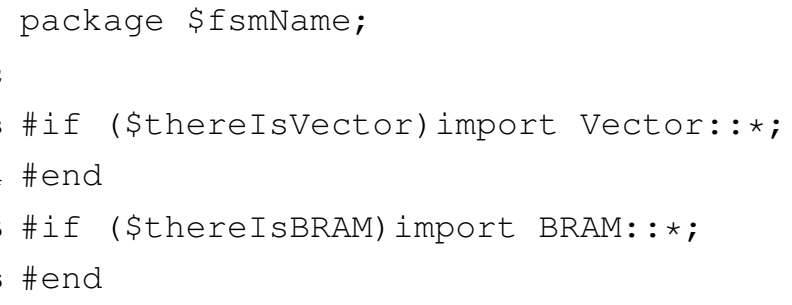




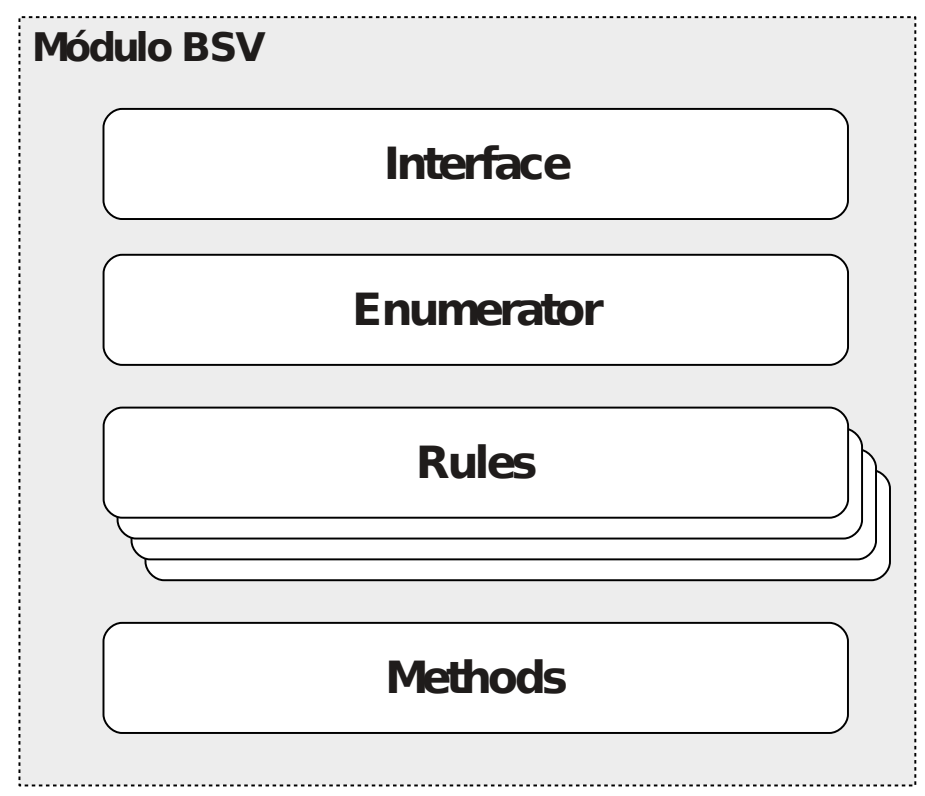

Figura 4.6: Estrutura de templates de um módulo BSV.

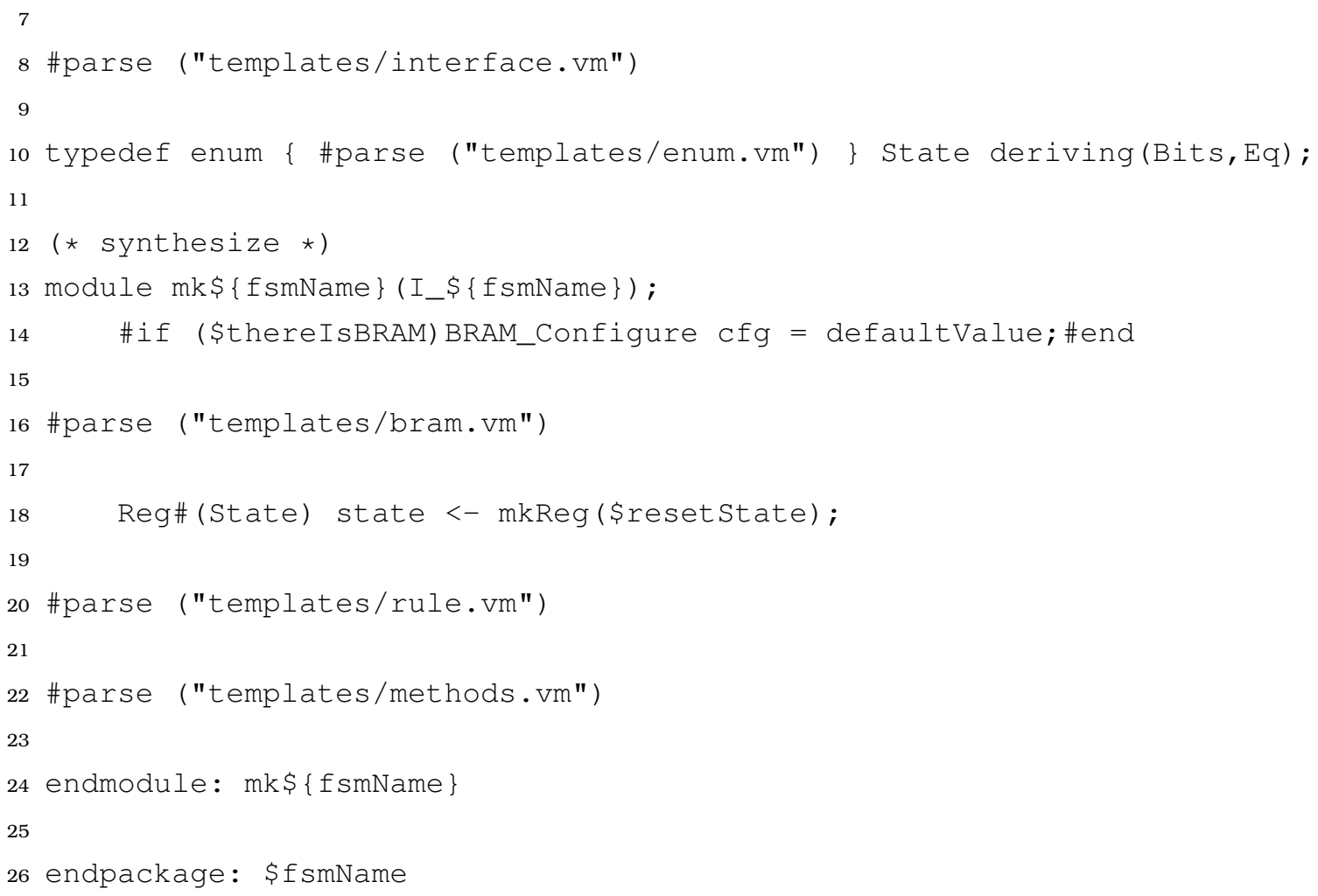

Na linha 3 ocorre a chamada a um template filho que será responsável por listar todos os estados que foram previamente modelados. Esta chamada é feita através da palavra-chave \#parse que recebe como parâmetro o nome do arquivo deste outro template. Neste momento o Velocity passa a interpretar o template chamado e todo o resultado da renderização deste será inserido exatamente no ponto onde o template foi chamado.

Na listagem 4.6 observa-se um bom exemplo do uso da VTL de como fica simples realizar iterações de uma determinada coleção de objetos, neste caso 
um conjunto de regras da linguagem BSV. Na linha 1 inicia-se o laço com a palavra-chave \#foreach. Este tipo de laço irá percorrer cada elemento da coleção de dados \$states e, a cada iteração, um elemento de \$states será atribuído ao objeto \$state, que é da classe State. Na linha 2 observa-se as chamadas dos métodos getName() e getEnumName() a partir do objeto state que, em ambos os casos, retornam uma String. Caso a coleção \$states tenha armazenado três estados, todo esse bloco da listagem 4.6 será repetido três vezes e o resultado da renderização será inserido na linha 10 da listagem 4.5, local que foi chamado este template.

\section{Listagem 4.6: Exemplo de um template no qual é realizada uma iteração em uma coleção de regras da linguagem BSV.}

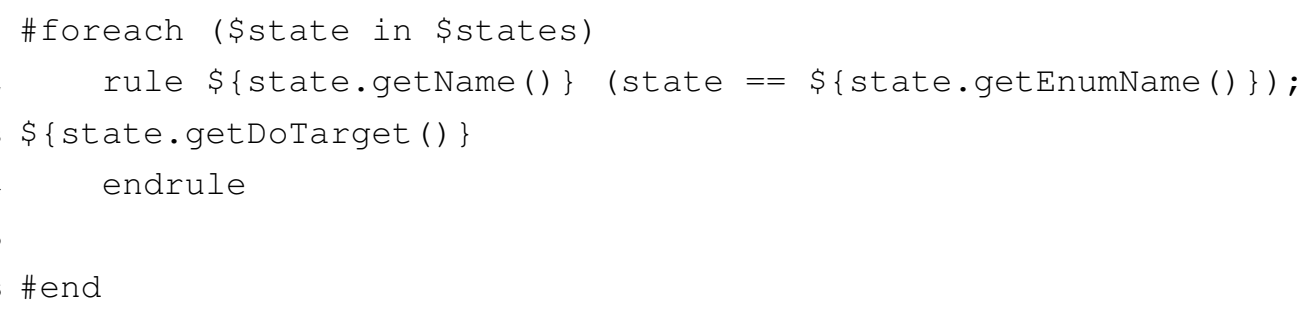

Voltando ao exemplo referente à primeira linha da listagem 4.5, a informação do nome do pacote é armazenada em uma estrutura de HashMap na qual os elementos inseridos nela são sempre aos pares, chave e valor. Neste caso, a chave tem o valor fsmName e o valor é o retorno de uma String da função getName() pertencente à classe FSM. O valor a ser inserido neste HashMap pode ser qualquer objeto, por exemplo, uma string, um estado ou até mesmo uma coleção de transições.

Na listagem 4.7 é demonstrado como tornar essas informações disponíveis para o template. Na linha 4 é passado ao Velocity qual o template principal que será utilizado para gerar o código. Na linha 5 é instanciado um objeto do tipo VelocityContext que utiliza uma estrutura de HashMap, explicada anteriormente, onde serão armazenados todas as informações relacionadas à máquina de estado modelada. Este é o objeto que faz a ligação entre as informações que estão em memória e os templates. Em seguida pode-se ter uma ou mais chamadas ao método put para inserir o par chave/valor no HashMap. Neste exemplo são armazenados no VelocityContext o nome da máquina de estado (como string) e a lista de estados e transições (ambos como List). E por último é feita a chamada que irá gerar o código baseado nas informações passadas ao template, onde o resultado fica armazenado em um objeto do tipo StringWriter que poderá ser salvo em um arquivo ou, como acontece neste exemplo, o conteúdo é enviado para a console.

Listagem 4.7: Trecho de código utilizado para passar as informações coletadas durante o parser do arquivo XMI para os templates do Velocity.

1 public void GenBSV(FSM fsm) \{ 


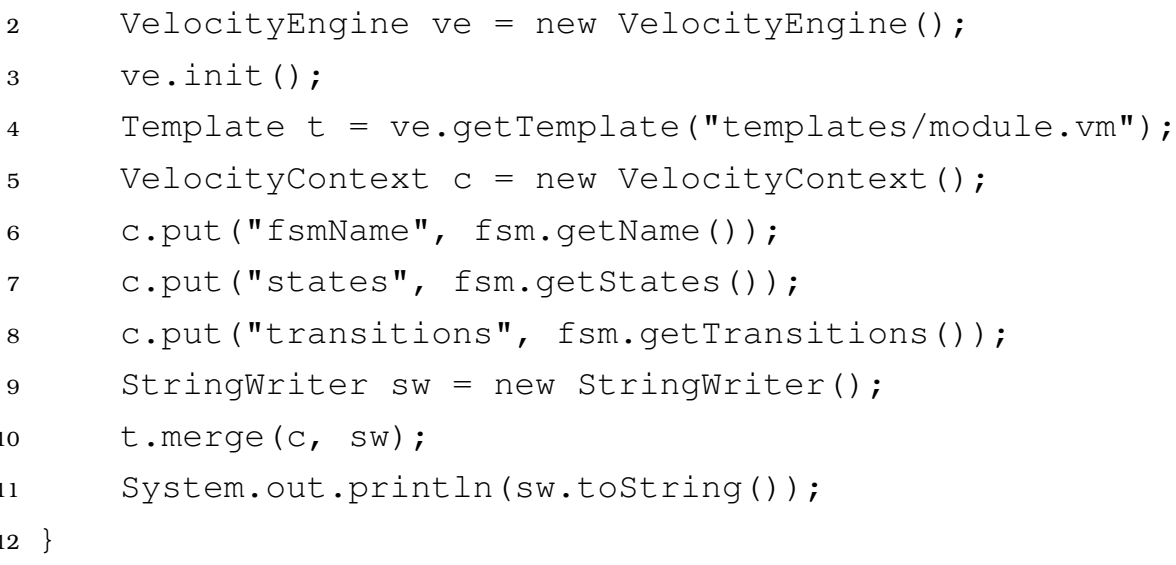

Neste ponto a geração do código BSV está concluída e o desenvolvedor pode utilizar o Bluespec Compiler para compilar, simular e gerar o respectivo código Verilog para ser sintetizado. Também será possivel armazenar o código BSV em um repositório de IP da ferramenta RoboArch para ser utilizado como um módulo em outros projetos.

\subsubsection{Exemplos de geração de código BSV}

Esta seção ilustra alguns momentos durante a transformação da modelagem UML para código BSV. As figuras 4.7, 4.8 e 4.9 mostram alguns trechos de códigos que serão gerados por esta ferramenta.

A figura 4.7 mostra como um conjunto de estados são representados na linguagem BSV. Um tipo de dado State é declarado através da instrução typedef. Neste exemplo, está sendo criado um enumerator que possui como elementos todos os estados presentes no diagrama de estados. Também são geradas rules para cada estado, seguidas com suas respectivas condições entre parênteses, que funcionam como um gatilho para controlar o momento certo em que cada rule será executada. Dessa forma, é garantido que apenas uma rule será disparada em um mesmo ciclo de relógio.

A figura 4.8 mostra parte da modelagem da figura 4.4 , focando na região onde é definido qual o estado inicial da máquina de estados. Esta definição é feita por meio de uma transição do pseudo-estado (círculo preto) a um estado. O resultado desta modelagem é a geração do código BSV onde, o estado em questão, anteriormente já definido pelo enumerator, é passado como parâmetro para o mkReg, que é responsável por inicializar a variável state do tipo State.

Por último, a figura 4.9 mostra uma outra região da modelagem UML da figura 4.4 destacando a transição que ocorre do estado Green para o Yellow, com a condição count $==20$. Esta condição irá controlar a mudança de um estado para o outro. Toda transição é representada em BSV por meio de uma instrução if cuja condição é a mesma utilizada na transição. Esta verificação 


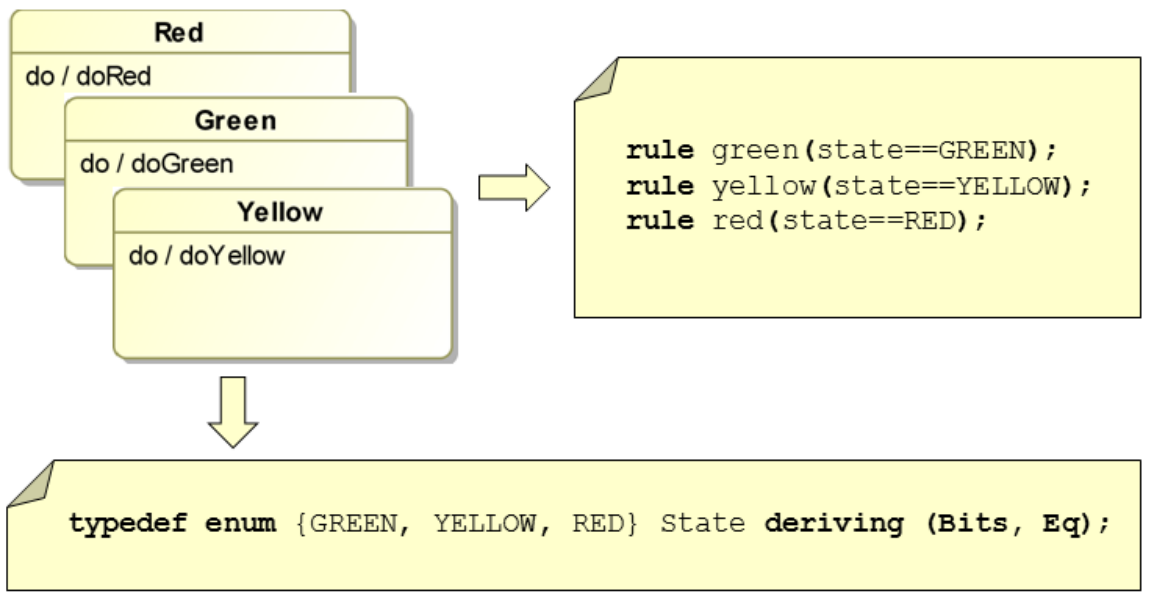

Figura 4.7: Representação de um conjunto de estados e suas respectivas definições em Bluespec. O código na parte inferior da imagem representa a declaração de um novo tipo de dado State, da categoria enumerator, onde estão incluídos todos os estados da modelagem. E o código à direita mostra trecho das rules para cada estado que foi modelado.

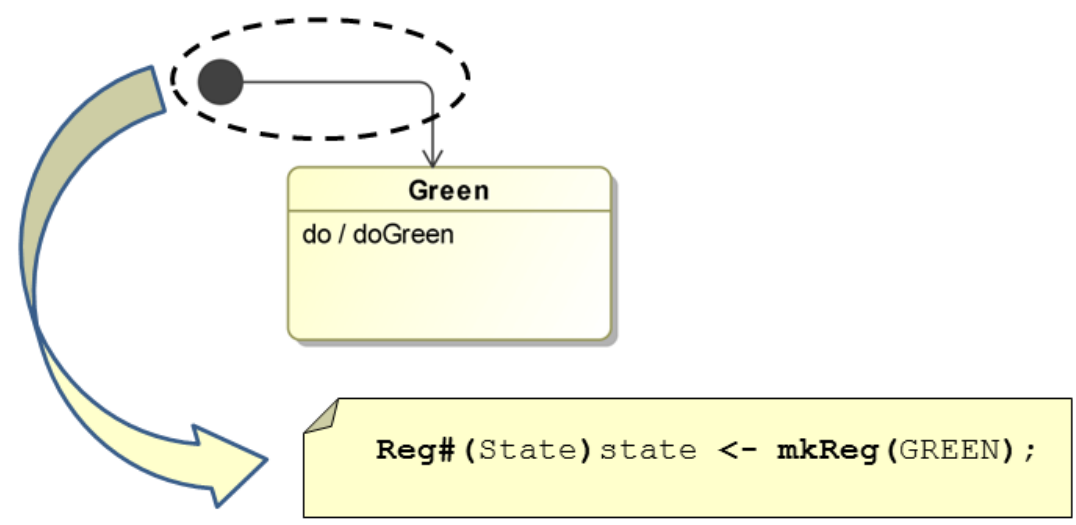

Figura 4.8: Definição de um estado inicial por meio de uma transição de um pseudo-estado, representado por um círculo preto, para um estado comum. $\mathrm{Na}$ parte inferior da figura é ilustrado o código BSV correspondente que cria e inicializa a variável state.

é realizada dentro de uma rule e, caso a condição seja verdadeira, o valor da variável state é atualizado e no próximo ciclo de relógio um outro estado (rule) será executado.

Caso a modelagem tenha alguma transição sem nenhuma condição declarada, situação permitida desde que não cause nenhuma ambiguidade na máquina de estados, a instrução if é omitida e a variável state é atualizada dentro da rule diretamente, sem nenhum tipo de verificação.

\subsection{Compilador C2BSV}

O compilador C2BSV é a segunda parte do projeto. Como seu próprio nome sugere, ele traduz código $\mathrm{C}$ para a linguagem Bluespec SystemVerilog. Ele foi 


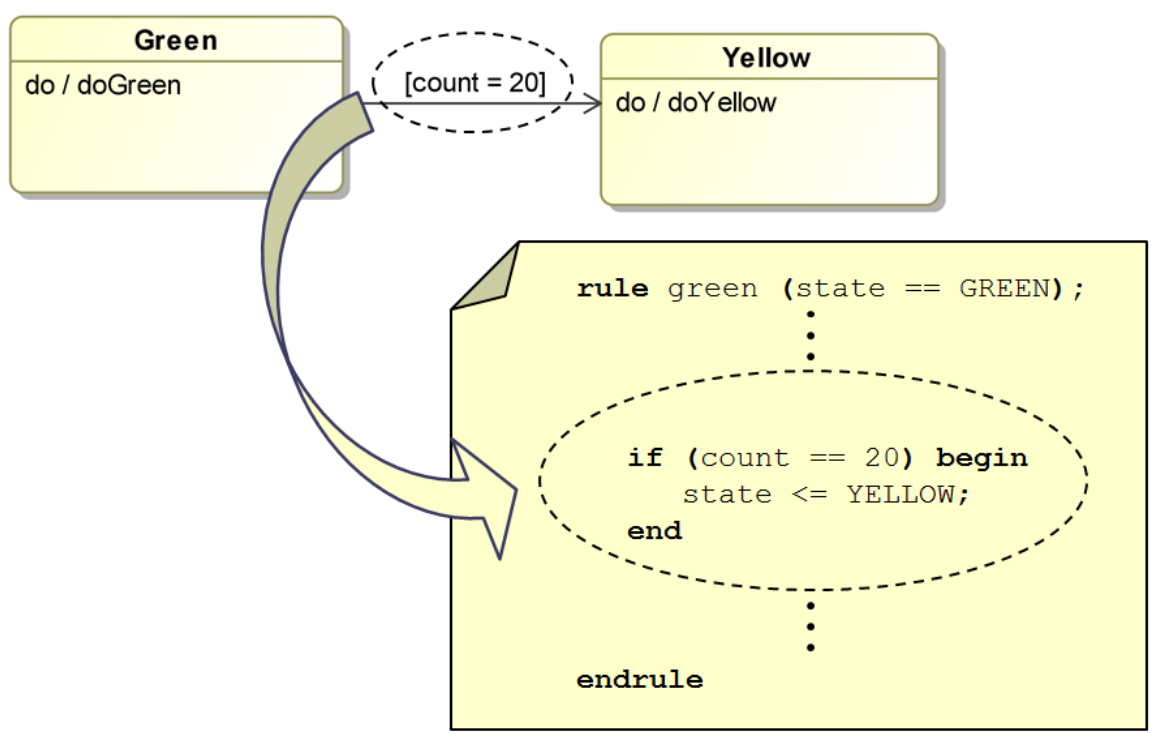

Figura 4.9: Parte do diagrama de estados mostrando uma transição com a condição count $==20$. Abaixo da figura é destacado o trecho de código BSV dentro da rule onde uma verificação condicional é realizada.

implementado utilizando a ferramenta JavaCC, já apresentada na seção 3.1, juntamente com o JJTree. No apêndice $\mathrm{C}$ encontra-se a gramática utilizada para construir o compilador C2BSV.

O desenvolvimento deste compilador foi realizado de forma a deixá-lo independente do UML2BSV, permitindo futuras melhorias e implementação de novos recursos sem a necessidade de alterar o projeto UML2BSV. Também é possivel utilizá-lo de forma standalone ou até ser incorporado em projetos de terceiros.

A gramática da linguagem $\mathrm{C}$ foi obtida do repositório de contribuições do site do JavaCC ${ }^{2}$, o qual foi modificada para se adequar às necessidades deste trabalho. As principais mudanças necessárias foram realizar as anotações para que fosse possivel trabalhar com a AST gerada de forma mais otimizada e a retirada de alguns nós da AST para simplificar a navegação pela árvore.

Para ilustrar como é estruturada a AST gerada pelo frontend, considere a seguinte instrução na linguagem $\mathrm{C}$ :

$$
\text { resultado }=9 /(1+3) * 4+5
$$

Esta instrução consiste em operações aritméticas tradicionais e o resultado do cálculo é atribuído à variável resultado. É importante observar neste caso que a precedência dos operadores aritméticos foram obedecidos pelo compilador. Enviando esta instrução ao compilador é possível imprimir a AST gerada pelo frontend, conforme a listagem 4.8 .

\footnotetext{
${ }^{2}$ Disponível em: http://java.net/projects/javacc/downloads/directory/contrib/grammars
} 


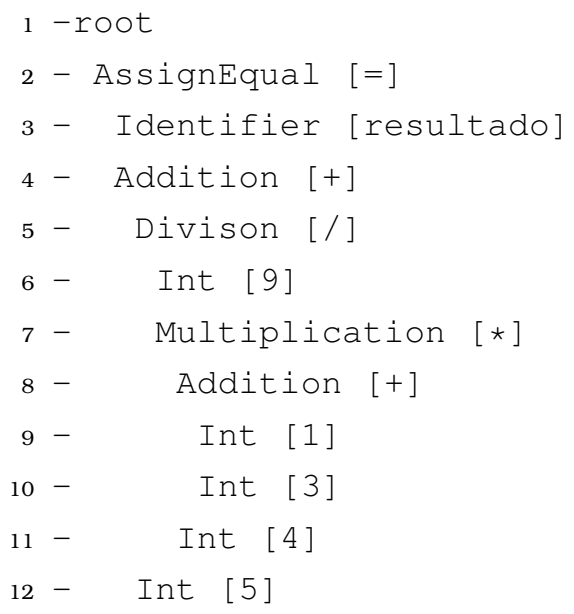

Na figura 4.10 encontra-se uma outra forma de representar a AST referente à instrução utilizada como exemplo.

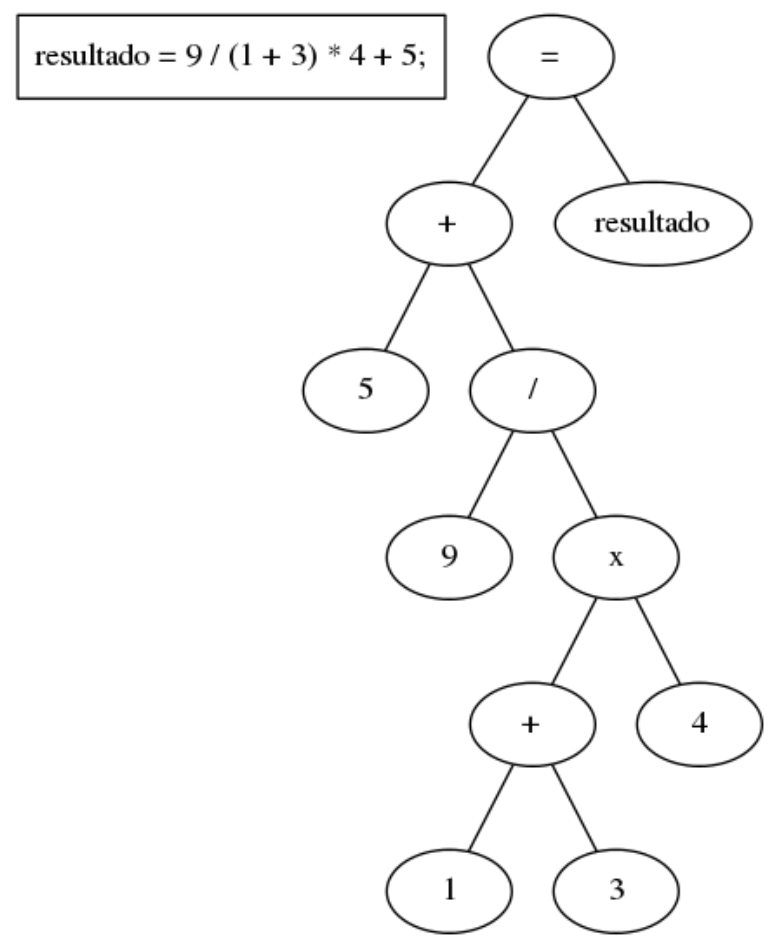

Figura 4.10: Instrução resultado $=9 /(1+3) * 4+5$; representada no formato da AST gerada pelo frontend.

O compilador foi construído com a opção do JJTree $M U L T I=$ true. Dessa forma, são geradas uma classe para cada nó da AST deixando a estrutura do compilador bem organizada, fácil de manter e evita redundâncias no backend. Toda vez que ele é invocado, caso tenha alguma instrução ainda não implementada, uma mensagem de erro é mostrada no console para o usuário, indicando inclusive qual o respectivo nó da AST que se trata, facilitando a sua localização.

Embora a instrução while faça parte da gramática em uso pelo C2BSV, ela 
ainda não foi implementada. Durante o parser, caso o compilador encontre a instrução while, será emitido um erro no console e todo o processo é abortado. Por exemplo, a saída do compilador para o seguinte código

$$
\text { while }(x==1)\{\ldots\}
$$

pode ser vista na listagem 4.9. Na linha 10 encontra-se a mensagem de erro [While] not implemented yet!.

Listagem 4.9: Saída da AST indicando que uma instrução ainda não foi implementada.

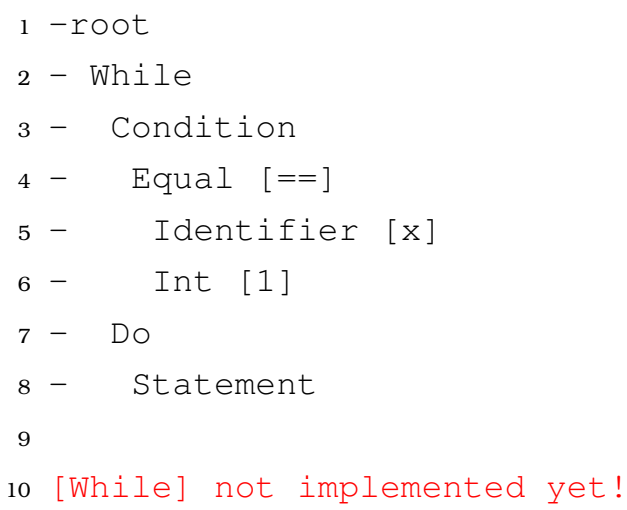

Atualmente este compilador abrange somente um subconjunto da linguagem C. Apesar da gramática utilizada estar bem completa, apenas parte das instruções foram implementadas. A tabela 4.2 mostra os nós da AST que foram implementados até o momento.

Tabela 4.2: Nós da AST do compilador C2BSV que foram implementados.

$\begin{array}{ll}\text { ASTStatement } & \text { ASTAssignEqual } \\ \text { ASTUnaryExpression } & \text { ASTPositive } \\ \text { ASTNegative } & \text { ASTAddition } \\ \text { ASTDivision } & \text { ASTSubtraction } \\ \text { ASTMultiplication } & \text { ASTIdentifier } \\ \text { ASTInt } & \text { ASTCondition } \\ \text { ASTAND } & \text { ASTOR } \\ \text { ASTEqual } & \text { ASTNotEqual } \\ \text { ASTGreater } & \text { ASTGreaterOrEqual } \\ \text { ASTLess } & \text { ASTLessOrEqual } \\ \text { ASTIf } & \text { ASTThen } \\ \text { ASTElse } & \text { ASTPosition }\end{array}$

Instruções de decisão e laços podem ser representadas na própria máquina de estados em UML de forma visual. Por exemplo, as estruturas de decisões como if e case poderão ser representadas através das transições entre os estados com sua respectiva condição, como pode ser visualizado na figura 4.11(a). 
Também é possivel expressar estruturas de laços como for e while através de “estados aninhados”, conforme é mostrado na figura 4.11(b).

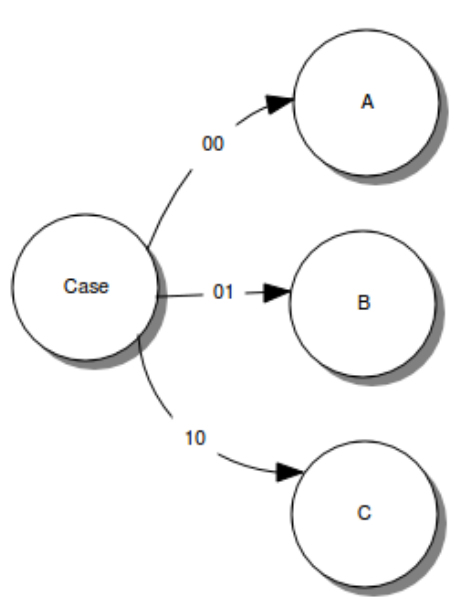

(a) Estrutura case utilizando máquina de estado.

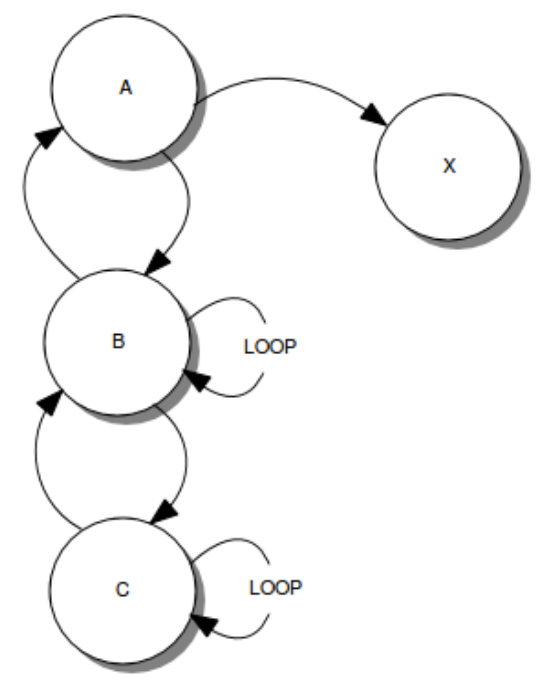

(b) Estrutura de laços aninhados utilizando máquina de estado.

Figura 4.11: Representações de estruturas de decisões e laços como máquina de estados. 


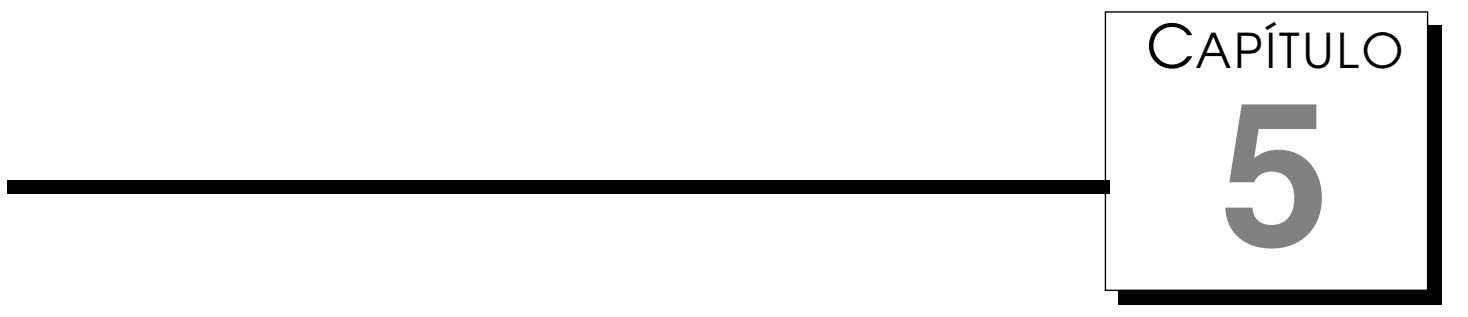

\section{Aplicações da Ferramenta Proposta}

Como forma de validar a ferramenta, foram desenvolvidos dois testes com finalidades bem distintas entre si: um processador de uso geral e um elemento de processamento de imagem Sobel para detecção de bordas. A intenção com estes dois casos é a de explorar todos os recursos desenvolvidos neste trabalho como declaração de tipos de dados, utilização de vetores e memória, uso de laços aninhados de forma gráfica, entre outros.

Para validar o comportamento destes dois exemplos, foram realizadas simulações com a ferramenta Bluesim e os respectivos resultados analisados. Estes dois exemplos também foram sintetizados utilizando a ferramenta Quartus II da Altera, tendo como alvo o kit de desenvolvimento da Terasic DE2-70 ${ }^{1}$. Dentre as características desde kit, ele possui um FPGA da família Cyclone II modelo EP2C70F896C6. Os resultados das simulações e o relatório das sínteses realizada, à partir do Verilog gerado pelo compilador Bluespec, são apresentados no final de cada seção.

\section{1 Processador}

O processador desenvolvido foi baseado no mesmo que é utilizado na disciplina Elementos de Lógica Digital II (SSC-113) no Instituto de Ciências Matemáticas e de Computação (ICMC).

O processador tem a arquitetura do tipo RISC com instruções de 16 bits, possui 8 registradores de uso geral e uma única memória dividida em duas partes, sendo o início reservado para as instruções e o restante para os da-

\footnotetext{
${ }^{1}$ Mais detalhes sobre o kit de desenvolvimento Terasic DE2-70 pode ser encontrado no site: http://www.terasic.com.tw/cgi-bin/page/archive.pl?No=226
} 
dos. Foram implementadas onze instruções desde processador, divididas em três grupos, onde foram mantidos os mesmos opcodes utilizados nas aulas de laboratório.

\subsubsection{Modelagem do processador}

Antes de começar a modelagem do processador com o diagrama de estados, é necessário definir, no diagrama de classes, os tipos de dados que serão utilizados. Conforme ilustrado na figura 5.1, foram definidos cinco tipos de dados:

- três tipos Bit com tamanhos 3, 6 e 16 bits;

- um vetor para armazenar 8 elementos de 16 bits;

- e uma memória com a seguinte configuração:

- largura de endereço de 6 bits, possibilitando endereçar 64 posições de memória, ficando 32 posições para as instruções e o restante para os dados;

- largura de dados de 16 bits para comportar o tamanho das instruções do processador;

- tipo single port;

- dados, que serão carregados na memória no início da simulação, em codificação binária;

- arquivo com o conteúdo inicial da memória nomeado como memory.bin.
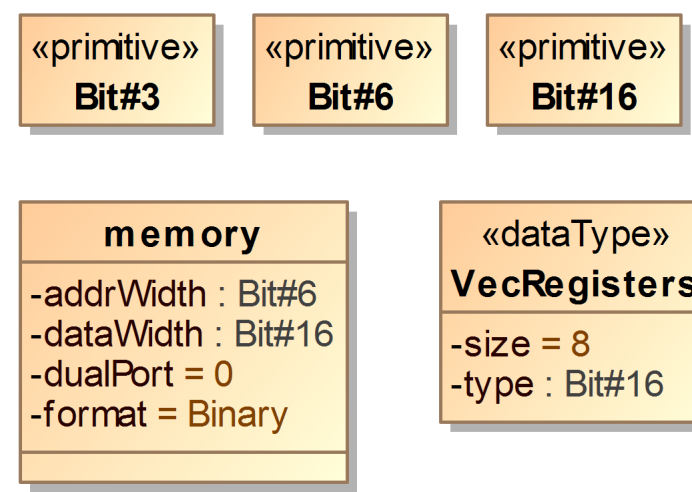

\begin{tabular}{|c|}
\hline $\begin{array}{c}\text { «dataType» } \\
\text { VecRegisters }\end{array}$ \\
\hline -size $=8$ \\
-type : Bit\#16
\end{tabular}

Figura 5.1: Definição dos tipos de dados utilizados na modelagem do processador.

O próximo passo é fazer a modelagem da máquina de estados que irá representar o processador. 
Como é possível observar na figura 5.2, o primeiro estado a ser executado é o Fetch. Nele é feita uma requisição de leitura à memória no endereço armazenado no registrador PC (program counter), que no início tem o valor 0; o valor do PC é incrementado; e a execução é direcionada para o estado Decode. É importante lembrar que todas as operações dentro do estado são executadas em paralelo em um único ciclo de relógio.

No estado Decode, a instrução já está disponivel na porta da memória para ser lida. Este valor é então armazenado no registrador IR (instruction register) para então seguir ao estado PostDecode.

O estado PostDecode é um estado auxiliar do Decode que não executa instrução. Ele é necessário apenas para que o valor do registrador IR, modificado no estado anterior, fique com seu valor atualizado. É a partir deste estado que saem as diversas transições para os estados que irão executar suas respectivas instruções. Cada transição tem como condição os 6 primeiros bits do registrador IR para identificar qual instrução deverá ser executada.

As instruções implementadas podem ser divididas em três grupos. As tabelas 5.1, 5.2 e 5.3 listam os conjuntos de instruções relacionadas à manipulações de dados, operações aritméticas e de controle, respectivamente.

Tabela 5.1: Instruções de manipulação de dados.

\begin{tabular}{lll}
\multicolumn{1}{c}{ Instrução } & \multicolumn{1}{c}{ Significado } & \multicolumn{1}{c}{ Opcode } \\
MOV RX RY & $\mathrm{RX} \leftarrow \mathrm{RY}$ & $110011|\mathrm{RX}| \mathrm{RY}|\mathrm{xxx}| \mathbf{x}$ \\
LOADINDEX RX RY & $\mathrm{RX} \leftarrow \mathrm{MEM}(\mathrm{RY})$ & $111100|\mathrm{RX}| \mathrm{RY}|\mathrm{xxx}| \mathbf{x}$ \\
STOREINDEX RX RY & $\mathrm{MEM}(\mathrm{RY}) \leftarrow \mathrm{RX}$ & $111101|\mathrm{RX}| \mathrm{RY}|\mathbf{x x x}| \mathbf{x}$ \\
LOADIMED RX & $\mathrm{RX} \leftarrow \# N R$ & $111000|\mathrm{RX}| \mathrm{xxx}|\mathbf{x x x}| \mathbf{x}$ \\
& & $N R$ \\
STOREIMED & $\mathrm{MEM}(\mathrm{RX}) \leftarrow \# N R$ & $111001|\mathrm{RX}| \mathrm{xxx}|\mathrm{xxx}| \mathrm{x}$ \\
& & $N R$
\end{tabular}

Tabela 5.2: Instruções aritméticas.

\begin{tabular}{lcc}
\multicolumn{1}{c}{ Instrução } & Significado & Opcode \\
ADD RX RY RZ & $\mathrm{RX} \leftarrow \mathrm{RY}+\mathrm{RZ}$ & $100000|\mathrm{RX}| \mathrm{RY}|\mathrm{RZ}| 0$ \\
SUB RX RY RZ & $\mathrm{RX} \leftarrow \mathrm{RY}-\mathrm{RZ}$ & $100001|\mathrm{RX}| \mathrm{RY}|\mathrm{RZ}| \mathrm{O}$ \\
MUL RX RY RZ & $\mathrm{RX} \leftarrow \mathrm{RY}{ }^{*} \mathrm{RZ}$ & $100010|\mathrm{RX}| \mathrm{RY}|\mathrm{RZ}| 0$ \\
DIV RX RY RZ & $\mathrm{RX} \leftarrow \mathrm{RY} / \mathrm{RZ}$ & $100011|\mathrm{RX}| \mathrm{RY}|\mathrm{RZ}| 0$
\end{tabular}

Algumas instruções necessitam de apenas um ciclo de relógio para serem executadas, já outras necessitam de 2 ciclos. No caso das instruções que necessitam de mais de um ciclo para completar sua execução, isto é feito colocando um estado a mais para a instrução em questão, como pode ser visto, 
Tabela 5.3: Instruções de controle.

\begin{tabular}{|c|c|c|}
\hline مอ̃ก & do & \\
\hline & $\mathrm{Se}$ & 00 \\
\hline & a exe & 0011111 \\
\hline
\end{tabular}

por exemplo, com a instrução LOADIMED onde foram necessários utilizar os estados LoadImed1 e LoadImed2.

No final da execução de cada instrução, as transições fazem o fluxo de execução retornar ao estado Fetch, fechando assim o ciclo de operação. A única exceção é da instrução HALT, cujo o objetivo é justamente encerrar o ciclo de execução.

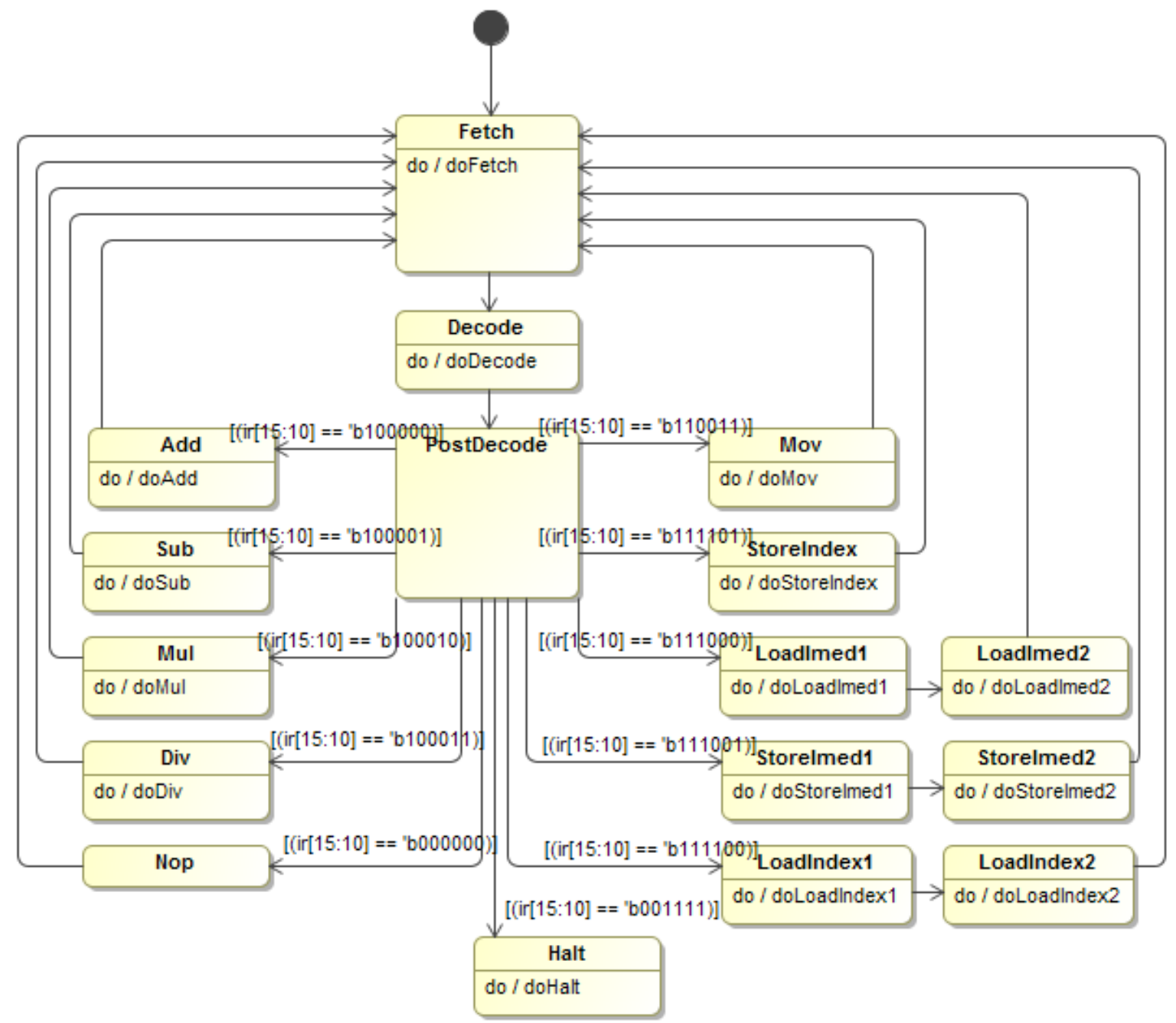

Figura 5.2: Diagrama de estados do processador.

Para finalizar a modelagem do processador é necessário criar uma ação no diagrama de atividades, apresentado na figura 5.3. Nesta ação é atribuído que seu comportamento é representado pelo diagrama de estados, cujo o mo- 
delo é o da máquina de estados em UML da figura 5.2. Adicionalmente, são criados os sinais de entrada/saída e as variáveis locais. No caso deste processador foram definidas apenas variáveis locais utilizando os tipos definidos no diagrama de classes, conforme segue:

- $\mathrm{pc} \rightarrow \mathrm{Bit}$ 6

- ir $\rightarrow$ Bit\# 16

- $(\mathrm{rx}, \mathrm{ry}, \mathrm{rz}) \rightarrow \mathrm{Bit} \# 3$

- registers $\rightarrow$ VecRegisters (8 elementos do tipo Bit\#16)

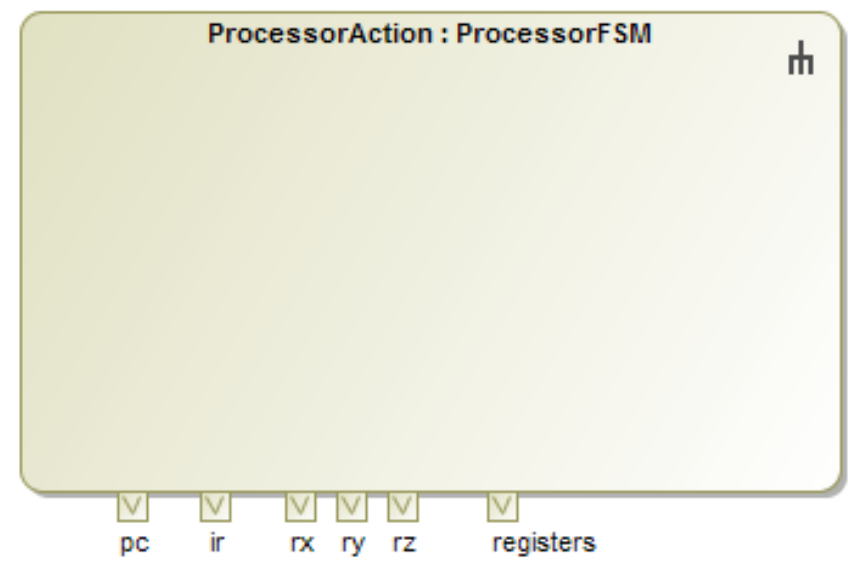

Figura 5.3: Ação que representa o processador com as variáveis utilizadas localmente na região inferior.

\subsubsection{Resultados}

Foi criado um programa com algumas instruções para testar o funcionamento do processador. Estas instruções já estão em codificação binária no arquivo texto que será carregado na memória. Na listagem 5.1 encontra-se um trecho deste arquivo. Junto com as instruções, estão alguns dados que fazem parte dos testes.

\section{Listagem 5.1: Instruções utilizadas para testar o processador.}

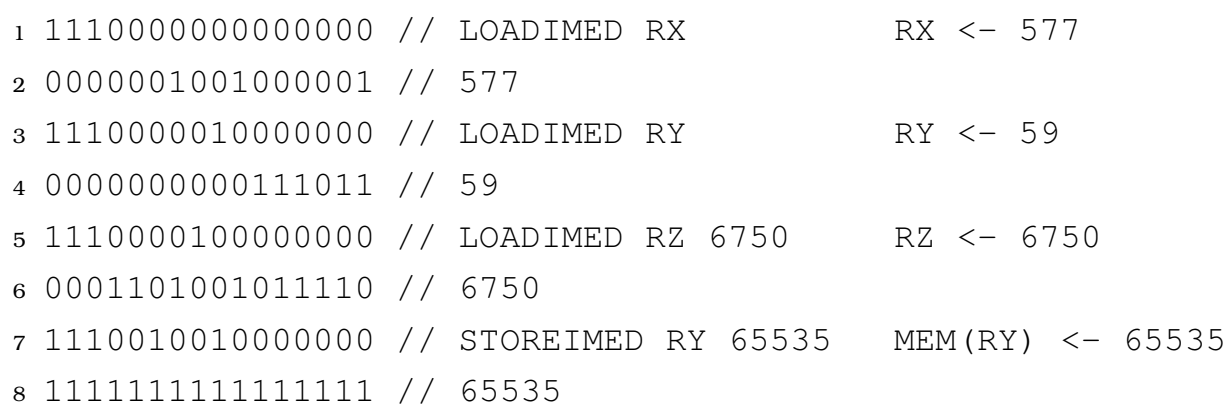




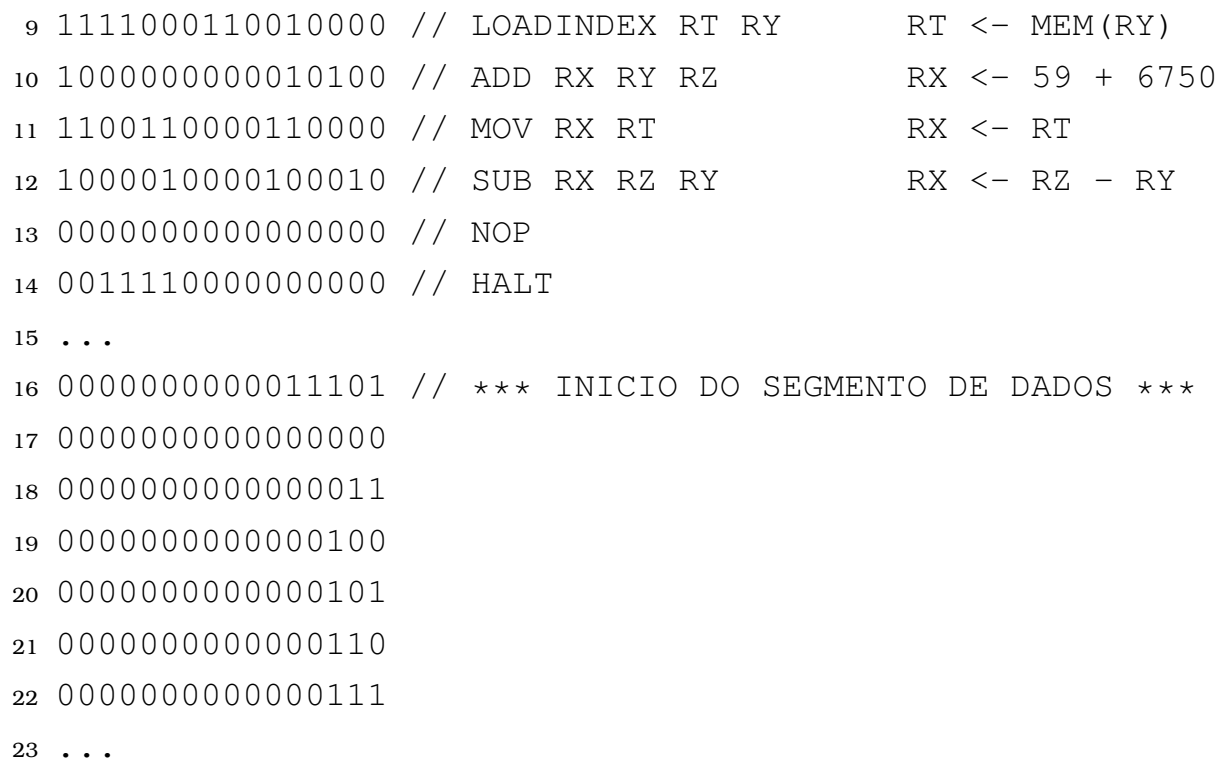

A validação do processador foi realizada através da simulação com o Bluesim. Durante a simulação observou-se as saídas impressas no terminal com os valores dos registradores a cada instrução para avaliar se estavam corretos. Todas as instruções implementadas tiveram o comportamento esperado e o programa foi executado com sucesso.

Também foi realizada a síntese na ferramenta Quartus II do código Verilog gerado a partir da compilação do código BSV pelo Bluespec. O resultado da sintese encontra-se na listagem 5.2

\section{Listagem 5.2: Resultado da sintese do processador pela ferramenta Quartus II.}

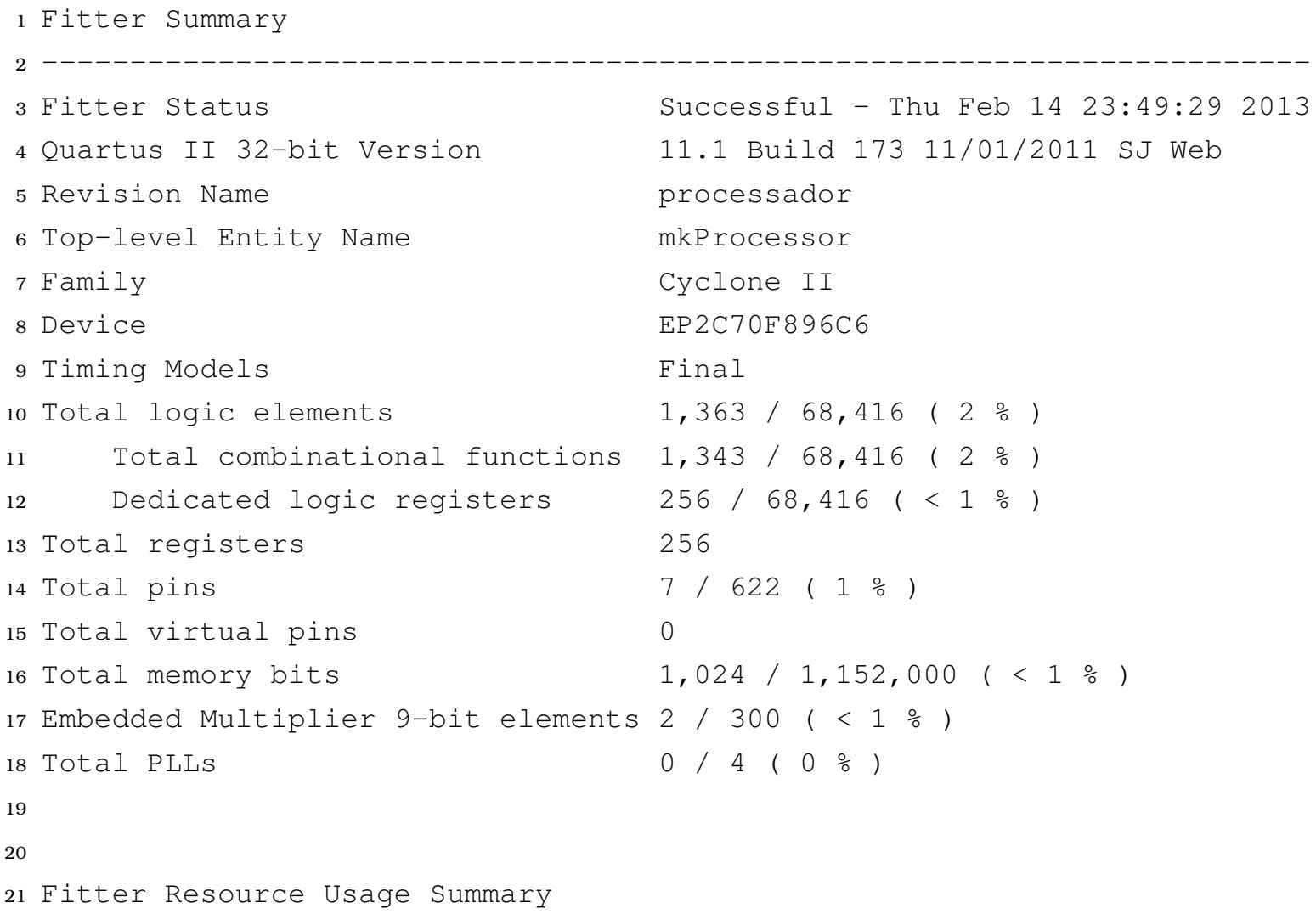




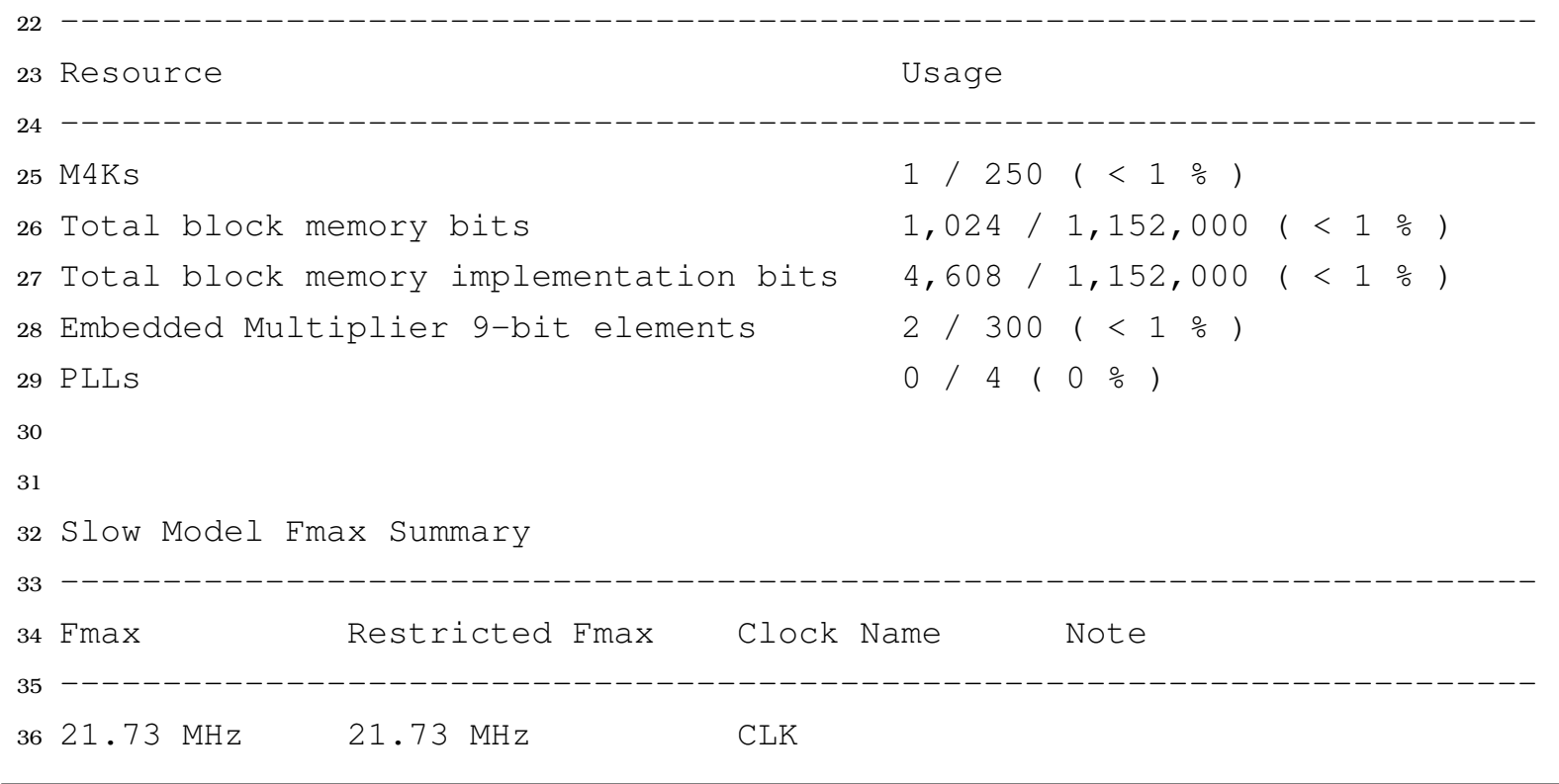

No apêndice A encontra-se o código fonte BSV completo gerado pela ferramenta UML2BSV deste processador.

\subsection{Elemento de Processamento de Imagem Sobel}

Para explorar outras funcionalidades da ferramenta UML2BSV, modelou-se um elemento de processamento para detecção de borda em imagens digitais por meio do algoritmo Sobel (Marques Filho e Neto, 1999). Este método trabalha com duas máscaras $3 \times 3$ que são aplicadas a cada pixel da imagem original. Uma máscara é responsável por detectar as variações horizontais e outra para as verticais.

As máscaras utilizadas no filtro Sobel são:

$$
H=\left|\begin{array}{rrr}
-1 & -2 & -1 \\
0 & 0 & 0 \\
1 & 2 & 1
\end{array}\right|, V=\left|\begin{array}{lll}
-1 & 0 & 1 \\
-2 & 0 & 2 \\
-1 & 0 & 1
\end{array}\right|
$$

A cada janela formada pela máscara na imagem original resulta em um pixel na nova imagem. No início da operação a máscara é localizada no canto superior esquerdo da imagem, com deslocamento da esquerda para a direita, pixel por pixel, até que a janela alcance a lateral direita da imagem. Após isso, ela é recolocada totalmente à esquerda da imagem novamente, mas uma linha a baixo, e segue deslocando-se novamente para a direita por todas as colunas. Todo o procedimento termina quando a janela ficar localizada no canto inferior direito da imagem. 


$\left|\begin{array}{ccccccc}\hline 96 & 118 & 104 & 76 & 68 & \cdots & 101 \\ 152 & 130 & 121 & 87 & 111 & \cdots & 109 \\ 146 & 128 & 117 & 91 & 106 & \cdots & 106 \\ 135 & 139 & 106 & 103 & 102 & \cdots & 109 \\ 134 & 141 & 100 & 92 & 106 & \cdots & 108 \\ 156 & 139 & 112 & 87 & 106 & \cdots & 115 \\ \vdots & \vdots & \vdots & \vdots & \vdots & \ddots & 140 \\ 156 & 156 & 116 & 98 & 103 & 118 & 134\end{array}\right| *\left|\begin{array}{lll}-1 & 0 & 1 \\ -2 & 0 & 2 \\ -1 & 0 & 1\end{array}\right|$

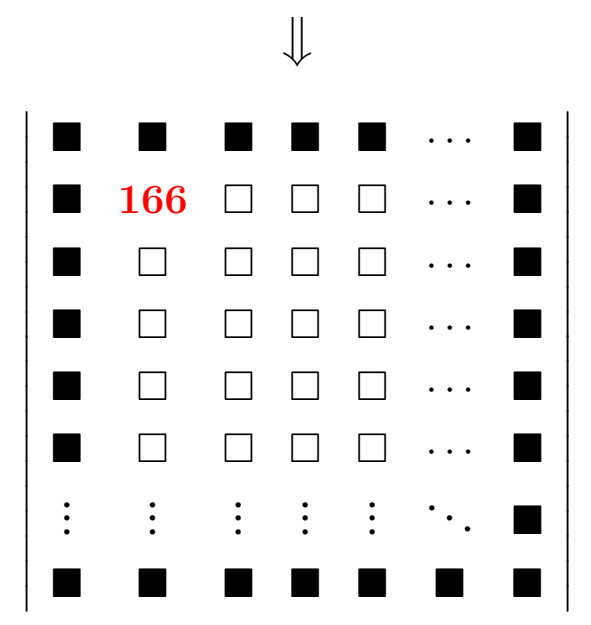

Os pixels que formam a borda da imagem não são calculados. Existem alguns métodos para tratar este problema, mas no caso deste trabalho, optouse por ignorar esta região. Com isso, a imagem $\mathrm{M} \times \mathrm{N}$ resultante fica com as dimensões $\mathrm{M}-2 \times \mathrm{N}-2$.

\subsection{Modelagem do filtro Sobel}

Para a implementação do filtro Sobel foram necessários definir no diagrama de classes quatro tipos de dados, conforme mostra a figura 5.4.

- dois tipos Bit com tamanhos 1 e 14 bits;

- um tipo Int com tamanho de 32 bits;

- e uma memória com a seguinte configuração:

- largura de endereço de 14 bits, possibilitando endereçar 16.384 posições de memória, o suficiente, por exemplo, para armazenar uma imagem com dimensões $128 \times 128$.

- largura de dados de um Inteiro, para armazenar as informações dos pixels;

- tipo single port; 
- dados, que serão carregados na memória no início da simulação, em codificação hexadecimal;

- arquivo com o conteúdo inicial da memória nomeado como mOriginal.hex.

\begin{tabular}{|l|}
\hline \multicolumn{1}{|c|}{ mOriginal } \\
\hline -addrType : Bit\#14 \\
-dataType : Int\#32 \\
-dualPort $=0$ \\
-format $=$ Hex \\
\hline
\end{tabular}

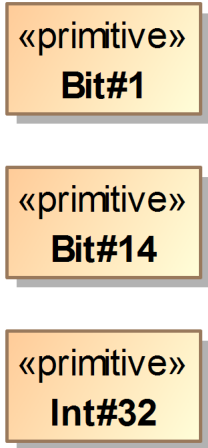

Figura 5.4: Definição dos tipos de dados utilizados na modelagem do filtro Sobel.

Com os tipos de dados definidos passa-se para a modelagem da máquina de estados do filtro Sobel, representado na figura 5.5.

Da forma que o filtro Sobel foi implementado neste trabalho, ele é capaz de processar imagens de diversas dimensões. O limitador está na quantidade de bits alocados para o endereçamento na memória, que, neste caso, a multiplicação do número de linhas vezes o de colunas $(\mathrm{M} \times \mathrm{N})$ não pode ser maior do que 16.384 .

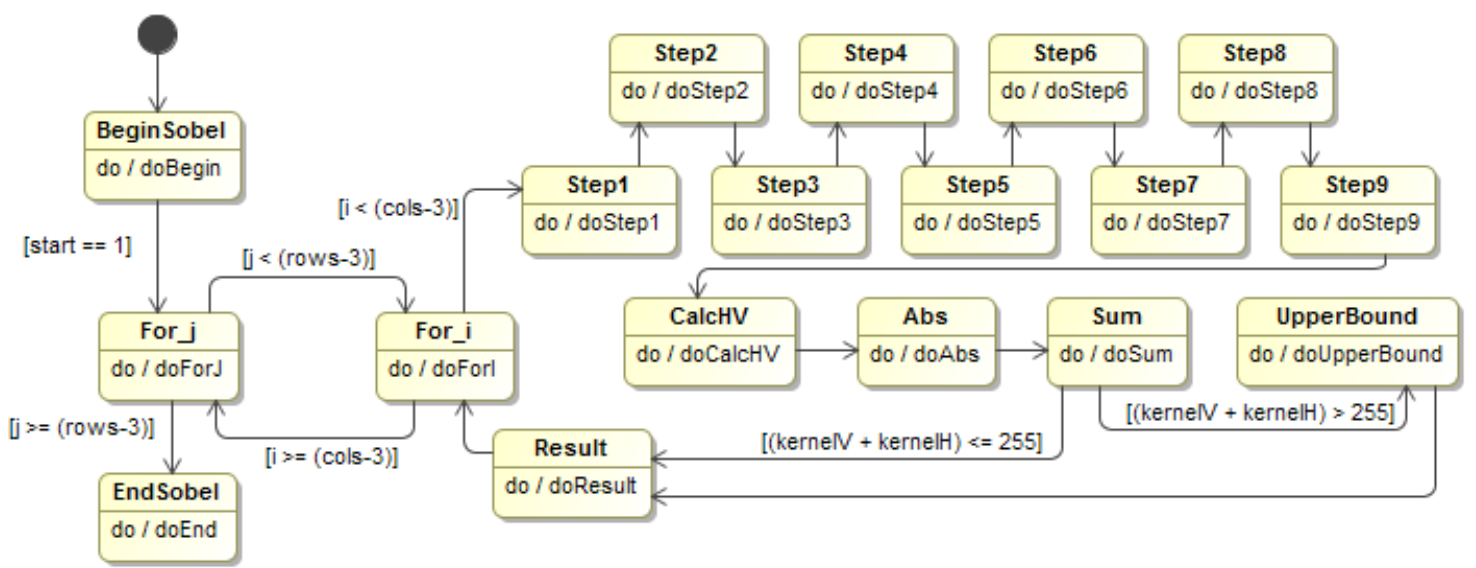

Figura 5.5: Diagrama de estados do filtro Sobel.

O primeiro estado, BeginSobel, faz inicialização de uma variável e fica aguardando um sinal externo para começar. Essa espera é necessária para que o módulo receba os valores com a dimensão da imagem que será processada. 
Quando o sinal start é recebido, a transição para o estado For_j é disparada. Neste ponto é possível observar a utilização dos estados For_j e For_i para formar um laço aninhado. O que seria a condição do laço é representada pela condição na transição entre os estados. As inicializações das variáveis de controle são feitas no estado anterior e seu incremento é feito nos respectivos estados.

Em seguida vem um conjunto de estados do Step1 ao Step9. Neles é carregada a janela de pixels utilizada para calcular um pixel da imagem destino. Note que foram necessários todos estes estados pois só é possivel ler um pixel a cada ciclo de relógio. Uma versão alternativa deste filtro seria utilizar uma memória dual port, assim num único ciclo de relógio seria possível ler dois pixels da memória de endereços distintos.

Depois de carregados os pixels necessários, são realizados os dois cálculos, um para convolução horizontal e o outro para a vertical. Como estas operações não tem dependência de dados entre si, é possível realizá-las em paralelo. Os estados seguintes complementam a operação do filtro Sobel e o último passo, deste ciclo, termina no estado Result.

Neste caso, onde a simulação deste hardware foi realizada num computador, optou-se por imprimir diretamente na tela o valor do pixel calculado. Assim, na hora de simular, toda a saída foi direcionada para um arquivo para posteriormente ser analisado e validar o resultado. Alternativamente, este estado poderia ser responsável por armazenar todos os pixels de saída em uma segunda memória.

Depois de passar pelo estado Result, a execução retorna ao estado For_i. Caso ainda tenha colunas de pixels a serem processadas ele incrementa sua variável de controle e passa novamente para o Step1 e assim sucessivamente. Caso contrário ele retorna ao estado For_j que também verifica se ainda há linhas a serem processadas. Existindo, a sua variável de controle é incrementada e ele volta ao estado For_i, caso contrário a execução é desviada para o estado final.

No estado EndSobel, o sinal ready é ativado, indicando que toda a imagem já foi processada, assim o processo é encerrado.

O diagrama de estados da figura 5.5 mostra apenas os estados e transições, ocultando todas as instruções que definem o comportamento de cada estado. Afim de ilustrar melhor como é definido o comportamento de cada estado, a figura 5.6 mostra uma captura de tela da ferramenta UML utilizada neste trabalho.

Esta é uma janela de propriedades referente ao estado CalcHV, onde é possível observar duas delas em destaque:

- Language, onde é definida qual a linguagem utilizada para descrever o 


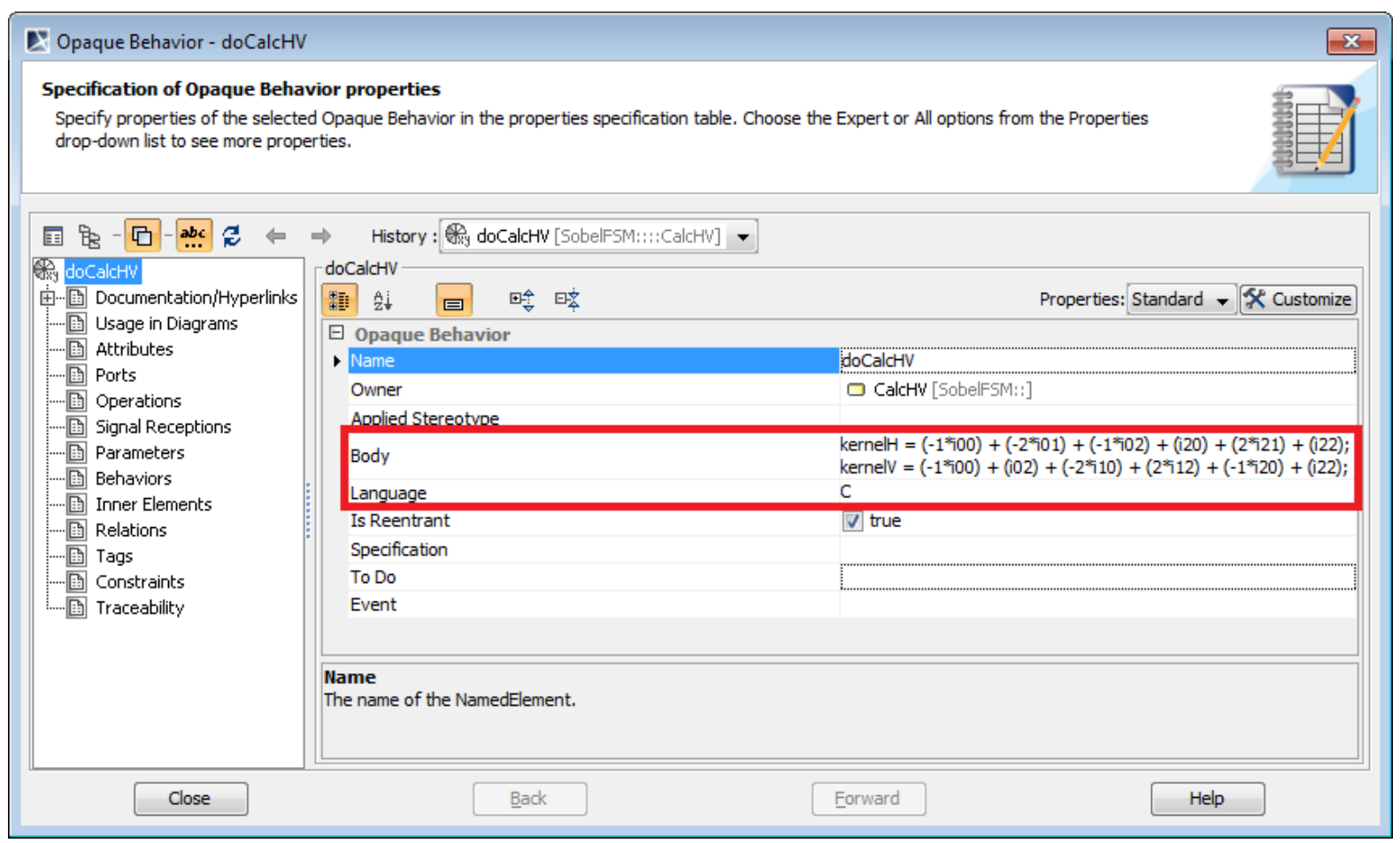

Figura 5.6: Captura de tela da ferramenta UML onde o comportamento do estado CalcHV é definido utilizando a linguagem C.

comportamento do estado, que neste caso foi o C;

- Body, onde encontra-se o comportamento do estado CalcHV escrito em C e que será traduzido para Bluespec pelo compilador C2BSV.

O código do estado CalcHV faz parte do cálculo do filtro Sobel e, como já foi explicado neste trabalho, estas duas instruções serão executadas num mesmo ciclo de relógio. Para finalizar a modelagem do filtro Sobel, é necessário criar uma ação no diagrama de atividades, apresentado na figura 5.7.

Assim como no exemplo anterior, o comportamento desta ação será a máquina de estados da figura 5.5. Para o filtro Sobel foram declarados sinais de entrada e saída além de variáveis locais, listadas a seguir com seus respectivos tipos:

- Sinais de entrada:

- start $\rightarrow$ Bit\# 1

- rows, cols $\rightarrow$ Int\#32

- Sinal de saída:

- ready $\rightarrow$ Bit\# 1

- Variáveis locais:

$$
\text { - i00 ao i22 } \rightarrow \text { Int\#32 }
$$




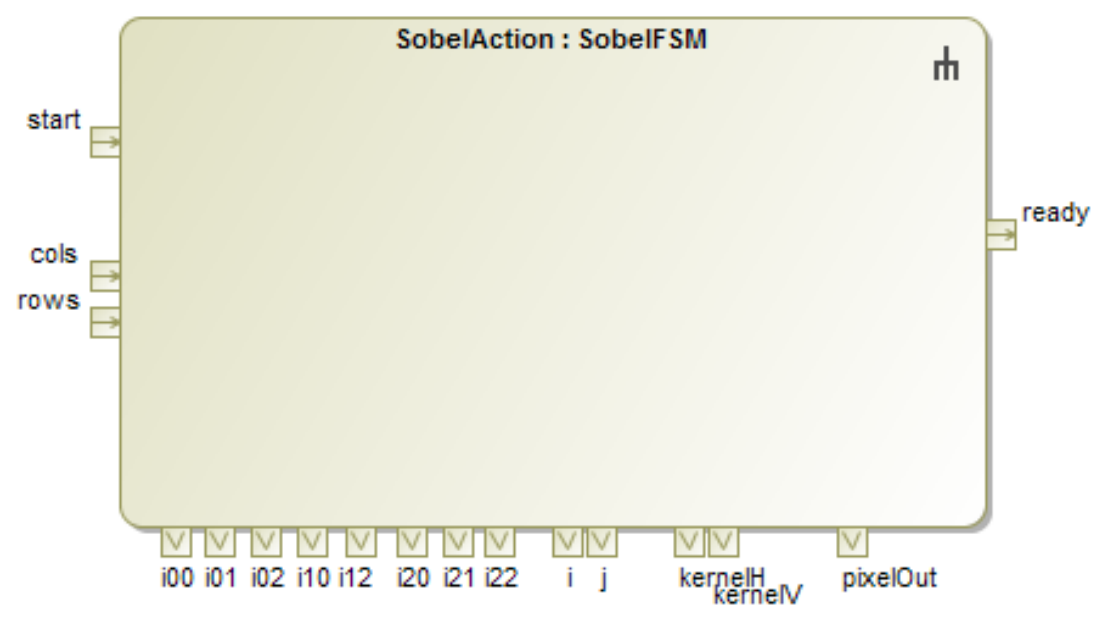

Figura 5.7: Ação que representa o filtro Sobel com os sinais de entrada localizados à esquerda, os de saída à direita e as variáveis de uso local na região inferior.

- i, j $\rightarrow$ Int\#32

- kernelH, kernelV $\rightarrow$ Int\#32

- pixelOut $\rightarrow$ Int\#32

\subsubsection{Resultados}

Como forma de testar o filtro Sobel gerado pela ferramenta UML2BSV, a partir da modelagem UML, foi utilizada uma imagem colorida (5.8(a)) com dimensões $128 \times 128$ pixels.

Para que seja possível realizar a simulação do filtro Sobel é necessário antes trabalhar com a imagem para carregá-la na memória em codificação hexadecimal. Nesta tarefa foi utilizado o software GNU Octave, sendo necessário executar os seguintes passos:

- abrir o arquivo contendo a imagem através da função fopen0;

- fazer a leitura do conteúdo do arquivo com a função fread(). O resultado desta função é uma matriz contendo os valores de cada pixel da imagem;

- rotacionar a imagem para que ela fique na posição correta. Isto pode ser feito achando a transposta da matriz da imagem;

- salvar esta matriz em um arquivo no formato texto com o comando save.

Neste exemplo, o conteúdo que será carregado na memória deve estar no formato hexadecimal. Portanto é necessário converter os valores de cada pixel da matriz. Para isto foi desenvolvido um pequeno script em Python para converter números da base decimal para hexadecimal. 
Depois que o filtro Sobel foi aplicado, é necessário ler a matriz resultante e realizar o processo inverso, gerando a imagem a partir desta matriz. Novamente utilizando o GNU Octave, primeiro a matriz é lida, depois é utilizada a função reshape() para deixar a imagem com as dimensões corretas e por fim utilizada a função imagesc() para visualizar a imagem resultante.

Pelo fato da imagem utilizada ser colorida, o filtro Sobel precisa ser aplicado nos três canais $(R, G, B)$ separadamente, portanto são necessários realizar os passos descritos anteriormente para cada canal de cor da imagem.

O resultado da aplicação do filtro Sobel pode ser visualizado na figura 5.8(b).

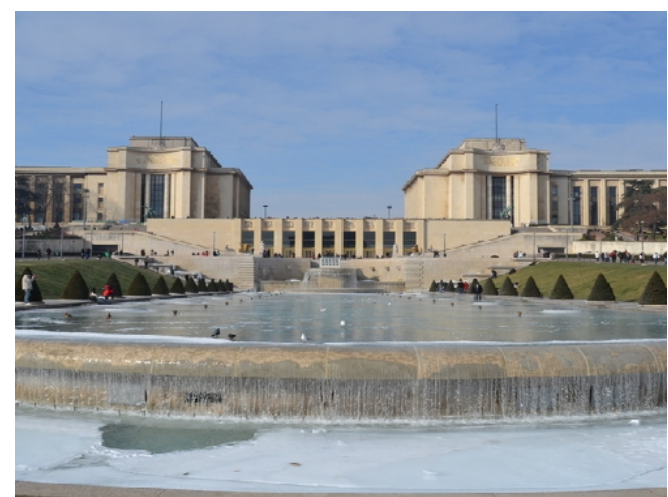

(a) Imagem original

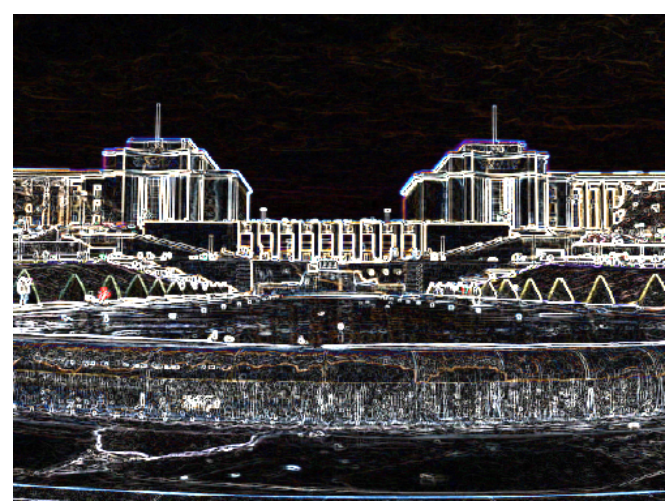

(b) Imagem após a aplicação do filtro Sobel nos três canais R, G e B, separadamente

Figura 5.8: Resultado da aplicação do filtro Sobel na imagem (a) pelo circuito modelado em UML na figura 5.5.

O resultado da síntese realizada na ferramenta Quartus II do código Verilog gerado a partir da compilação do código BSV pelo Bluespec encontra-se na listagem 5.3

\section{Listagem 5.3: Resultado da sintese do filtro Sobel pela ferramenta Quartus II.}

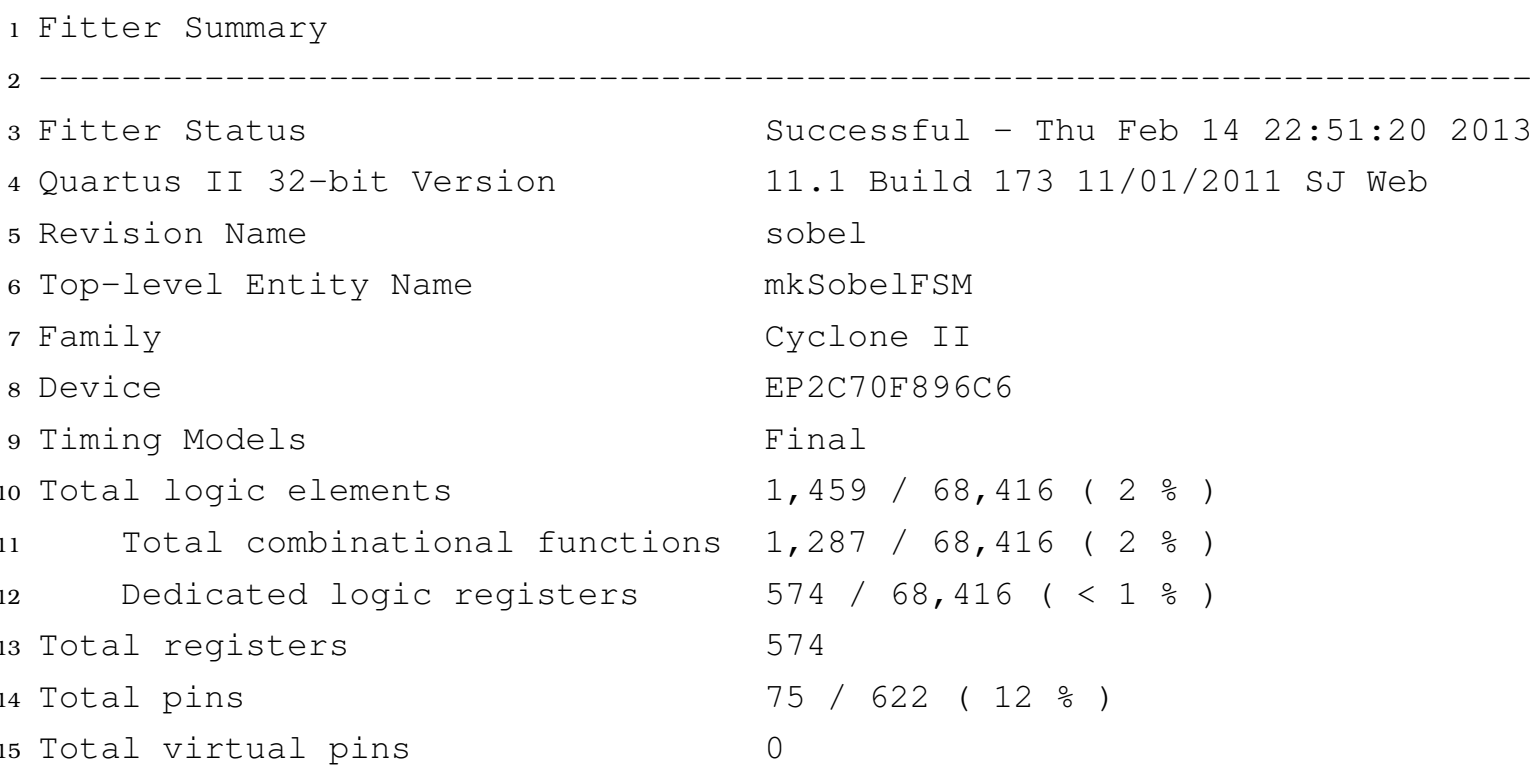




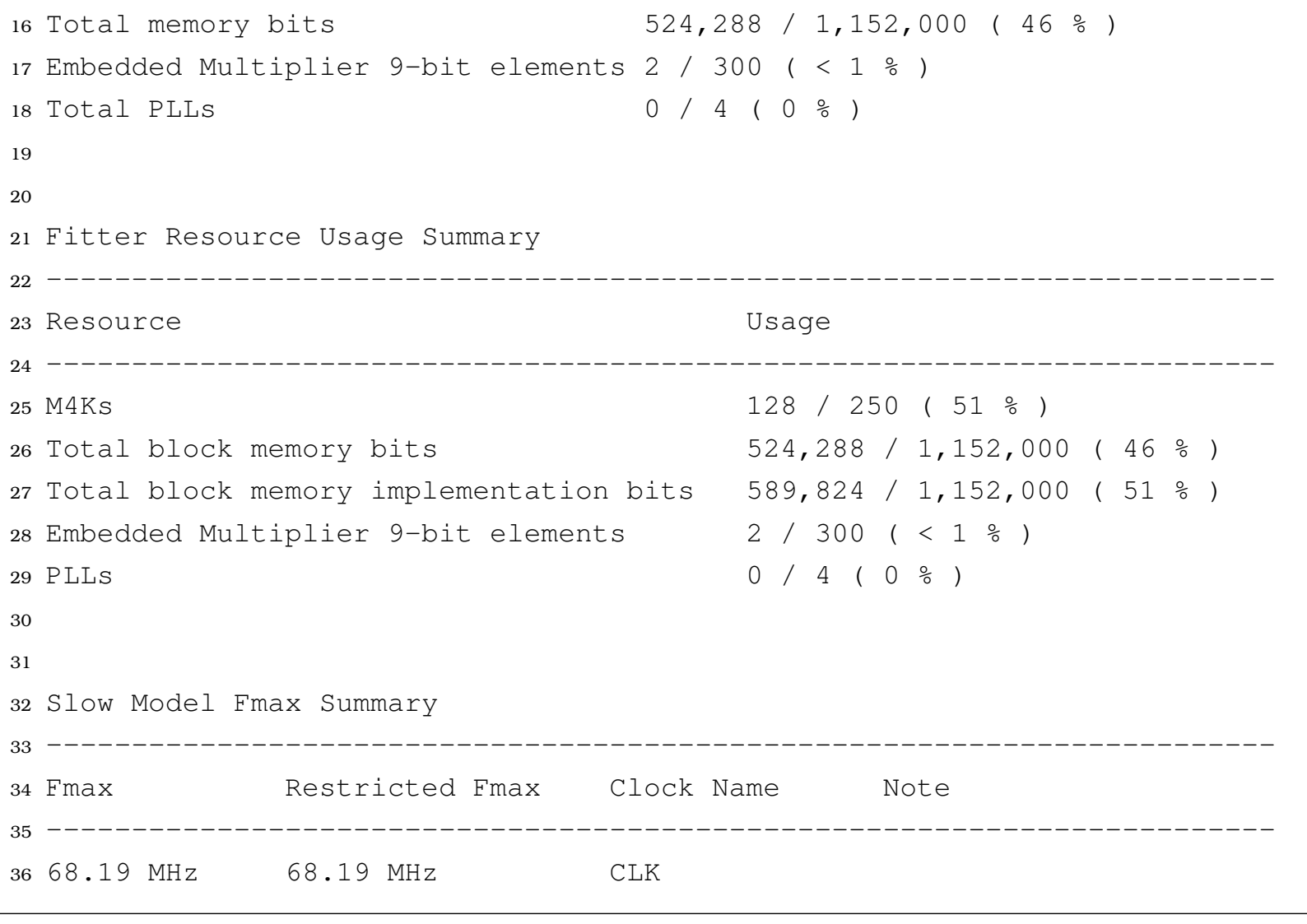

No apêndice B encontra-se o código fonte BSV completo gerado pela ferramenta UML2BSV do filtro Sobel. 


\section{Conclusão}

Este trabalho apresentou uma nova ferramenta capaz de gerar código Bluespec SystemVerilog através de uma modelagem UML. A ferramenta também permite a utilização de um subconjunto da linguagem $\mathrm{C}$ para descrever o comportamento dos estados. Para isso, também foi desenvolvido um compilador que realiza a tradução da linguagem C para código BSV.

Uma das preocupações deste trabalho foi a de não realizar extensão na UML. Desta forma, utilizando apenas os diagramas e seus respectivos elementos da UML padrão é possível modelar e gerar arquiteturas de hardware por meio de qualquer ferramenta de modelagem UML que tenha suporte a exportação no formato XMI 2.1.

Apesar das duas ferramentas trabalharem de forma bem integrada, o desenvolvimento delas foi pensado em deixá-las independentes. Portanto, tanto a UML2BSV quanto o compilador C2BSV podem ser utilizados em outros projetos de pesquisa.

Como validação da ferramenta foram implementados dois casos bem distintos: um processador de propósito geral e um elemento de processamento do filtro Sobel. Nos dois casos foi possivel perceber que a ferramenta facilitou a geração de hardware. Um programador que conheça a linguagem C, máquina de estados e que tenha o mínimo de noção de hardware é capaz de gerar circuitos como os utilizados neste exemplo.

Outra facilidade proporcionada pela ferramenta é a programação de código em paralelo, ficando a cargo do programador a análise do que pode ser executado no mesmo ciclo de relógio, e colocar estas instruções em um mesmo estado.

Durante o desenvolvimento deste trabalho foram observadas algumas melhorias e novas funcionalidades que agregariam ainda mais funcionalidades a esta ferramenta. O principal seria o desenvolvimento para dar suporte à execução de máquinas de estados paralelas. Até o momento apenas uma Ação é modelada no diagrama de atividades. Como cada Ação está associada a 
um diagrama de estados, seria possivel modelar um diagrama de atividades com diversas ações. Utilizando elementos do tipo Fork, seria possível dividir o fluxo de execução em $n$ ações, cada uma executando uma máquina de estado de forma concorrente.

Outra melhoria poderia incluir o uso das ações Entry e Exit dentro dos estados. Com isso seria possível reduzir o número de estados de uma modelagem. Atualmente apenas a ação Do é permitida.

Outra limitação desta ferramenta é que atualmente não é possível fazer uso de outros módulos durante a modelagem de um hardware. Caso esta situação seja necessária é preciso fazer modificações manualmente no código fonte BSV gerado.

Por fim, outras instruções poderiam ser implementadas ao subconjunto da linguagem $\mathrm{C}$, como por exemplo operações com números em ponto flutuante.

Parte dos trabalhos relacionados limitam-se a apenas gerar a parte de controle da máquina de estados, deixando o programador responsável por escrever o comportamento de cada estado num momento posterior à geração do código. Outros trabalhos limitam-se apenas a copiar o código do comportamento descrito pelo programador para regiões correspondentes do controle da máquina. Já esta ferramenta se diferencia destes trabalhos dando opção ao desenvolvedor de codificar o comportamento na própria modelagem com a opção de utilizar o C, uma linguagem diferente da linguagem alvo, de alto nível e muito popular.

Parte deste trabalho resultou na publicação do artigo por Durand e Bonato (2012) e um novo artigo está em fase final de escrita, abrangendo o trabalho como um todo e será submetido para uma revista especializada da área. 


\section{Referências Bibliográficas}

IEEE Standard for IP-XACT, Standard Structure for Packaging, Integrating, and Reusing IP within Tools Flows. IEEE Std 1685-2009, p. C1 -360, 18, 2010.

ABDEL-HAMID, A.; ZAKI, M.; TAHAR, S. A tool converting finite state machine to VHDL. In: Electrical and Computer Engineering, 2004. Canadian Conference on, 2004, p. 1907 - 1910 Vol.4.

AcCellera Organization InC. IP-XACT Technical Committee. http: //www.accellera.org/activities/ip-xact, [Online; acessado em 02Fevereiro-2011], 2011.

AGARWAL, A. Comparison of high level design methodologies for algorithmic IPs: Bluespec and C-based synthesis. 2009. Dissertação (Mestrado), Massachusetts Institute of Technology, 2009.

Aho, A. V.; Sethi, R.; Ullman, J. D. Compilers: Principles, techniques, and tools. Addison Wesley, 1986.

ALDEC Active-HDL. http://www.aldec.com/activehdl/, [Online; acessado em 20-Novembro-2010], 2010.

Altera Corporation Stratix IV GX FPGA Development Board, 530 Edition - Reference Manual. http://www.altera.com/products/devkits/ altera/kit-siv-gx.html, [Online; acessado em 21-Fevereiro-2011], 2010.

Apache Software Foundation The Apache Velocity Project. [On-line], [Online; acessado em 04-Outubro-2011].

Disponivel em: <http://velocity.apache.org/>.

BERGER, A. S. Embedded systems design: An introduction to processes, tools and techniques. CMP Books, 2001. 
BLuespeC InC Complete set of Training Slides for BSV. http:// www.bluespec.com/forum/viewtopic.php?t=7, [Online; acessado em 12Março-2010], 2007.

Bluespec InC The Synthesizable Modeling Company. http://www . bluespec.com/, [Online; acessado em 10-Outubro-2010], 2010.

BoBDA, C. Introduction to reconfigurable computing. Berlin: Springer, 2007.

Bonato, V.; Margues, E. Roboarch: A component-based tool proposal for developing hardware architecture for mobile robots. In: Industrial Embedded Systems, 2009. SIES '09. IEEE International Symposium on, 2009, p. $249-252$.

Brown, S. D. Fundamentals of Digital Logic with VHDL Design (McGrawHill Series in Electrical and Computer Engineering). McGraw-Hill Companies, 2005.

CARBou, M. xmltool - XML tool to manage XML documents through a Fluent Interface. [On-line], [Online; acessado em 10-Agosto-2011].

Disponivel em: <http://code.google.com/p/xmltool/>.

DEDASys LLC Programming Language Popularity. http://langpop.com/, [Online; acessado em 29-Novembro-2010], 2010.

Delamaro, M. E. Como Construir um Compilador: Utilizando Ferramentas Java. 1 ed.. Novatec, 2004.

Densmore, D.; Passerone, R. A Platform-Based Taxonomy for ESL Design. Design Test of Computers, IEEE, v. 23, n. 5, p. 359 -374, maio, 2006.

Duffner, S.; Strobel, R. Qfsm - A graphical tool for designing finite state machines. http://qfsm.sourceforge.net/, [Online; acessado em 20Novembro-2010], 2010.

Durand, S.; Bonato, V. A tool to support Bluespec SystemVerilog coding based on UML diagrams. In: 38th Annual Conference of the IEEE Industrial Electronics Society. IECON '12, IEEE, 2012, p. 4652 -4657.

EDwARDS, S. The Challenges of Synthesizing Hardware from C-Like Languages. Design Test of Computers, IEEE, v. 23, n. 5, p. 375 -386, maio, 2006.

FOWLER, M. UML distilled: a brief guide to the standard object modeling language (3rd Edition). Boston: Addison-Wesley, 2003. 
Fuller, S.; Millett, L. Computing performance: Game over or next level? Computer, v. 44, n. 1, p. 31 -38, janeiro, 2011.

GHOSH, K. L. IP-XACT Solutions. [On-line], [Online; acessado em 15-Abril2012].

Disponivel em: <http://www.edautils.com/ip-xact.html>.

GILL, A. Introduction to the theory of finite-state machines. McGrawHill, 1962.

GRÄSSLE, P. UML 2.0 in action a project based tutorial. Birmingham, U.K: Packt Pub, 2005.

Gruian, F.; WestmiJZE, M. VHDL vs. Bluespec system verilog: a case study on a Java embedded architecture. In: Proceedings of the 2008 ACM symposium on Applied computing, SAC '08, New York, NY, USA: ACM, 2008, p. 1492-1497 (SAC '08, v.).

HAUCK, S.; DeHON, A. Reconfigurable computing: the theory and practice of FPGA-based computation. San Diego: Morgan Kaufmann, 2008.

HDL WORKS EASE Graphical HDL Entry. [On-line].

Disponível em: <http://www.hdlworks.com/products/ease/index. html/>.

Hopcroft, J. E.; MOtWANi, R.; Ullman, J. D. Introduction to automata theory, languages, and computation. 2nd ed.. Addison Wesley, 2000.

Margues Filho, O.; Neto, H. Processamento digital de imagens. Brasport, 1999.

Martin, G.; Bailey, B.; Piziali, A. ESL Design and Verification: A Prescription for Electronic System Level Methodology (Systems on Silicon). Morgan Kaufmann, 2007.

Mealy, G. A method for synthesizing sequential circuits. Bell systems Technical Journal, v. 34, n. 5, p. 1045-1079, september, 1955.

Mentor GRAPHICs Handel-C Synthesis Methodology. http://www.mentor. com/products/fpga/handel-c/, [Online; acessado em 19-Novembro2010], 2010.

Mentor Graphics Corporation HDL Designer. [On-line].

Disponível em: <http://www.mentor.com/products/fpga/hdl_design/ hdl_designer_series/ $>$. 
Moore, E. F. Gedanken Experiments on Sequential Machines. In: Automata Studies. Princeton U., 1956. p. 129-153.

Moreira, T.; Wehrmeister, M.; Pereira, C.; Petin, J.-F.; Levrat, E. Automatic code generation for embedded systems: From UML specifications to VHDL code. In: Industrial Informatics (INDIN), 2010 8th IEEE International Conference on, 2010, p. $1085-1090$.

Muchnick, S. Advanced compiler design and implementation. San Diego: Morgan Kaufmann, 1997.

Nelson, V. P.; Nagle, H. T.; Carroll, B. D.; Irwin, D. Digital logic circuit analysis and design. Prentice Hall, 1995.

Nikhil, R.; Czeck, K. BSv by Example. City: CreateSpace, 2010.

Norvell, T. S. The JavaCC FAQ. http://www.engr.mun.ca/ theo/ JavaCC-FAQ/, [Online; acessado em 17-Outubro-2010], 2007.

OSCI Open SystemC Initiative. http://www.systemc.org/, [Online; acessado em 27-Novembro-2010], 2010.

de Pablo, S.; Caceres, S.; Cebrian, J.; Berrocal, M. A proposal for ASM++ diagrams. In: Design and Diagnostics of Electronic Circuits and Systems, 2007. DDECS '07. IEEE, 2007, p. 1 -4.

Pablo, S.; CÁceres, S.; Cebrián, J.; SAnZ, F. Diseño de Circuitos Digitales a Nivel de Registro empleando Diagramas ASM++. Información Tecnológica, v. 21, n. 2, p. 91-102, march, 2010.

PARR, T. The definitive antlr reference: Building domain-specific languages (pragmatic programmers). Pragmatic Bookshelf, 2007.

Pilone, D.; Pitman, N. UML 2.0 in a Nutshell. O'Reilly, 2005.

Rieder, M.; Steiner, R.; Berthouzoz, C.; Corthay, F.; Sterren, T. Synthesized UML, a Practical Approach to Map UML to VHDL. In: GUELFI, N.; SAVIDIS, A., eds. Rapid Integration of Software Engineering Techniques, v. 3943 de Lecture Notes in Computer Science. Springer Berlin Heidelberg, 2006. p. 203-217.

Disponivel em: <http://dx.doi.org/10.1007/11751113_15>.

SAFONOV, V. O. Trustworthy compilers (quantitative software engineering series). Wiley, 2010. 
Shukla, S.; PIXley, C.; Smith, G. Guest Editors' Introduction: The True State of the Art of ESL Design. Design Test of Computers, IEEE, v. 23, n. 5, p. 335 - 337, maio, 2006.

TIOBE SOFTwARE TIOBE Programming Community Index for November 2010. http://www.tiobe.com/index.php/content/paperinfo/tpci/ index.html, [Online; acessado em 29-Novembro-2010], 2010.

Tran, V.-A.; QIn, S.; ChIn, W. An Automatic Mapping from Statecharts to Verilog. In: LIU, Z.; ARAKI, K., eds. Theoretical Aspects of Computing ICTAC 2004, v. 3407 de Lecture Notes in Computer Science. Springer Berlin Heidelberg, 2005. p. 187-203.

Disponivel em: <http://dx.doi.org/10.1007/978-3-540-31862-0_15>

University of MAnnheim - COMPUter ARChitecture Group FSMDesigner4 - A high-level design entry tool. [On-line].

Disponivel em: <http://sourceforge. net/projects/fsmdesigner/>.

Wehrmeister, M.; Freitas, E.; Pereira, C.; RAmmig, F. Genertica: A tool for code generation and aspects weaving. In: Object Oriented RealTime Distributed Computing (ISORC), 2008 11th IEEE International Symposium on, Los Alamitos, CA, USA: IEEE Computer Society, 2008, p. $234-238$.

Wolf, W. Computers as components. San Diego: Morgan Kaufmann, 2005.

Wood, S.; AKehurst, D.; Uzenkov, O.; Howells, W.; McDonald-Maier, K. A Model-Driven Development Approach to Mapping UML State Diagrams to Synthesizable VHDL. Computers, IEEE Transactions on, v. 57, n. 10, p. $1357-1371$, oct., 2008.

XI, C.; HuA, L. J.; ZuCheng, Z.; YaOHui, S. Modeling SystemC design in UML and automatic code generation. In: Design Automation Conference, 2005. Proceedings of the ASP-DAC 2005. Asia and South Pacific, 2005, p. $932-935$ Vol. 2. 

APÊNDICE

\section{Código fonte BSV do Processador gerado automaticamente pela ferramenta UML2BSV}

Listagem do código fonte BSV do processador de uso geral, apresentado na seção 5.1, gerado automaticamente pela ferramenta UML2BSV.

\section{Listagem A.1: Código gerado do Processador.}

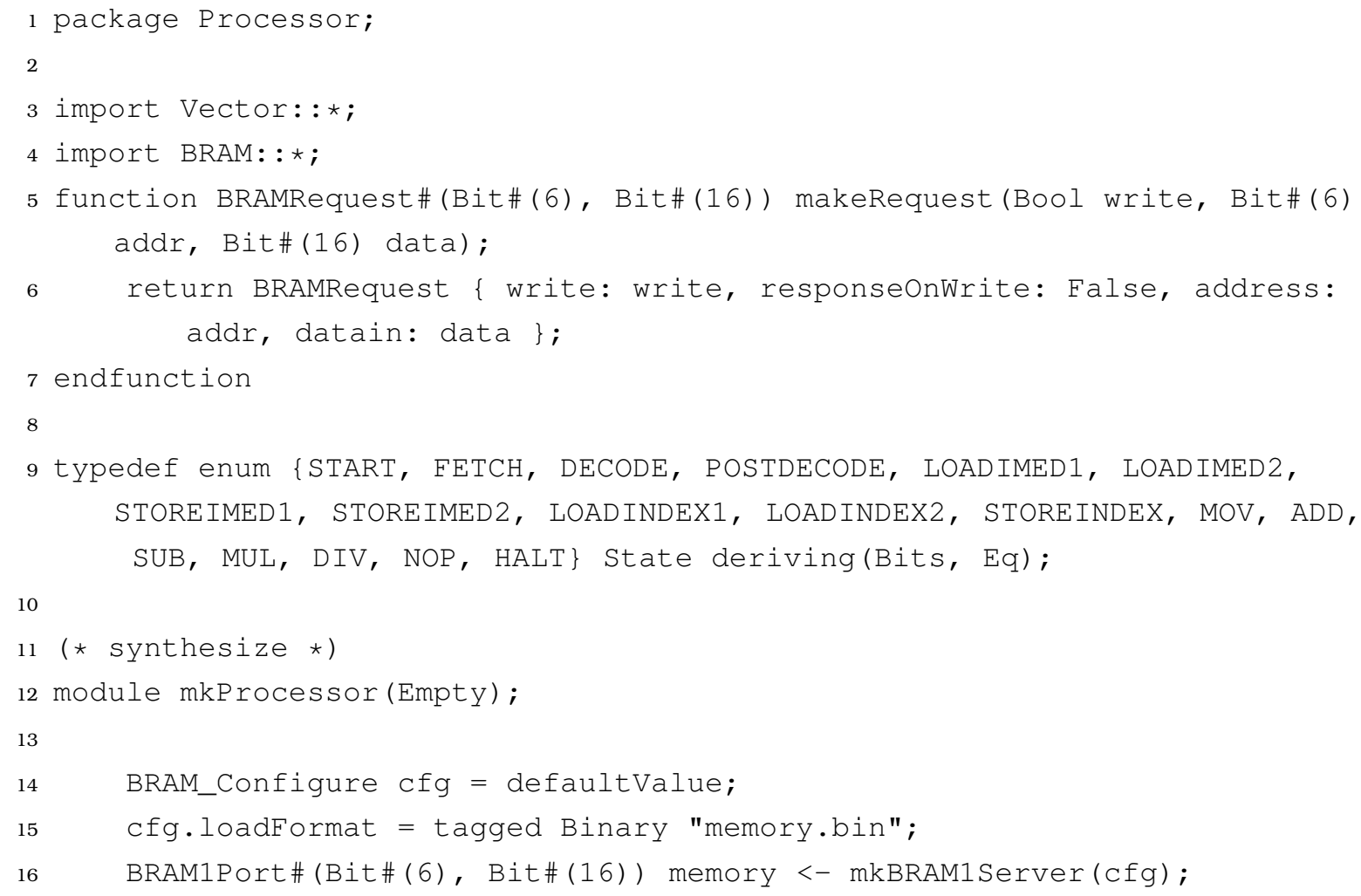




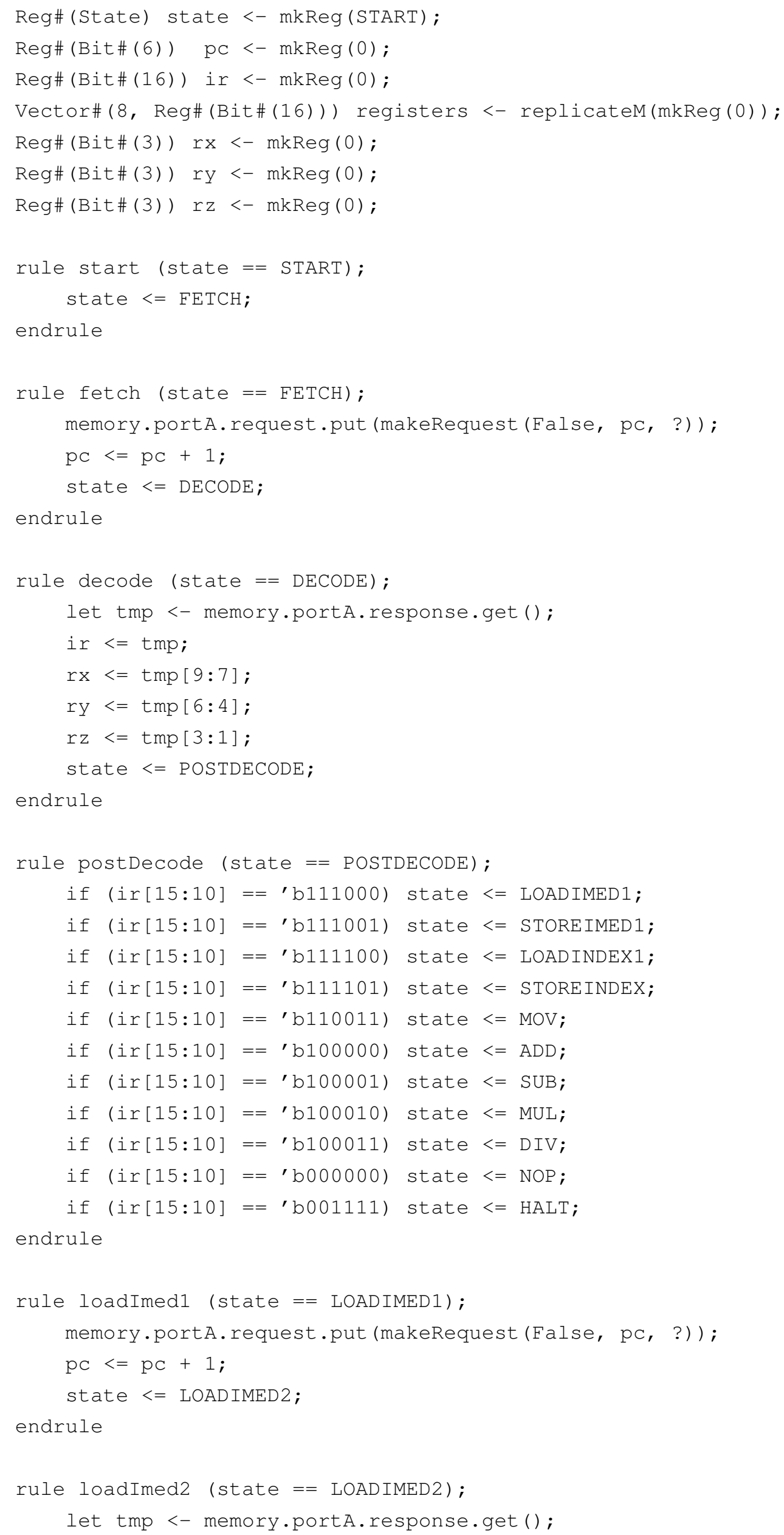




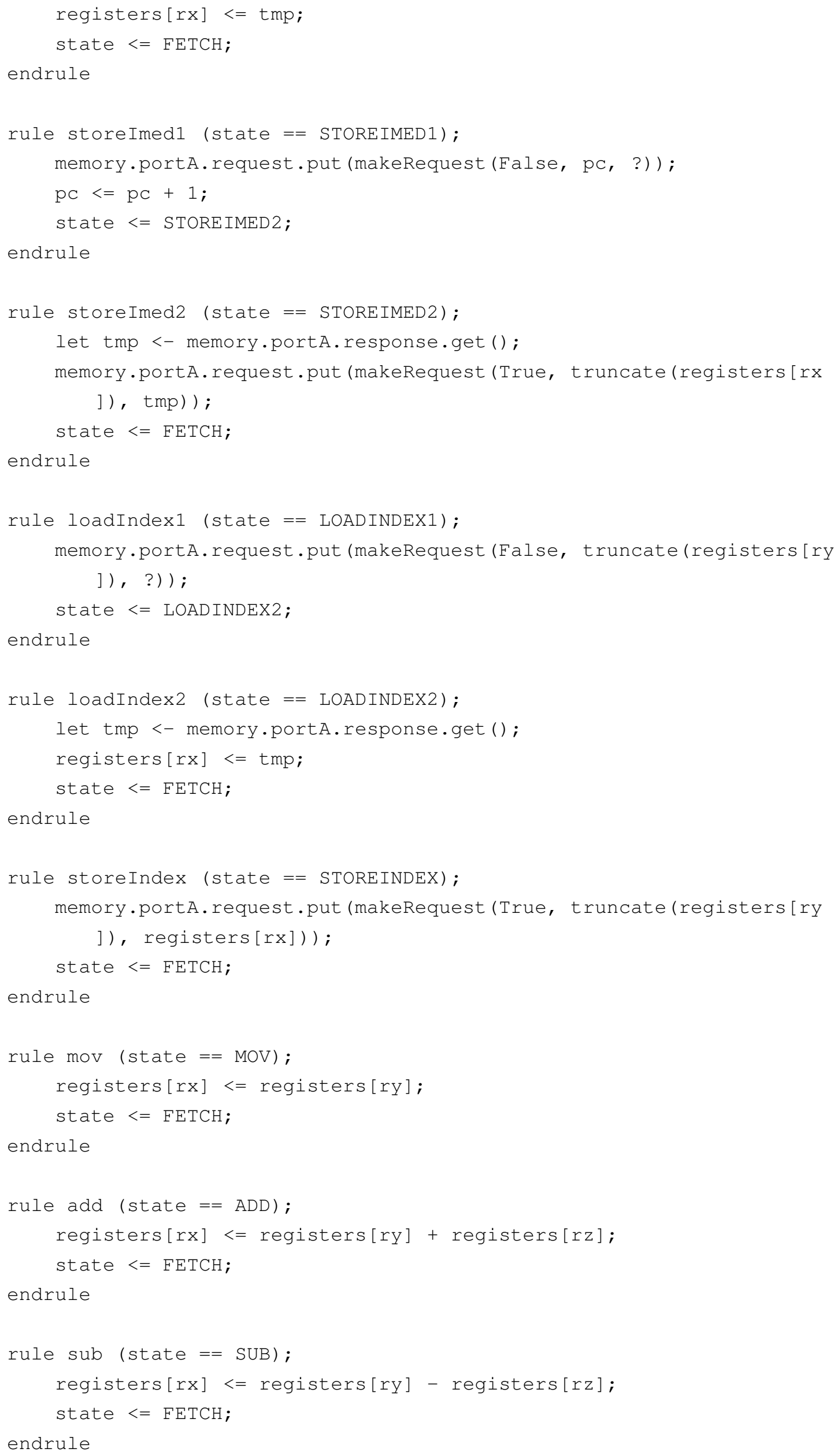




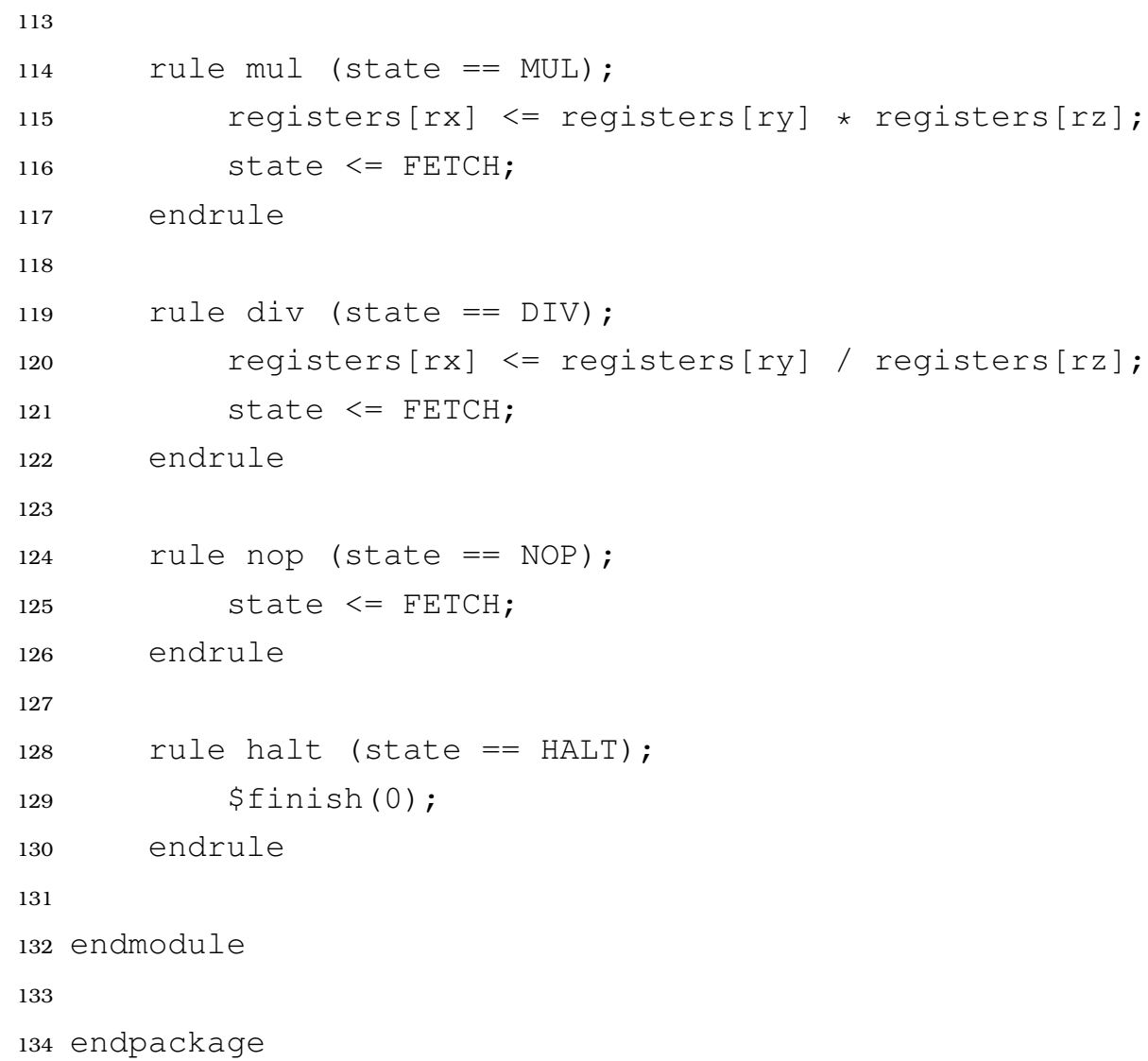


APÊNDICE

\section{Código fonte BSV do filtro Sobel gerado automaticamente pela ferramenta UML2BSV}

Listagem do código fonte BSV do elemento de processamento do filtro Sobel, apresentado na seção 5.2, gerado automaticamente pela ferramenta UML2BSV.

\section{Listagem B.1: Código gerado do Sobel.}

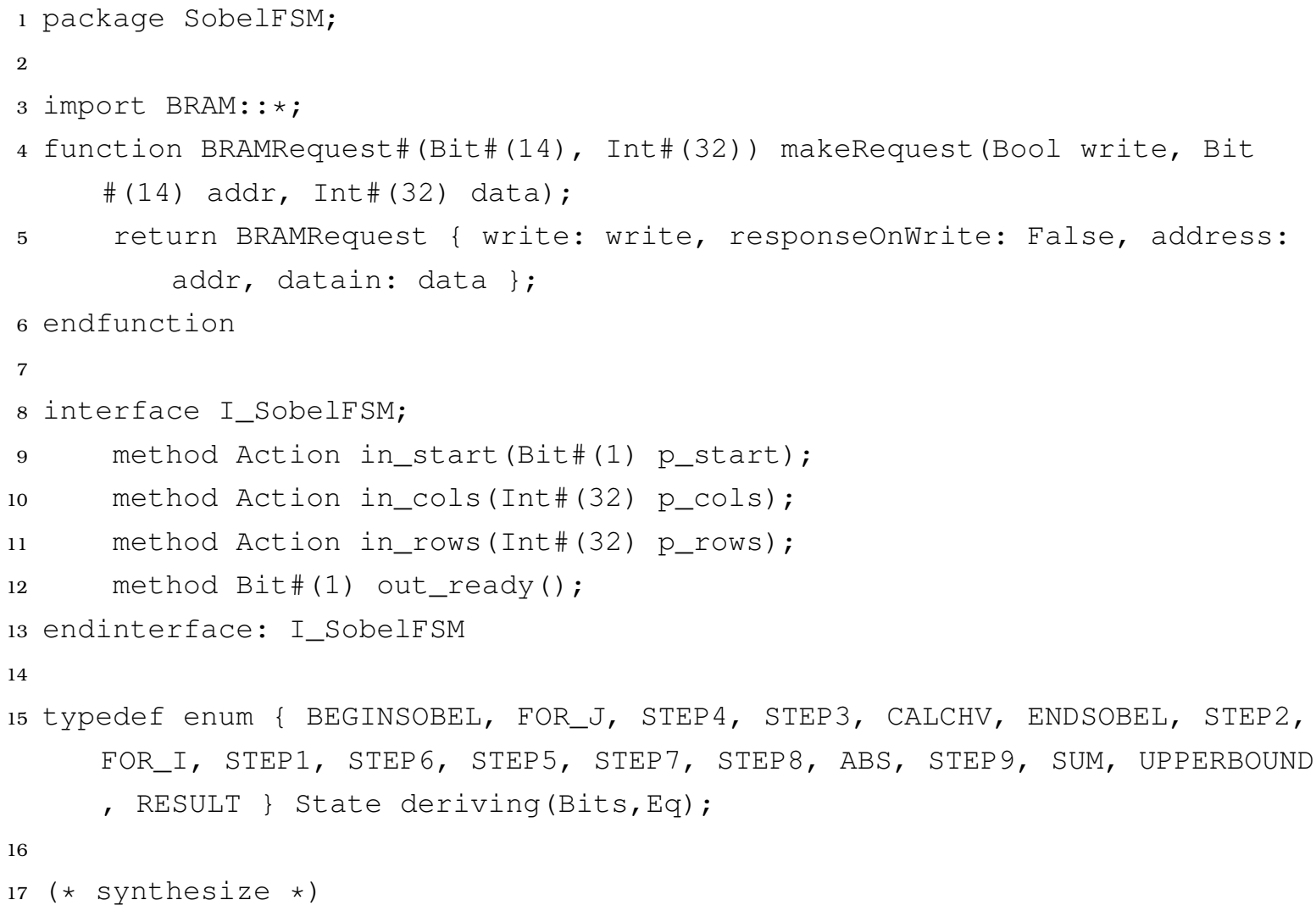


19

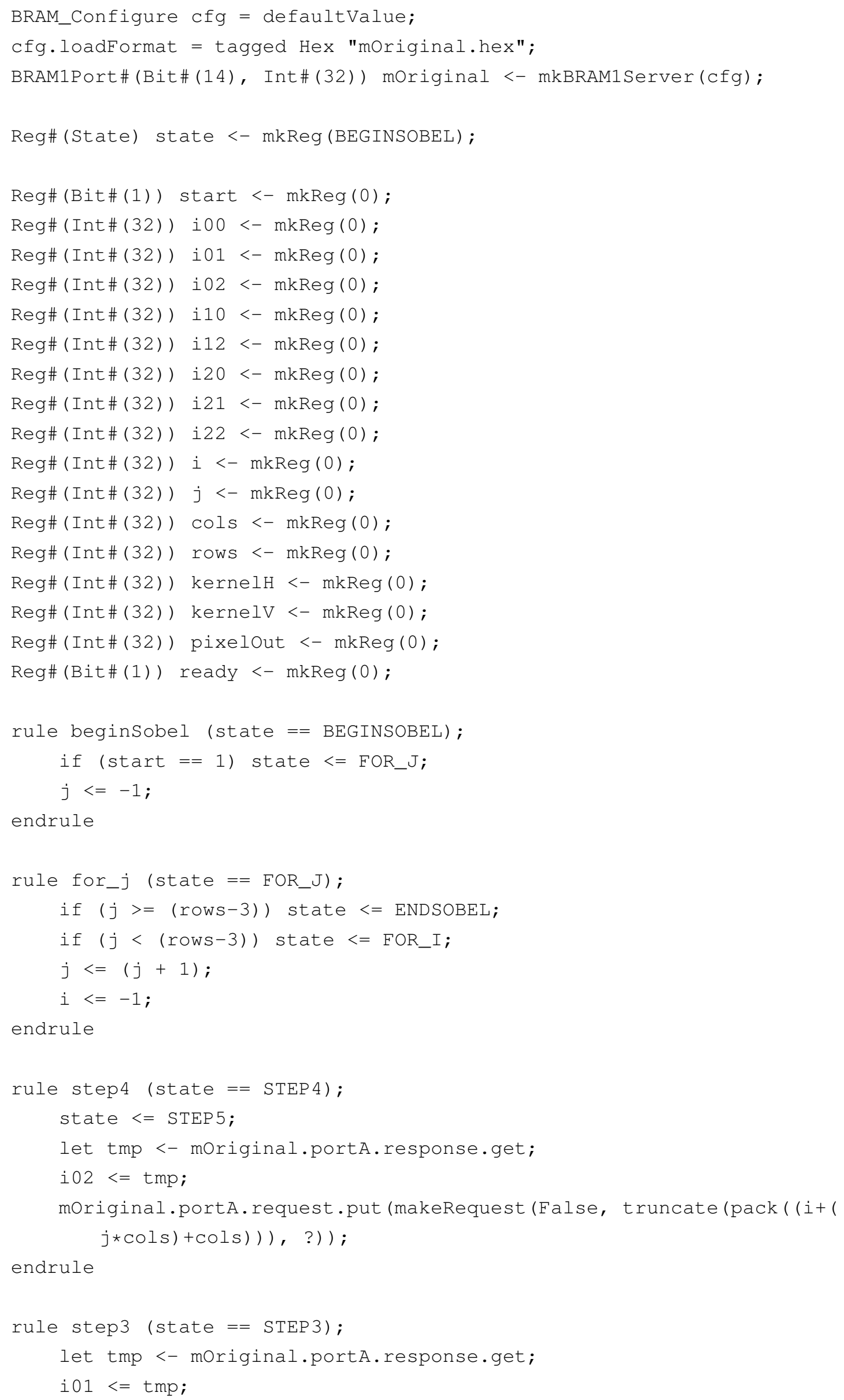


97

98

99

100

101

104

105

106

107

moriginal.portA.request.put (makeRequest (False, truncate (pack ( i+ ( j*(COIs) +2 )) ), ?)) ;

state $<=\operatorname{STEP} 4$;

endrule

rule calcHV (state $==$ CALCHV);

state $<=$ ABS;

kernelH $<=((-1 * i 00)+((-2 * i 01)+((-1 * i 02)+(i 20+((2 *$ i21) + i22)))) )

kernelV $<=((-1 \star i 00)+(i 02+((-2 \star i 10)+((2 \star i 12)+((-1 *$ i20) + i22)))l);

endrule

rule endSobel (state == ENDSOBEL);

ready $<=1$;

endrule

rule step2 (state = STEP2);

let tmp <- moriginal.portA.response.get;

i00<= tmp;

moriginal.portA.request.put (makeRequest (False, truncate (pack ( i+ ( j*(COIs) +1)) ), ?)) ;

state $<=$ STEP3;

endrule

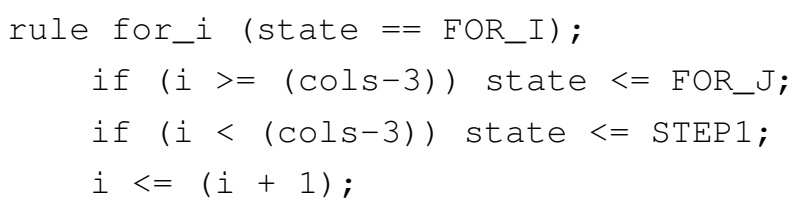




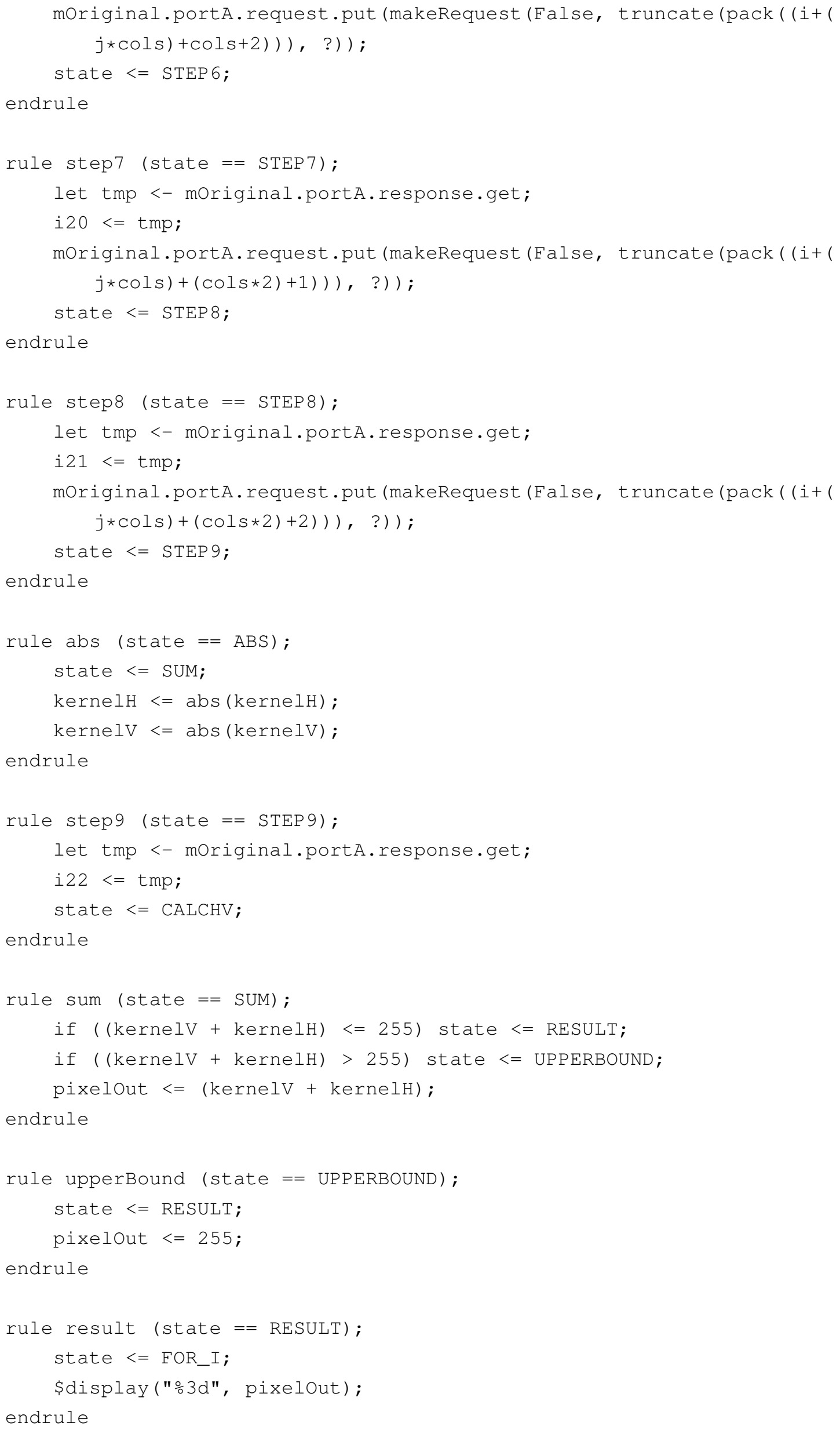


155 method Action in_start (Bit\# (1) P_start);

156 start $<=$ P_start;

157 endmethod

158

159 method Action in_cols (Int\# (32) p_cols);

$160 \quad$ Cols $<=$ P_cols;

161 endmethod

162

163 method Action in_rows (Int\# (32) p_rows);

164 rows $<=$ p_rows;

165 endmethod

166

167 method Bit\#(1) out_ready ();

168 return ready;

169 endmethod

170

171

172 endmodule: mkSobelFSM

173

174 endpackage: SobelFSM 



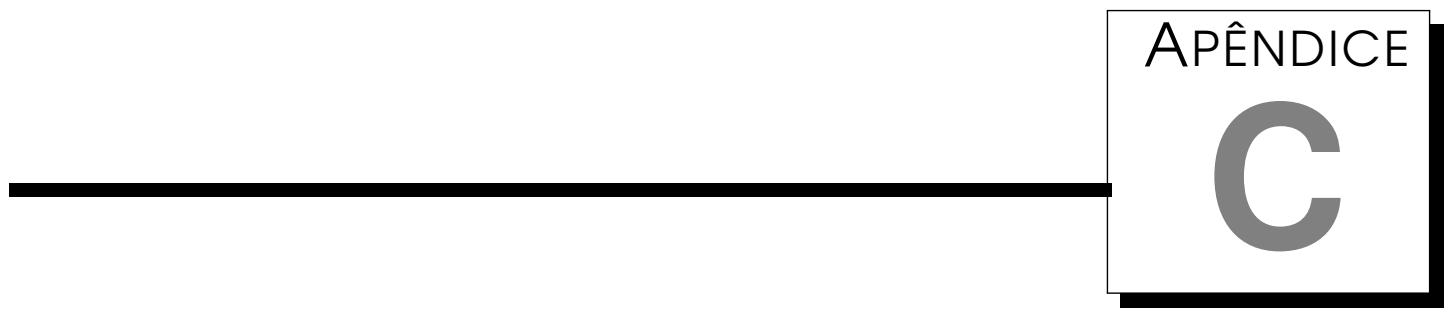

\section{Gramática do compilador C2BSV}

Listagem da gramática utilizada para construir o compilador C2BSV, gerada pelo programa JJDoc, parte do pacote do JavaCC.

\section{Listagem C.1: Gramática do compilador C2BSV.}

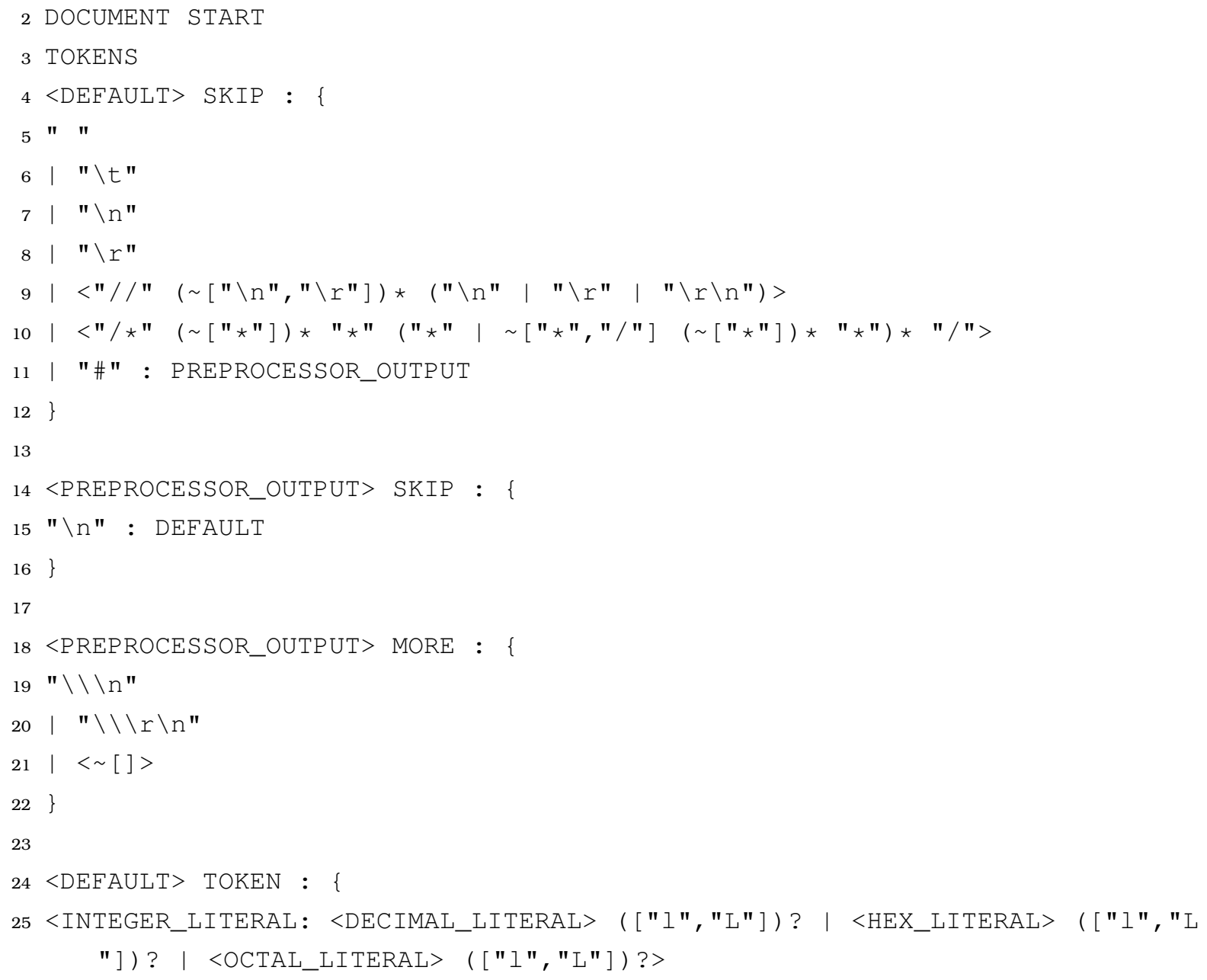




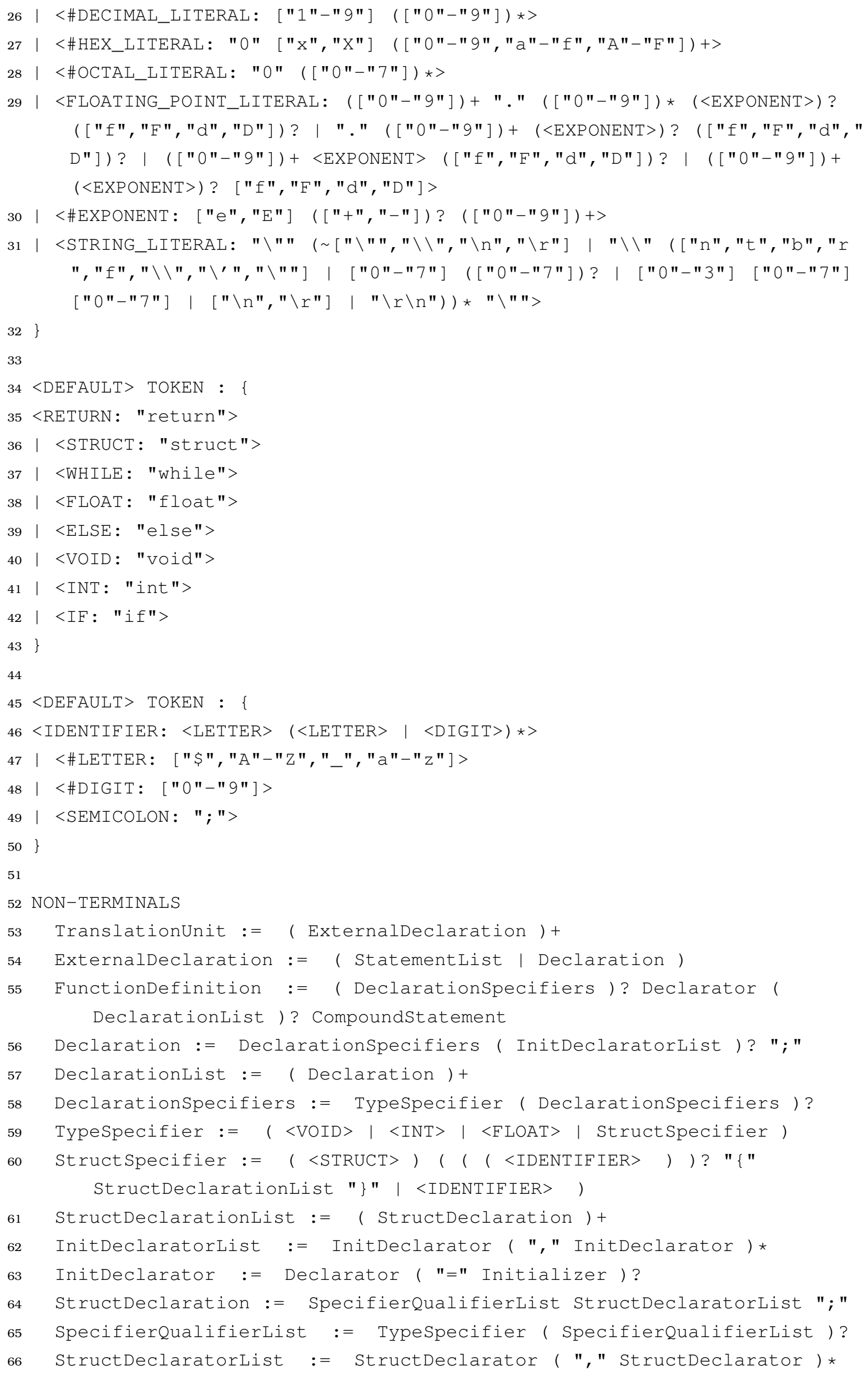


StructDeclarator := (Declarator | (Declarator ) ? ":"

ConstantExpression )

Declarator $:=$ DirectDeclarator

DirectDeclarator : : ( lDENTIFIER> | " " Declarator ") " ) ( " ConstantExpression "]" ) | (" [" "]" ) ) ? ) (" (" ParameterTypeList

") " | "(" ( IdentifierList ) ? ") " )*

ParameterTypeList := ParameterList ( ", "...") ?

ParameterList := ParameterDeclaration ( ", " ParameterDeclaration )* ParameterDeclaration := Declarationspecifiers ( Declarator | (

AbstractDeclarator ) ? )

IdentifierList $\quad:=($ IDENTIfIER $>\quad)(", "(<\operatorname{IDENTIFIER}>\quad) \quad$ * Initializer := (AssignmentExpression | "\{" InitializerList ( ", ")? " \} " )

InitializerList := Initializer ( "," Initializer)*

TypeName := SpecifierQualifierList ( AbstractDeclarator) ?

AbstractDeclarator $:=$ ( DirectAbstractDeclarator )

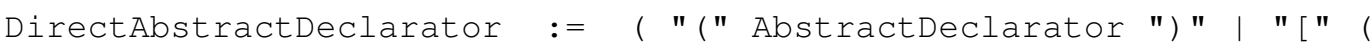
ConstantExpression ) ? "]" | " " ( ParameterTypeList ) ? ") " ) ( " " ( ConstantExpression ) ? "] " | "(" ( ParameterTypelist ) ? ") " )* Statement $:=$ ( Expressionstatement | CompoundStatement |

Selectionstatement | Iterationstatement | Jumpstatement )

Expressionstatement $:=$ ( Expression ) ? ";"

CompoundStatement := "\{" ( DeclarationList ) ? ( StatementList ) ? " $\}$ " Statementlist $:=$ ( Expressionstatement | CompoundStatement |

Selectionstatement | IterationStatement | Jumpstatement )+ Selectionstatement $:=(\langle\mathrm{IF}>$ "(" Expression ") " Statement ( <ELSE>

Statement )? )

Iterationstatement $:=$ ( <WHILE> " (" Expression ") " Statement ) Jumpstatement $:=($ RETURN> ( Expression ) ? ";" )

Expression := AssignmentExpression ( ", "AssignmentExpression )* AssignmentExpression $:=$ Assignmentoperator

I ConditionalExpression

Assignmentoperator := UnaryExpression ( "=" AssignmentExpression | " $\star="$ AssignmentExpression | "/=" AssignmentExpression | "\%="

AssignmentExpression | "+=" AssignmentExpression | "-="

AssignmentExpression | "<<=" AssignmentExpression | ">>="

AssignmentExpression | "\&=" AssignmentExpression | "^="

AssignmentExpression | "|=" AssignmentExpression ) ConditionalExpression := LogicaloRExpression ( ( "?" Expression ) ( ":" ConditionalExpression ) ) ) ?

ConstantExpression $:=$ ConditionalExpression

LogicaloRExpression := LogicalANDExpression ( " "|"

LogicaloRExpression ) ) ?

LogicalANDExpression := InclusiveORExpression ( ( \&\&"

LogicalANDExpression ) ) ?

InclusiveORExpression := ExclusiveORExpression ( " " "

InclusiveORExpression ) ) ?

ExclusiveORExpression := ANDExpression ( ( $\wedge "$ ExclusiveORExpression ) ) ? 


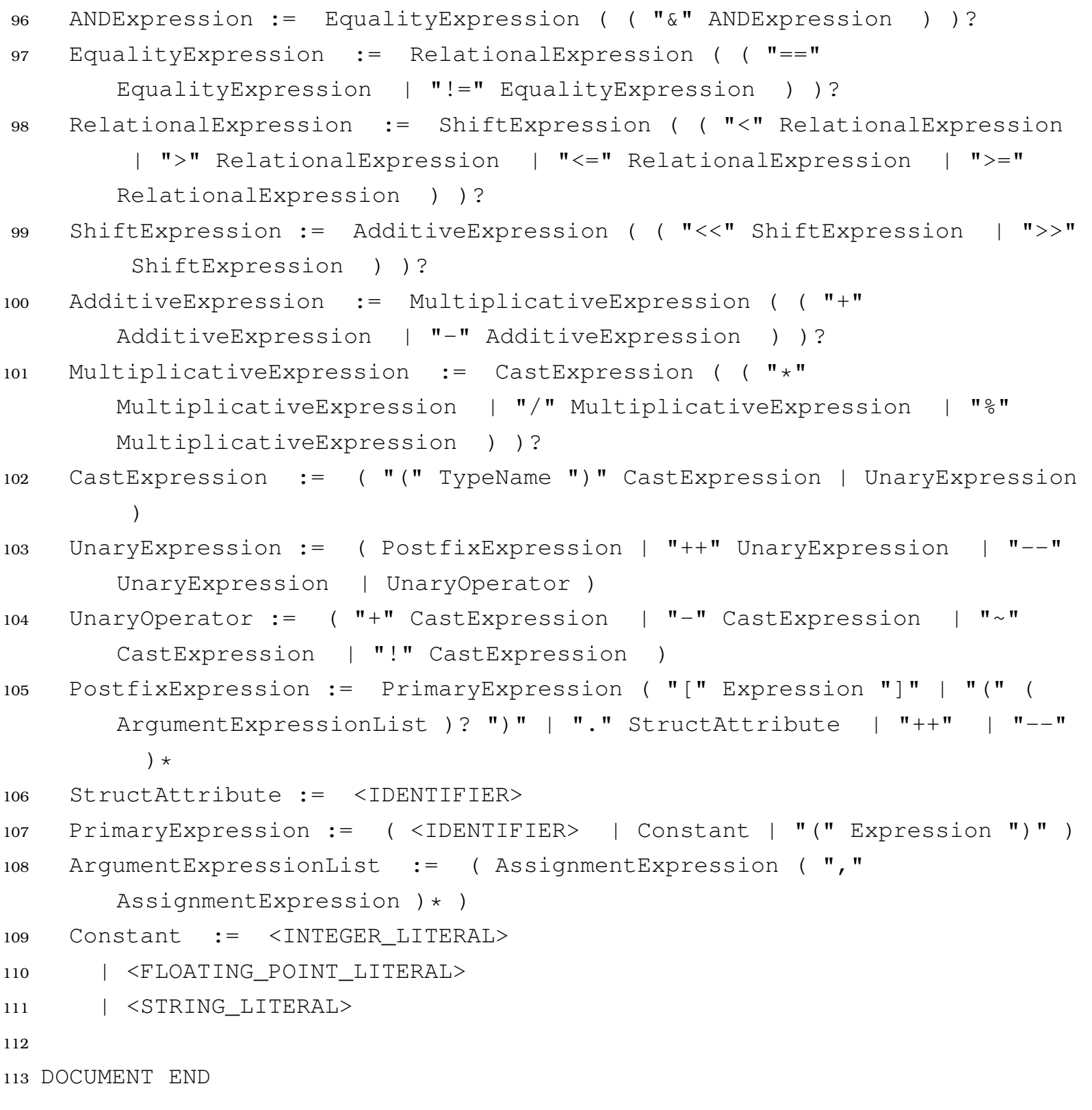

